\title{
DR. 972
}

\section{ORNL-5448}

\section{Assessment of the Radiological Impact of the Inactive Uranium-Mill Tailings at Mexican Hat, Utah}

\author{
F. F. Haywood \\ W. A. Goldsmith \\ B. S. Ellis \\ H. M. Hubbard, Jr. \\ W. F. Fox \\ W. H. Shinpaugh
}

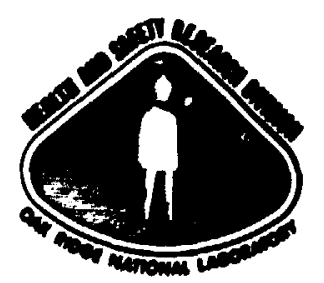


ORNL-5448

Dist. Category UC-41

Contract No. W-7405-eng-26

Health and Safety Research Division

\section{ASSESSMENT OF THE RADIOLOGICAL IMPACT OF THE INACTIVE URANIUA-MILL TAILINGS AT MEXICAN HAT, UTAH}

F. F. Haywood, W. A. Goldsmith, B. S. Ellis, H. M. Hubbard, Jr., W. F. Fox, and W. H. Shinpaugh

Date Published: March 1980

Appendix $I$ in this document is a direct reproduction of a previously unpublished report of the Phase I Interagency site visit prepared by Lucius Pitkin, Inc., under AEC Contract AT(ग5-1)912

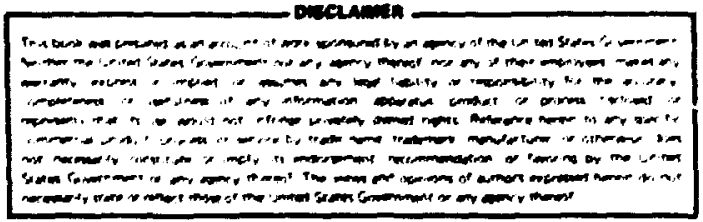

OAK RIDGE NATIONAL LABORATORY

Oak Ridge, Tennessee 37830 operated by

UNION CARBIDE CORPORATION

for the

DEPARTMENT OF ENERGY 
LIST OF REPOATS OF OAK RIOCE MIIOML LABORATOCX RADIOLOGICAL SURVEYS AT IMCTIVE URAIUA-MILL SITES

Numer

I
Iitle

Assessment of Radiological Imact of the Inactive UraniumMill lailings Pile at Salt Lake City, Utah

Assessment of the Radiological Impact of the Imactive UrariinMill Iailings at Shiprock. Mew trexice

Assesseent of the Radiological Imact of the Inactive UraniumMill Tailings at Mexican Hat, Utah

Assesseent of the Radiological Impact of the Inactive UraniumMill Tailings Piles at hominent Valley, Arizon

Raviological Survey of the Inactive Urantur-nill Tailings at Tusa iicy, Arizona

Radiological Survey of the Inzctive Uranium-Hill Tailings at Durango. Colorado

Radiological Survey of the Inactive Uranium-kill Iailings at Slick Rock. Colorado

Radiological Survey of the Inactive Uranium-Mill Iailings at Gunnison. Colorado

Radiological Survey of the Inactive Uraniun-nill Tailings at Macurita. Colorado

Radiological Survey of the Inactive Uraniun-Mill Tailings at Rifle, Colorado

Radiological Survey of the Inactive Uranium-mill Tailings at Maspell. Colorado

Assessaent of the Radiological Imact of the Inactive UraniumMill Tailings at Grand Junction. Colorado

Radiological Survey of the Inactive Uraniu-Mill Tailings at Ambrosis Lake, New Wexico

Radiological Survey of the Inactive Uranium-nill Tailings at Green River, Utah

Radiological Survey of the Inactive Uraniurmill Tailings at the Spook Sice. Converse County. Wyoming

Radiological Survey of the Inactive Uranium-Mill Tailings at Riverton, Hyoming

Radio:ogical Survey of the Inactive Uranturnill Iallings of falls Cfty. Iexas

Rediological Survey of the Inactive UraniurMill Tailings at Ray Point, Texas

Radiological Survey of the Inactive Uranium-nill Tailings at Lakeview, Oregen

Radiological Survey of the Radioactive Sands and Residues at Lowan. Idaho
Report to.

Oean $/ \mathrm{TH}-5251$

Oant-5447

ORNL-5448

0enu 5549

Oath-5A50

ORCL-5A51

ORNL-5452

DRNL -5453

ORNL-5A54

ORNL-5A55

ORNL-5456

OR'IL-5A5]

ORML-5458

ORNL-5459

OANL -5460

OANL-5461

ORANL-5462

ORNL-5463

ORML-5464

ORNL-5465 
CONTENTS

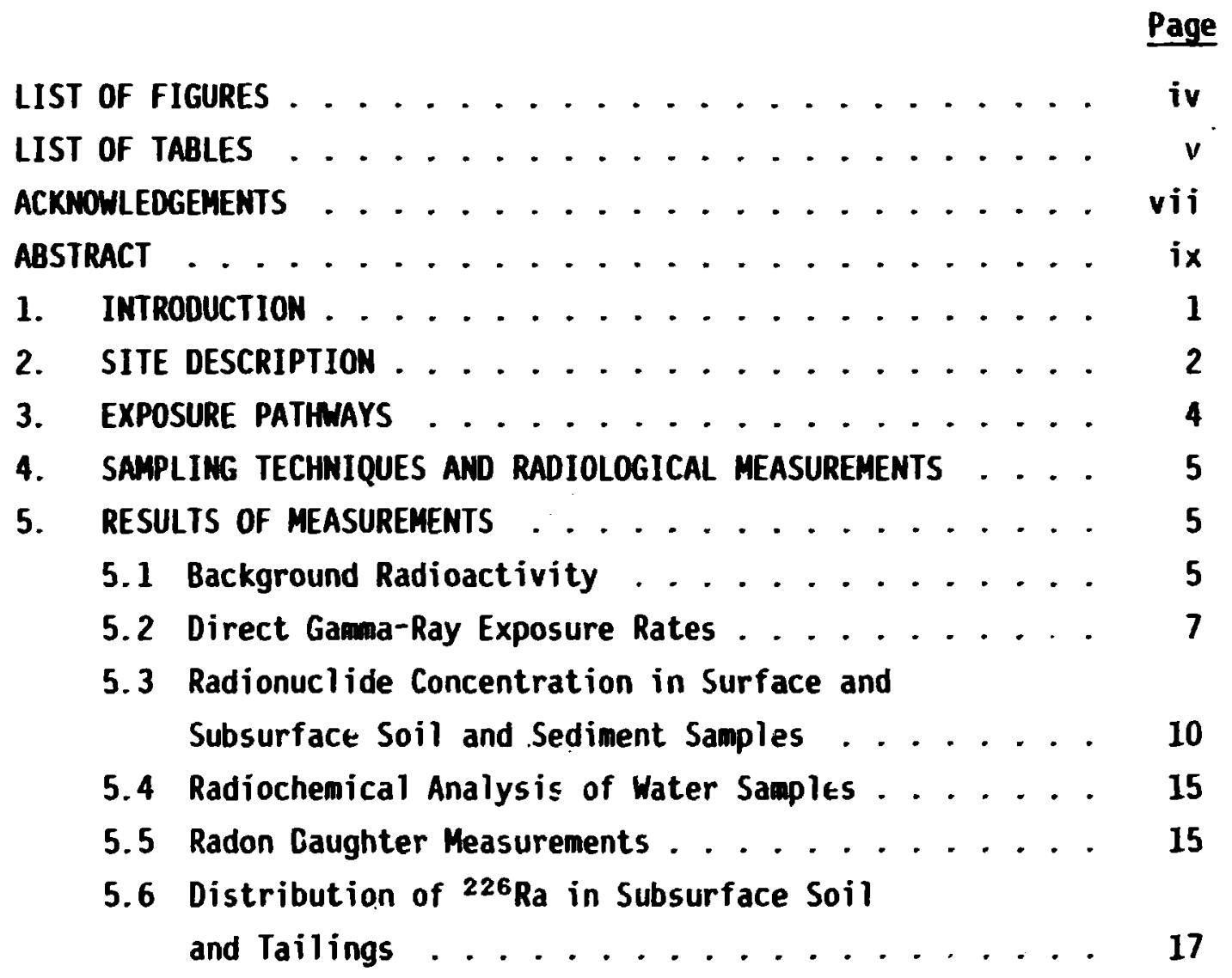

6. HEALTH EFFECTS ATTRIBUTABLE TO THE MEXICAN HAT

TAILIMGS .......................... 25

6.1 Direct Dose Effects ................ 25

6.2 Raden Exposure Pathway . . . . . . . . . 27

6.3 Health Effects Attributable to Other Exposure Pathways .................... 30

7.0 SUMMARY AND CONCLUSIONS ................... 33

REFERENCES .......................... 36

APPENDIX I, PHASE I, Report on Conditions of Uranium Mill

Site and Tailings at Mexican Hat, Utah . . . . . . . 39

APPENDIX II, Soil Sampling Techniques and Radiological

Measurements . . . . . . . . . . . . 59

APPENDIX III, Water Sampling and Analysis ........ 73 


\section{LIST OF FIGURES}

Figure

Page

I Aerial photograph of the Mexican Hat site...... 3

2 Locations of background external gama

measurements and background soil samples . . . . 6

3 Measurements of external gama exposure rates

1 above the ground ............. 9

4 locations and identifications of environmental samples................. 11

5 Locations of holes dril!ed at Mexican Hat ..... 19

6 Calculated concentrations of ${ }^{226}$ Ra in holes 1,2 , 3 , and $4 \ldots . . \ldots 20$

7 Calculated concentrations of ${ }^{226} \mathrm{Ra}$ in holes 6,7

8 , and $9 . \ldots . . . . . . . . .21$

8 Calculated concentrations of ${ }^{226} \mathrm{Ra}$ in holes 10,11 , 12 , and 14 .................. 22

9 Calculated concentrations of ${ }^{226} \mathrm{Ra}$ in holes 15,16 , 18 , and 19 ................. 23

10 Calculated concentrations of ${ }^{226} \mathrm{Ra}$ in holes 20 and 21 ..................... 24 


\section{LIST OF TABI.ES}

Table

1 Background radiation ievels and background concentrations of radionuclides in surface soil near Mexican Hat, Utah ............ 8

2 Concentration of ${ }^{226} \mathrm{Ra}$ and ${ }^{232} \mathrm{Th}$ in surface and near-suriace soil samples at Mexican Hat . . . . . 12

3 Radiochemical al .lysis of water samples . . . . . . 16

4 Concentration of ${ }^{222} \mathrm{Rn}$ daughters in the Salt

Palace (former mill building) at Mexican Hat, Utah, during the period March 12-13, 1976 ...... 18

$5 \quad 222 R n$ concentration resulting from the Mexican Hat tailings ................ 28

6 Estimated increased risk of lung cancer death per year attributable to radon dispersed from the Mexican Hat tailings ................. 31 


\section{ACKNOWLEDGEMENTS}

The authors of this series of reports wish to express their deep appreciation to the following persons: to $L$. J. Deal and R. H. Kennedy, Department of Energy, Washington, D. C., for their encouragement and support during the field operatioris phase of this project; to Dr. Charles J. Barton of Science Applications, Inc. (SAI), Oak Ridge, for his diligent work in preparing, under subcontract, the drafts of this series, and to Vilma Minor, also of SAI for typing the manuscripts; to the many members of the Health and Safety Research Division who provided technical reviews of the individual reports; to Jenny Vinson, Health and Safety Research Division Technical Editor, special thanks is extended for her careful review of each manuscript, especially for helping ensure that a uniform format was followed; to Dr. Barry Berven for his as:istance in organizing the final drafts. Appreciation is extended to John G. Themelij and Frank McGinley, Department of Energy, Grand Junction Operations office, for their support and advice during the conduct of this project; to Charles Brunner, Bendix Field Engineering Company, Grand Junction, Colorado, for his assistance in arranging for tra grinding of approximately 1600 soil samples wich were collected during the project; also to Dr. Vern Rogers and his staff, Ford, Bacon ard Dayis Utah Inc., for assistance during the field operations phase of this project. Finally, the authors wish to acknowledge the efforts of Mr. Ev Haldane, Department of Energy, Grand Junctici, who was associated with the uranium-mill tailings program from its earliest days. Ev passed away suddenly on June 30, 1979, and it is to his menory that this series of reports is dedicated. 
ASSESSHENT OF THE RADIOLOGICAL IMPACT OF THE IMACTIVE URANIU.A-MILL TAILIMGS AT MEXICAN HAT, UTAH

F. F. Hayrood, W. A. Goldswith, B. S. Ellis, H. H. Hubbard, Jr., W. F. Fox, and H. H. Shinpaugh

\begin{abstract}
High surface soil concentrations of ${ }^{226}$ Ra and high above-ground measurements of gama-ray intensity in the vicinity of the inactive uraniu-nill tailings at Mexican Hat show both wind and water erosion of the tailings. The former mill area, occupied by a trade school at the time of this survey, shows a comparatively high level of contanination, probably from unprccessed ore on the surface of the ore storage area near the location of the former aill buildings. However, the estimated health effect of exposure to gama rays during a 2000-hr work year in the area represents an increase of $0.1 \%$ in the risk of death from cancer. Exposure of less than 600 persons within $1.6 \mathrm{~km}$ of the tailings to radon daughters results in an estimated $0.2 \%$ year increase in risk of lung cancer.

It appears that nothing has been done to implement the recomendation of an earlier (1968) survey that tailings at this site be stabilized or that access be restricted with periodic monitoring to assure that population exposures are acceptably low. Data provided in this report and in an engineering assessment report by ford, Bacon and Davis Utah Inc. will provide guidance for renedial action if that should be undertaken.
\end{abstract}




\section{INTRODUCTION}

This report is the fourth of a series of reports on results of radiological surveys of uranium-mill tailings at inactive mill sites in western United States and attempts to assess potential health effects at some of these :ites. A complete list of the reports in this series is presented at the front of this report. The first (Salt Lake City) report' also contains a discussion of modes of radiation exposure to individuals and to population groups from radionuclides in these tailings piles and a survey of the pertinent literature on this subject. The present eport deals with an inactive mill site on land owned by the Navajo Nation $r$ ar Mexican Hat, Utah.

Earlier surveys of this site were reported by Snelling ${ }^{2}$ and by Brown et al. (see Appendix I). Gamma survey data at this site designed to show the extent of movement of tailings were reported by Douglas and Hans. ${ }^{3}$ The survey reported here was conducted by a team of health physicists from the Oak Ridge National Laboratory (ORNL) during March 1976 in cooperation with an engineering team from Ford, Bacon and Davis Utah Inc. (FB\&DU). The latter organization, an architect-engineering firm, was responsible for the Phase II eagineering assessment of this site. Their work included estimates of costs of alternate ways of reducing potential health effects of radiation and radionuclides from ine tailings. Results of their studies of this site nave been reported. 4 Data obtained by FB\&DU in the course of their investigation, part of which have not been previously reported, are included in the present report.

In addition to documentation of the results of the radiological survey, including descriptions of the equipment and techniques used to obtain the data, this report presents results of a limited effort to evaluate potential health effects among people who may be exposed to direct gamma radiation or to radionuclides from the Mexican Hat site. 


\section{SITE DESCRIPTION}

An aerial photograph of the Mexican Hat mill and tailings, and the surrounding area is shown in Fig. 1. The site is on the Navajo Indian Reservation approximately $2.4 \mathrm{~km}$ (1.5 miles) southwest of the Highway 47 bridge crossing the San Juan River at Mexican Hat.

The mill was built by Texas-Zinc Minerals Corporation, and it was operated by that company from 1957 until it was acquired by Atlas Corporation in 1963. Atlas operated the mill through its subsidiary, $A Z$ Minerals, until operations ceased early in 1965. Following termination of the lease on the site in 1970 , control reverted to the Navajo Mation. During its period of operation, the mill is reported (Appendix I) to have processed 2.0 million metric tons of ore with an average concentration of $0.28 \% \mathrm{U}_{3} \mathrm{O}_{8}$, and it produced 5692 metric tons of $\mathrm{U}_{3} \mathrm{O}_{8}$ in concentrate. The estimated ${ }^{226}$ Ra content of the tailings at this site is 1560 curies ( $\mathrm{C}$ ) and the theoretical average ${ }^{226} \mathrm{Ra}$ concentration in tailings is $780 \mathrm{pCi} / \mathrm{g}$ (Appendix I).

The two tailings piles at this site are reported (Appendix I) to be bounded by fairly steep hills on the south and to lie on ground that slopes gently toward the San Juan River about $0.8 \mathrm{~km}(0.5 \mathrm{mile})$ to the northeast. The western (No. 1) pile covers an area of 7.3 hectares (18 acres) east of the former mill buildings, and the eastern (No. 2) pile covers about 13 hectares ( 32 acres) immediately east of the No. 1 pile.

A Navajo trade school, operated by the Utah Trades Commission, is located in some of the buildings on the former mill site. It is reported (Appendix I) to have 100 or more students. The nearest population group is housed in the former company housing area $0.8 \mathrm{~km}(0.5 \mathrm{mile})$ southwest of the mill site. Seventy families with about 250 people are reported (Appendix I) to reside in this community, which is now called Halchita. An elementary school exists between Halchita and the former mill site, $0.5 \mathrm{~km}$ ( $0.33 \mathrm{mile})$ southwest of the site (see Appendix 1 ).

The tailings piles are near the path of small dry wash channels leading into Gypsum Wash from which any water flow discharges into the San Juan River. The travel distance from the No. 2 tailings pile to the 


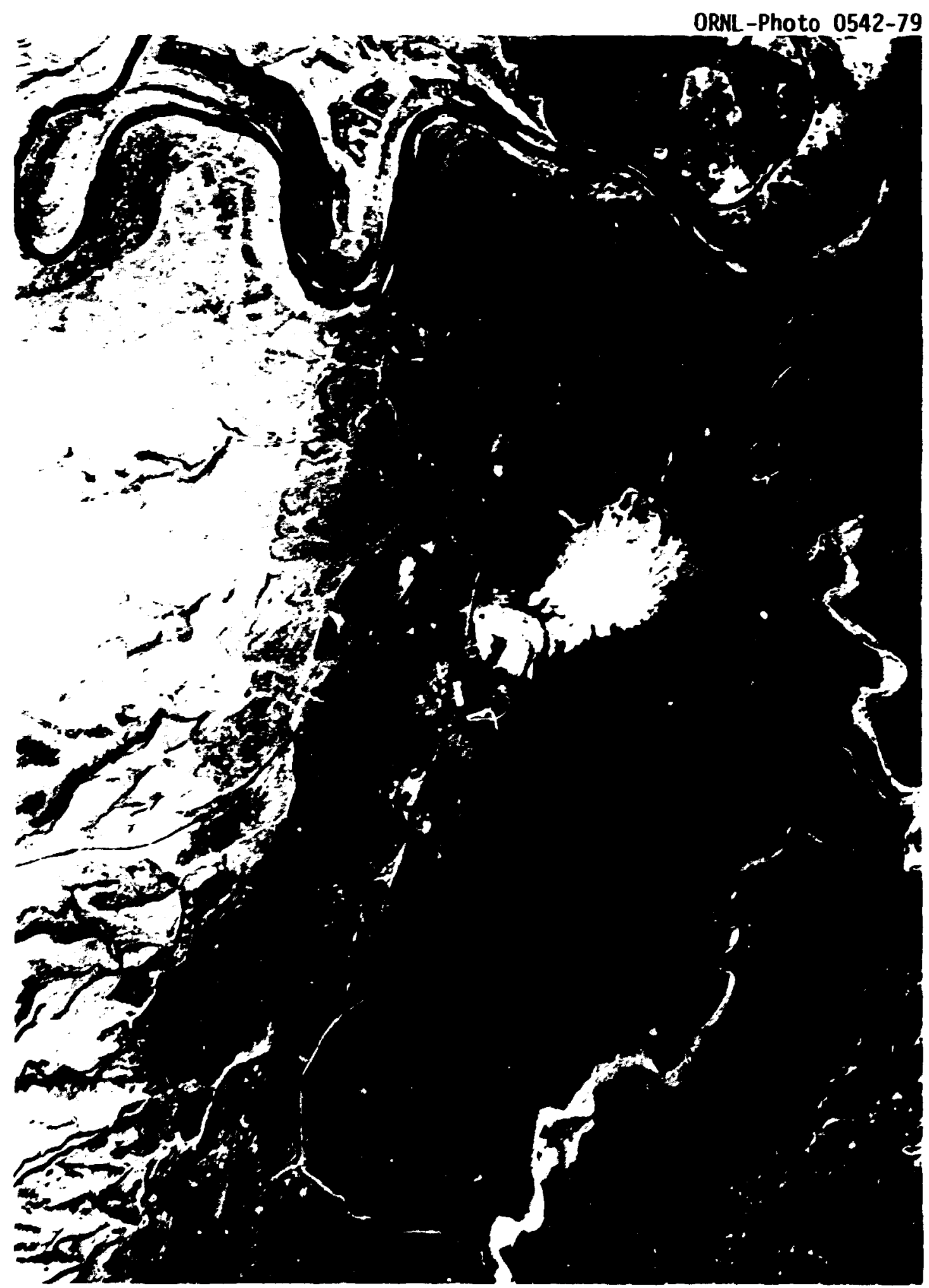

Fig. 1. Aerial photograph of the Mexican Hat site. Source: EG\&G, Inc. 
river is approximately $1.6 \mathrm{~km}$. The drainage direction is also the direction of the prevailing winds, toward the northeast, and some wind erosion in that direction was reported (Appendix I). Also, it was observed at the time of the 1974 Phase I site visit tilat the tailings surface was crusted and that water erosion was minimal.

\section{EXPOSURE PATHAYS}

The behavior of radionuclides in tailings piles and the potential modes of exposure of man to radiation from these radionuclides were discussed in the first (Salt Lake City) report' ${ }^{1}$ of this series, along with coverage of the pertinent literature. Briefiy, the authors of that report concurred $w^{\text {th }}$ the conclusion of earlier reports ${ }^{5-8}$ that radon diffusion followed by inhalation of radon daughters is the most important exposure pathway. * Other pathways invo:ve: (1) inhalation of, and body surface contamination by, airborne tailings particles with ${ }^{226} \mathrm{Ra}$, ${ }^{230} \mathrm{Th}$, and ${ }^{231} \mathrm{~Pa}$ as the principal radionuclides of concern; (2) deposition of airborne tailings particles on foliage or soil followed by uptake by edible plants and/or intake by animals and consimption of contaminated plants, meat, or milk $\left({ }^{225} R_{3}\right.$ and $210 \mathrm{~Pb}$ are the principal radionuclides of concern in the terrestrial pathways); (3) radionuclides in the pile dissolve in water and migrate to water suppiies where exposure to man can occur through consumption of contiminated drinking water, immersion in the water, or by uptake of nuclides by aquatic plants and animals followed by consumption by man $\left({ }^{226} \mathrm{Ra}\right.$ and $210 \mathrm{~Pb}$ are also the principal radionuclides of concern in the aquatic pathways); and (4) direct exposure to gamma radiation, principally from ${ }^{226} \mathrm{Ra}$ and its daughters.

*Although this assumption is made for most tailings sites, the authors are aware that in all cases it is necessary to examine physical evidence to evaluate the importance of each pathway. 
4. SAMPLING TECHNIQUES AND RADIOLOGICAL MEASUREMENTS

Sampling techniques as well as equipment and methods used for radiochemical analyses of soil samples and radiological monitoring are described in Appendix II while the analytical method used to analyze water samples is contained in Appendix III.

\section{RESULTS OF MEASUREMENTS}

Measurements were made near the Mexican Hat site to determine the background radiation levels and background radionuclide concentrations in surface soil samples; external gamma exposure rates $1 \mathrm{~m}$ above the ground both on the site and in the area immediately around the site; radionuslide concentratioris in surface soil, sediment and water samples; radon daughter concentrations in one former mill building; and the subsurface distribution of ${ }^{226} \mathrm{Ra}$ in tailings piles and other ccntaminated areas as a function of depth. No radon measurements were attempted by ORNL at this site, but data obtained by FB\&DU at six locations at or near the tailings piles were reported. 4 Earlier radon and radon daughter measurements were reported by Snelling who also has published data on the concentration of other airborne radionuclides measured at nine locations during a period of 11 days. ${ }^{2}$ other data obtained by J. M. Hans, Jr., at the Environmental Protection Agency, Office of Radiation Proyrams, Las Vegas Facility (EPA-ORR-LVF) on the concentration of airborne radionuclides are quoted by FB\&DU. 4

Results of the various types of neasurements made by ORNL at the Mexican Hat site are discussed in separate sections below.

\subsection{Background Radioactivity}

Knowledge of background external gamma radiation levels and of background concentrations of radionuclides in the surface soil is needed in order to evaiuate the extent of spread of tailings from the site and t.o provide data needed in implementing clean-up procedures.

In Fig. 2, points are shown where measurements were made of e; ernal garma-ray dose rates $1 \mathrm{~m}$ above the ground and where surface soil 


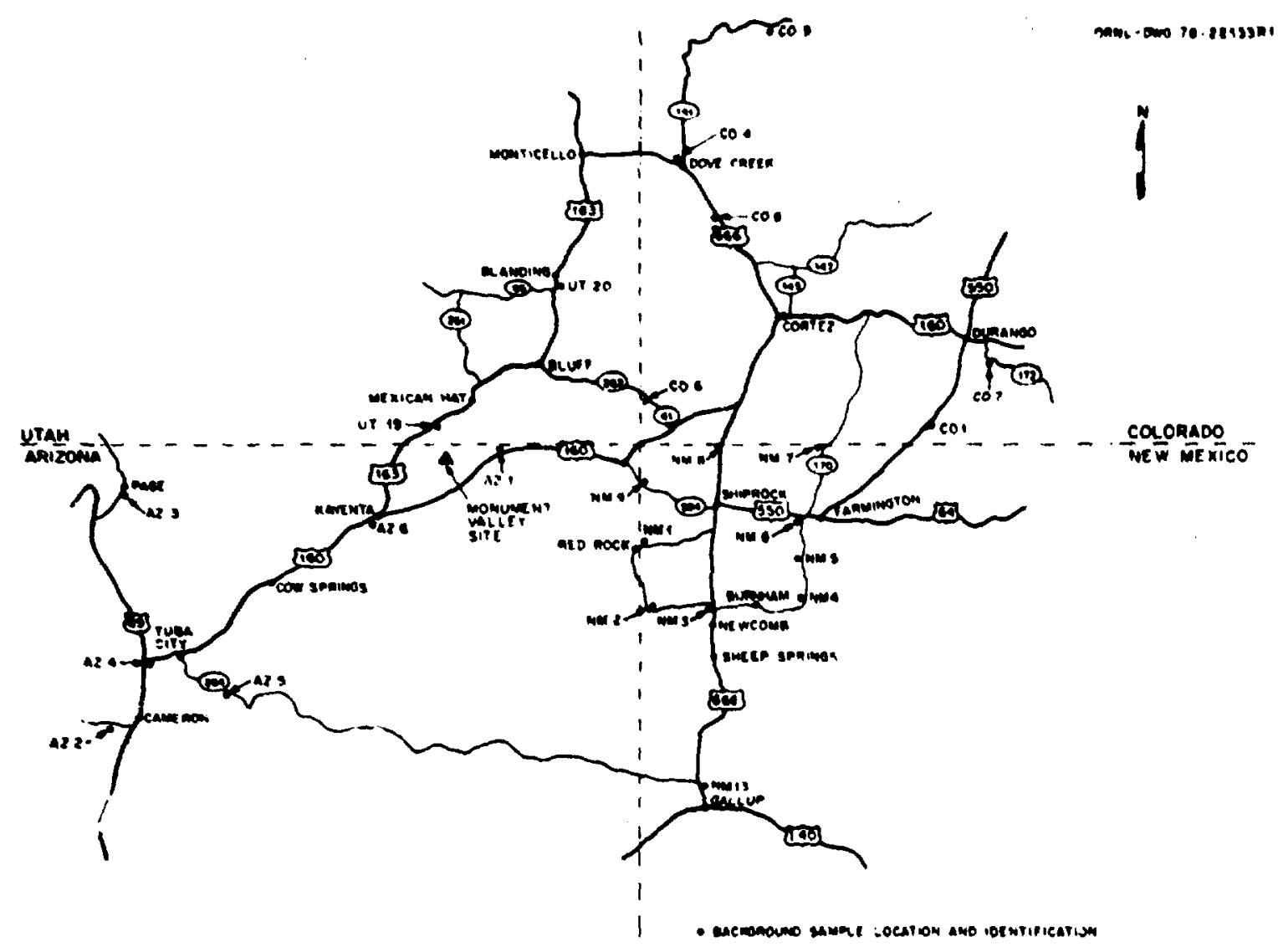

Fig. 2. Locations of background external gamma measurements and background soil samples. 
samples were obtained for analysis. Because of proximity to the Monument Valley site (see Fig. 2), the background data from these two sites are identical. Details of the sample sites and the results obtained are displayed in Table 1.

The data in Table 1 show a variation in measured values of background gamma exposure rate $1 \mathrm{~m}$ above the ground from 5 to $12 \mu \mathrm{R} / \mathrm{hr}$. The average value of $9 \mu \mathrm{R} / \mathrm{hr}$ corresponds to an annual background dose equivalent of 79 miliirem. There is not a good correlation between the direct gamma exposure rate and the ${ }^{226}$ Ra concentration in the surface soil. Poor instrumental accuracy and other factors such as the variation in cosmic ray intensity with altitude and the presence of other radionuclides in surface soil may affect above-surface background gamma exposure rate measurements. Snelling reports ${ }^{2}$ an exposure rate of $30 \mu \mathrm{R} / \mathrm{hr}$ in the vicinity of the former mill housing area (now Halchita), and he staces that this represents normal background radiation. He used a Geiger counter for most of his measurements, which presumably was not energy compensated to prevent over response to scattered radiation (see Appendix (I).

The average ${ }^{226} \mathrm{Ra}$ background concentration $(0.9 \mathrm{pCi} / \mathrm{g})$ and the average ${ }^{232} \mathrm{Th}$ concentration $(0.6 \mathrm{pCi} / \mathrm{g})$ in area surface soil samples are both lower than the corresponding averages observed in the area around the Shiprock, New Mexico, site.

\subsection{Direct Gamma-Ray Exposure Rates}

Measurements were made of direct gamma-ray exposure rates $1 \mathrm{~m}$ above the ground using the "Phil" gamma-ray dosimeter described in Appendix II. These measurements were made at approximately $46 m$ (50 yd) intervals in the tailings area and at approximately $91 \mathrm{~m}$ ( $100 \mathrm{yd})$ intervals at distances greater than about $91 \mathrm{~m}$ from the edge of the tailings piles. The resulting data displayed in fig. 3 show that exposure rates are above the background level outside the unfenced site boundary in every direction. Since the prevailing winds at this site are reported (Appendix I and Ref. 2) to be from the southwest and there is visual evidence of tailings transportation toward the northeast, it seems probable that 
Table 1. Background radiation levels and background concentrations of radionuclides in surface

soil near Mexican Hat, Utah

\begin{tabular}{|c|c|c|c|c|c|}
\hline \multirow{2}{*}{$\begin{array}{l}\text { Sample } \\
\text { point }\end{array}$} & \multirow{2}{*}{$\begin{array}{l}\text { Description of } \\
\text { sample location }\end{array}$} & \multirow{2}{*}{$\begin{array}{l}\text { External y } \\
\text { exposure } \\
\text { rate } \\
(\mu R / h r)\end{array}$} & \multicolumn{3}{|c|}{$\begin{array}{l}\text { Nuclide concentration } \\
\qquad(\mathrm{p} \mathrm{C} / \mathrm{g})\end{array}$} \\
\hline & & & $226 \mathrm{Ra}$ & $232 \mathrm{Th}$ & $\overline{238 U}$ \\
\hline$A Z 1$ & $\begin{array}{l}\text { In valley } 9.7 \mathrm{~km} \text { south of } \\
\text { tailings }\end{array}$ & 9 & 1.7 & 0.5 & 0.5 \\
\hline AZ2 & $\begin{array}{l}\text { South side of thy } 64,20.6 \\
k \text { west of intersection of } \\
\text { Hyys. } 89 \text { and } 64\end{array}$ & 10 & 0.9 & 1.3 & 0.5 \\
\hline$A 23$ & $\begin{array}{l}\text { North side of Hwy } 89,2.4 \mathrm{~km} \\
\text { east of Glen Canyon Dam } \\
\text { (mi leage marker } 548 \text { ) }\end{array}$ & 5 & $0 . ?$ & 0.2 & 0.1 \\
\hline AZ4 & $\begin{array}{l}\text { South side of thy } 160,20.4 \\
\text { kn east of intersection of } \\
\text { Hwys } 160 \text { and } 89\end{array}$ & 11 & 2.0 & 1.0 & 0.9 \\
\hline A.7.5 & $\begin{array}{l}\text { Near rest stop on thry } 264 \text {, } \\
11.4 \mathrm{~km} \text { east of Tuba City, } \\
\text { Ariz. }\end{array}$ & 6 & 0.4 & 0.4 & 0.2 \\
\hline AZ6 & $\begin{array}{l}\text { South side of Hwy } 160,3.2 \\
k=\text { west of Kayenta, Ariz. }\end{array}$ & 12 & 0.4 & 0.4 & 0.2 \\
\hline UT19 & $\begin{array}{l}12.9 \mathrm{~km} \text { south of Mexican Hat, } \\
\text { northeast corner of inter- } \\
\text { section of Hoy } 163 \text { and road } \\
\text { to Monument Valley site }\end{array}$ & 8 & 0.8 & $b$ & 0.3 \\
\hline UT20 & $\begin{array}{l}\text { East side of Hwy } 163,4.8 \mathrm{~km} \\
\text { south of Blanding, Utah }\end{array}$ & 10 & 1.1 & $b$ & 0.4 \\
\hline & Average & 9 & 0.9 & 0.6 & 0.4 \\
\hline
\end{tabular}

$a_{\text {One meter above the ground. }}$

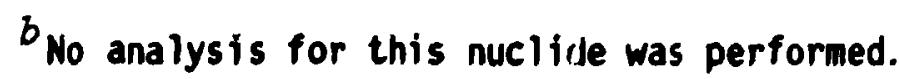




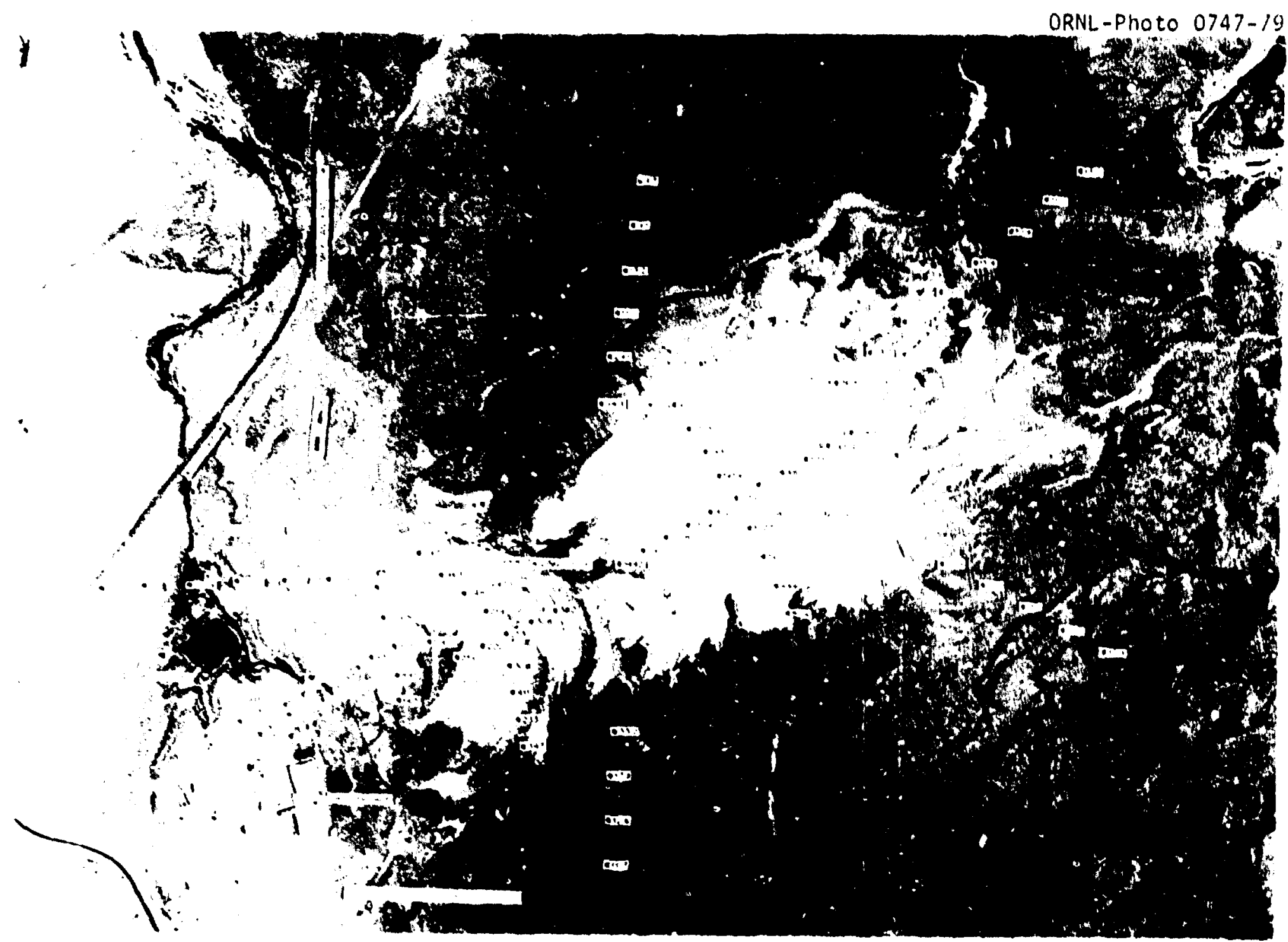

Fig. 3. Measurements of external gamma exposure rates $\{: R / h r\}, m$ above the ground. Original photo by EG\&, Inc. 
the observed high radiation level in that direction is due, at least in part, to wind transportatic, of tai.ings. Exposure rates in the former will and ore storage area reported by FB\&DU range from 39 to $630 \mu \mathrm{R} / \mathrm{hr}$ (average $180 \mu R / h r$ ), whereas the upper tailings pile gave readings in the range 219 to $1060 \mu R / h r$ (.sverage $460 \mu R / h r$ ) with the highest readings observed above the lower tailings pile (range 318 to $1458 \mu R / h r$, average $850 \mu R / h r$ ). "Differential" gamma-ray measurements made at this site in April 1974, reported by Douglas and Hans, ${ }^{3}$ help to define the spread of tailings and/or uranium ore particles.

\subsection{Radionuclide Concentration in Surface and Subsurface Soil and Sediment Samples}

Analysis of surface and near-surface soil and sediment samples for $226 R a$ provides a sensitive measure of the spread of tailings or uranium ore particles. Aiso, since ${ }^{222} R n$ is the daughter of ${ }^{226} R a$, data on ${ }^{226}$ Ra distribution in surface and subsurface soil show areas where the emanation of this gas into air is likely to be high. Analysis of sediment samples from streans and dry washes shows the extent of movement of particles by water.

Locations of surface and subsurface soil and sediment samples are displayed in Fig. 4, and analytical results are given, in Table 2. Also shown in Fig. 4 are locations where water samples, discussed in the following section, were taken.

The data in Table 2 confirm the spread of contamination from the Mexican Hat mill site, especially toward the north and northeast. The high ${ }^{226} \mathrm{Ra}$ concentrations in the area between the upper tailings pile and Highway 163 probably show the presence of unprocessed ore, which was stored on the ground south of the former mill buildings, rather than movement of tailings particles in that direction. Analyses of dry wash samples show that water is moving tailings particles toward the San Juan River but, since samples were not obtained at or near the points where the dry washes discharge into the river, the ${ }^{226} \mathbf{R a}$ concentration in material reaching the river is unknown. Only one of the river sediment samples, that from tine south side of the river upstream from the dry 


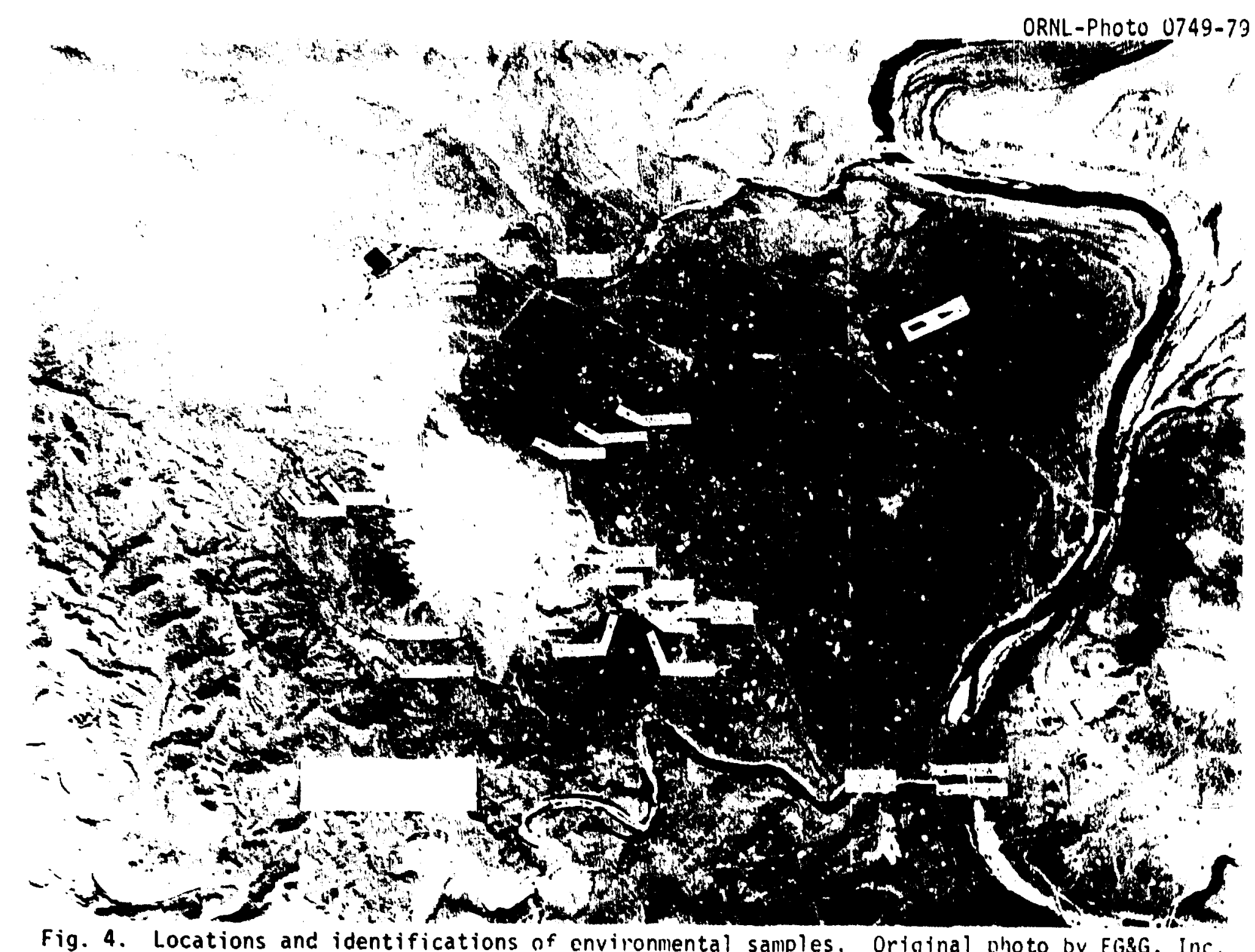


Table 2. Concentration of ${ }^{226} \mathrm{Ra}$ and ${ }^{232} \mathrm{Th}$ in surface and near-surface soil samples at Mexican Hat

\begin{tabular}{|c|c|c|c|}
\hline \multirow{2}{*}{$\begin{array}{c}\text { Sample } \\
\text { designation }\end{array}$} & \multirow{2}{*}{$\begin{array}{l}\text { Sample location } \\
\text { and description }\end{array}$} & \multicolumn{2}{|c|}{$\begin{array}{l}\text { Nur.l ide concentration } \\
(\mathrm{p} C \mathrm{i} / \mathrm{g})\end{array}$} \\
\hline & & $226 R a$ & ${ }^{232} \mathrm{Th}$ \\
\hline MHNS1 & $\begin{array}{l}\text { Gypsum Creek below where dry wash } \\
\text { that drains the northeast corner of } \\
\text { pile empties into it, about } 183 \text {. } \\
\text { (200 yd) upstrean from the San } \\
\text { Juan River. }\end{array}$ & 1.4 & $1 . \mathrm{C}$ \\
\hline MHSL2 & $\begin{array}{l}\text { Bank of San Juan River a few meters } \\
\text { upstream from Gypsu Creek inlet. }\end{array}$ & 1.4 & $a$ \\
\hline MWS3 & $\begin{array}{l}\text { Bank of San Juan River a few meters } \\
\text { downstream from Gypsum Creek. }\end{array}$ & 1.0 & 0.7 \\
\hline MNS4 & $\begin{array}{l}\text { Bank of San Juan River a few meters } \\
\text { downstrean from where stream fror } \\
\text { sewage pond at pile empties into , iver. }\end{array}$ & 2.5 & $a$ \\
\hline MWNS5 & $\begin{array}{l}\text { Bank of San Juan River a few meters } \\
\text { downstream from where stream from } \\
\text { sewage pond at pile empties into river. }\end{array}$ & 0.9 & 0.9 \\
\hline Mans6 & $\begin{array}{l}\text { About } 470 \text { (500 yd) downstream in } \\
\text { the stream from sewage pond. }\end{array}$ & 2.6 & 1.1 \\
\hline MiroON & $\begin{array}{l}183 \text { ( } 200 \text { yd) north from the base } \\
\text { of the dike surrounding pond. }\end{array}$ & 66 & 4.6 \\
\hline MHAOON & $\begin{array}{l}366 \text { ( } 400 \text { yd) north from the base } \\
\text { of the dike surrounding pond. }\end{array}$ & 3.4 & 0.7 \\
\hline MH6OON & $\begin{array}{l}549 \text { ( } 600 \mathrm{yd}) \text { north from the base } \\
\text { of the dike surrounding pond. }\end{array}$ & 3.9 & 0.8 \\
\hline NH2OONE & $\begin{array}{l}183 \text { ( } 200 \text { yd) northeast from base } \\
\text { of the aike surrounding pond. }\end{array}$ & 91 & $a$ \\
\hline MHAOONE & $\begin{array}{l}366 \text { ( } 400 \text { yd) northeast from base } \\
\text { of the dike surrounding pond. }\end{array}$ & 24 & $a$ \\
\hline MH6OONE & $\begin{array}{l}549 \text { ( } 600 \text { yd) northeast from base } \\
\text { of the dike surrounding pond. }\end{array}$ & 18 & 1.6 \\
\hline
\end{tabular}


rable 2 (Continued)

\begin{tabular}{|c|c|c|c|}
\hline \multirow{2}{*}{$\begin{array}{l}\text { Sacple } \\
\text { designation }\end{array}$} & \multirow{2}{*}{$\begin{array}{l}\text { Sample location } \\
\text { and description }\end{array}$} & \multicolumn{2}{|c|}{$\begin{array}{l}\text { Nuclide concentration } \\
(\mathrm{pCi} / \mathrm{g})\end{array}$} \\
\hline & & ${ }^{226} \mathrm{Ra}$ & 232Th \\
\hline MHBOONE & $\begin{array}{l}732 \text { ( }(800 \mathrm{yd}) \text { northeast from base } \\
\text { of the dike surrounding pond. }\end{array}$ & 8.3 & 1.2 \\
\hline MH200E & $\begin{array}{l}183 \text { a ( } 200 \text { yd) east from the base } \\
\text { of the dike surrounding pond. }\end{array}$ & 14 & 1.8 \\
\hline MHOOE & $\begin{array}{l}366 \text { ( }(400 \mathrm{yd}) \text { east from the base } \\
\text { of the dike surrounding the pond. }\end{array}$ & 3 & 0.9 \\
\hline HW200N & $\begin{array}{l}183 \text { ( }(200 \mathrm{yd}) \text { mest from the base } \\
\text { of the dike surrounding the pond. }\end{array}$ & 7.5 & $a$ \\
\hline ru250N & $\begin{array}{l}229 \text { ( }(250 \mathrm{yd}) \text { west from the base } \\
\text { of the dike surrounding the pond. }\end{array}$ & 310 & $a$ \\
\hline PH3CGi & $\begin{array}{l}274 \text { a }(300 \mathrm{yd}) \text { west from the base } \\
\text { of the dike surrounding the pond. }\end{array}$ & 110 & 3.3 \\
\hline MHAOON & $\begin{array}{l}366 \text { ( }(400 \mathrm{yd}) \text { west from the base } \\
\text { of the dike surrounding the pond. }\end{array}$ & 1.6 & 0.7 \\
\hline rH200S & $\begin{array}{l}183 \text { in (200 yd) south from the base } \\
\text { of the dike surrounding the pond. }\end{array}$ & 3.5 & 0.9 \\
\hline MH400S & $\begin{array}{l}366 \text { in ( } 400 \mathrm{yd}) \text { south from the base } \\
\text { of the dike surrounding the pond. }\end{array}$ & 2.5 & 1.1 \\
\hline MHOW1 & $\begin{array}{l}\text { Surface approxinately } 274 \text { m }(300 \\
\text { ydj from base of pile in the dry } \\
\text { wash or the east end. }\end{array}$ & 160 & $a$ \\
\hline MHOW2 & $\begin{array}{l}15 \mathrm{~cm} \text { below surface, at the same } \\
\text { point as Whowl }\end{array}$ & 120 & $a$ \\
\hline MHOH3 & $\begin{array}{l}\text { Surface approximately } 274 \text { a }(300 \\
\text { yd) from base pile in dry wash } \\
\text { north side of pile. }\end{array}$ & 110 & $a$ \\
\hline MHOW4 & $\begin{array}{l}15 \mathrm{~cm} \text { below surface at the sane } \\
\text { point as Mow } 3 \text {. }\end{array}$ & 31 & $a$ \\
\hline
\end{tabular}


Table 2 (Continued)

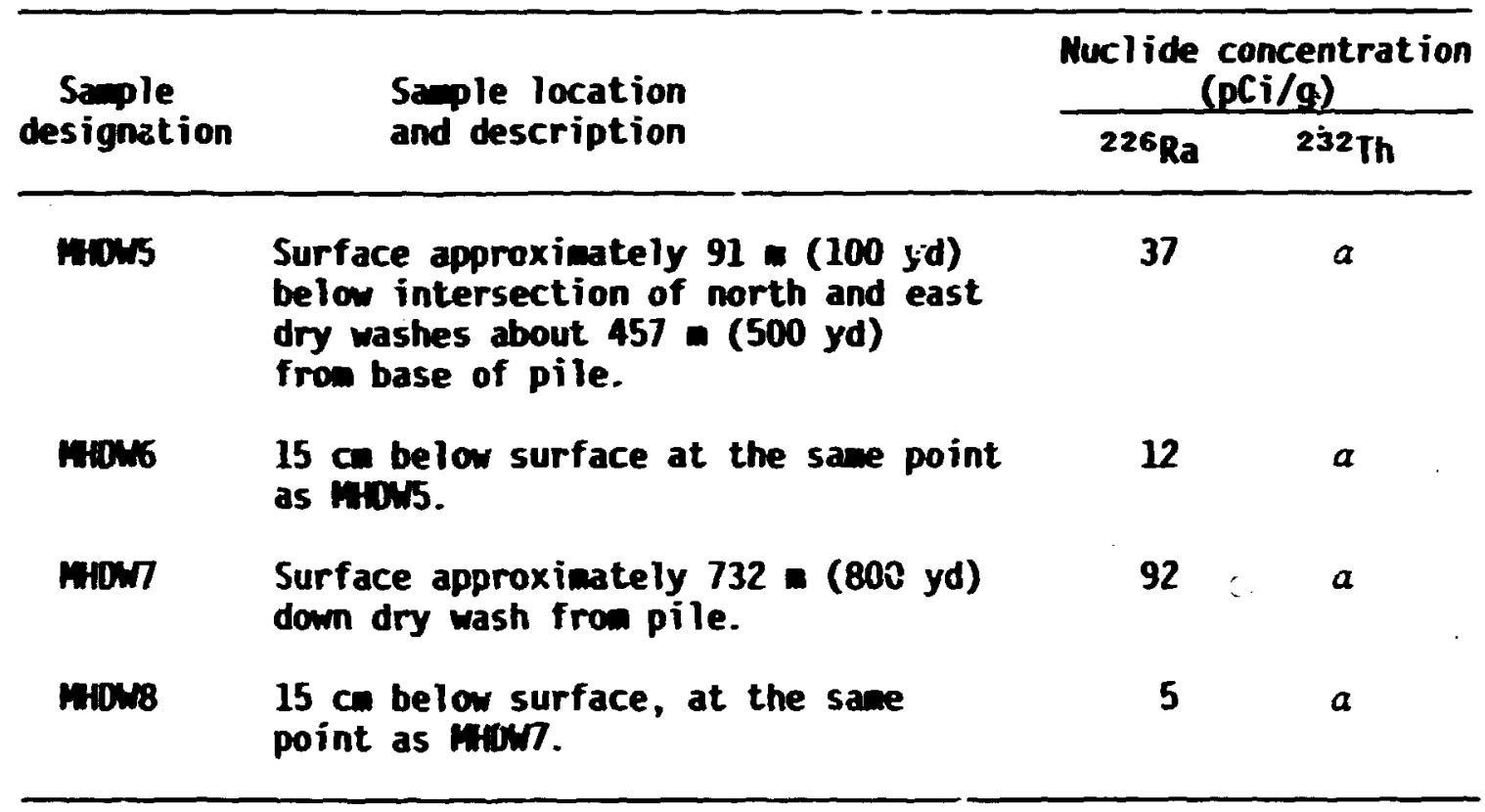

$a_{\text {This nuclide not sought. }}$ 
wash leading from the former will area (MWS4), showed concentration of ${ }^{226} \mathrm{Ra}$ significantly above the background level $(0.9 \mathrm{pCi} / \mathrm{g}$.$) . The nearby$ Jownstream sample (mWS5) was at the background level of ${ }^{226}$ Ra concentration.

\subsection{Radiochemical Analysis of Mater Samples}

Locations of water samples are shown in Fig. 4, and results of analysis of the samples, using the procedure outlined in Appendix III, are given in Table 3 . Only one sample (miw1), taken from a stagnant pond in the dry wash leading from the east end of the tailings toward the river, was significantly above the average concentration of ${ }^{226} R a$ reported by Snelling ${ }^{2}$ for five background water samples obtained in the Monument Valley area. The concentration of ${ }^{226} R a$ in the pond sample, 16 pCilliter, is below the 10CFR20 guide for discharge to uncontrolled areas $^{9}$ but it is several times the U.S. Public Health Service standard ${ }^{10}$ and the EPA concentration guide for drinking water. 11 However, it seems unlikely that anyone would drink water from this pool. The maximum ${ }^{226} \mathrm{Ra}$ concentration in other samples is approximately $30 \%$ of the Public Health Service standard ${ }^{10} \mathrm{for}{ }^{226} \mathrm{Ra}$ in drinking water (3.0 pCi/liter) and less than $20 \%$ of the EPA concentration guide value, $(5.0 \mathrm{pCi} / 1$ iter for ${ }^{226} R a+{ }^{228} R a$ ) assuming that the concentration of ${ }^{228} R a$ is negligible.

\subsection{Radon Daughter Measurements}

Five measurements of radon daughter concentrations were made in a very large $3812 \mathrm{~m}^{2}\left(41,000 \mathrm{ft}^{2}\right)$ former mill building (the Salt Palace), the closest building to the tailings pile. This building was being used for parking and for maintenance of heavy equipment. Three measurement.s were mace near the east (toward tailings) end of the building, one near the center, and the fifth measurement near the west epd. This building was observed to have many openings in the exterior walls and a large door in the east end was open at the time of measurements. Thus, the ventilation rate for this structure has probably two or more air changes 
Table 3. Radiochemical anaiysis of water samples

\begin{tabular}{|c|c|c|c|c|}
\hline \multirow{2}{*}{$\begin{array}{c}\text { Sample } \\
\text { designatior. }\end{array}$} & \multirow[b]{2}{*}{ Sample source } & \multicolumn{3}{|c|}{$\begin{array}{c}\text { Nuclide concentration } \\
\text { (pci/liter) }\end{array}$} \\
\hline & & ${ }^{226} \mathrm{Ra}$ & $210 \mathrm{~Pb}$ & ${ }^{230} \mathrm{Th}$ \\
\hline man & $\begin{array}{l}\text { Small stagnant pool } \sqrt{600} \mathrm{~m} \text { from } \\
\text { pile in dry wash running northeast } \\
\text { to San Juan River. }\end{array}$ & 16 & 190 & 11 \\
\hline MWN2 & $\begin{array}{l}\text { Gypsum Creek just downstream } \\
\text { from where northeast dry wash } \\
\text { empties into it and } 2200 \text { from } \\
\text { San Juan River. }\end{array}$ & 0.9 & 12 & 36 \\
\hline MHW3 & $\begin{array}{l}\text { Stream seeping from northeast } \\
\text { corner of building called Salt } \\
\text { Palace. }\end{array}$ & 0.5 & $a$ & 220 \\
\hline MHN4 & $\begin{array}{l}\text { Stream flowing from septic } \\
\text { pond. }\end{array}$ & 0.9 & $a$ & $a$ \\
\hline MHW5 & $\begin{array}{l}\text { Stream after seepage from } \\
\text { northeast corner of Salt } \\
\text { Palace and from sewage pond } \\
\text { run toget,her. }\end{array}$ & 0.9 & 15 & 390 \\
\hline
\end{tabular}

$a_{\text {Below the detection limit. }}$ 
per hour. The concrete floor of the building, which was very dirty at the time of the survey, is all that rewains of this building. It was demolished after this survey was completed.

Results of measurements that were made using the equipment and techniques described in Appendix II are given in Table 4. The first four measurements were made between 9:30 A.M. and 2:00 P.M. on March 12, 1976; that at the west end was made at approximately 9:00 A.M. on March 13.

Although no ${ }^{222}$ Rn measurements were obtained, the data in Table 4 demonstrate that equilibrium between ${ }^{222} \mathrm{Rn}$ and its daughters was not attained in this building, which is to be expected in a building with openings that permit natural ventilation to occur. This series of four measurements on the same day shows the normal decrease in radon daughter concentrations as the nighttime inversion conditions disappear.

\subsection{Distribution of ${ }^{226} \mathrm{Ra}$ in Subsurface Soil and Tailings}

Holes were drilled at 21 locations at the Mexican Hat site, and gamma monitoring data were obtained at the 18 locations shown in Fig. 5 .

Measurements of gamma-ray intensity in these holes as a function of depth were made by FB\&DU and ORNL personnel using the apparatus described in Appendix II. Since the subsurface gamma-rays are due primarily to ${ }^{226} \mathrm{Ra}$ and several of its daughters, it is possible to calibrate the instrument and, thus, to convert the gamma-ray measurements to concentration of ${ }^{226} \mathrm{Ra}$ by comparing these measurements with concentrations of ${ }^{226} \mathrm{Ra}$ measured in soil collected at depths corresponding to the gamma-ray measurements. The conversion was accomplished, and the results were plotted $(+)$ by use of a Hewlett-Packard (Model No. 9815A) desk calculator connected to a Hewlett-Packard (Model No. 9871A) printer. The printer supplies dots between calculated points. The available analytical data (excluding hole composite samples) determined by use of equipment described in Appendix II were plotted (0) using the same equipment. The calculated distribution of ${ }^{226}$ Ra in subsurface soil and tailings at the site is displayed in Figs. 6 through 10 . Similar graphs for holes 7 and 11 are included in another report. 4 
Table 4. Concentration of ${ }^{222} \mathrm{Rn}$ daughters in the Salt Palace (former mill building) at Mexican Hat, Utah, during the period March 12-13, 1976

\begin{tabular}{|c|c|c|c|c|c|c|}
\hline \multirow{2}{*}{$\begin{array}{l}\text { Sample } \\
\text { number }\end{array}$} & \multirow[b]{2}{*}{ Location } & \multicolumn{3}{|c|}{$\begin{array}{c}\text { Concen ration of nuclide } \\
\text { (pCi/liter) }\end{array}$} & \multirow{2}{*}{$\begin{array}{l}\text { Working } \\
\text { levelsa }\end{array}$} & \multirow[b]{2}{*}{ Time } \\
\hline & & Ra A & $\operatorname{Ra} B$ & $\operatorname{Ra} C$ & & \\
\hline 1 & East-Center & 3.1 & 2.7 & 1.7 & 0.023 & 9:30 AM \\
\hline 2 & Northeast & 2.8 & 2.0 & 0.9 & 0.016 & $10: 15 \mathrm{AM}$ \\
\hline 3 & Southeast & 2.0 & 0.8 & 0.07 & 0.007 & 2: $15 \mathrm{PM}$ \\
\hline 4 & Center & 2.4 & 1.0 & 0.14 & 0.008 & $2: 55 \mathrm{PH}$ \\
\hline 5 & West-Center & 4.7 & 4.6 & 1.7 & 0.034 & $8: 55 \mathrm{AM}$ \\
\hline
\end{tabular}

a The working level (WL) is defined as the concentration of short-lived radon daughters in one liter of air such that the total potential alpha energy is $1.3 \times 10^{5} \mathrm{MeV}$. 
ORNL-Photo 0748-79

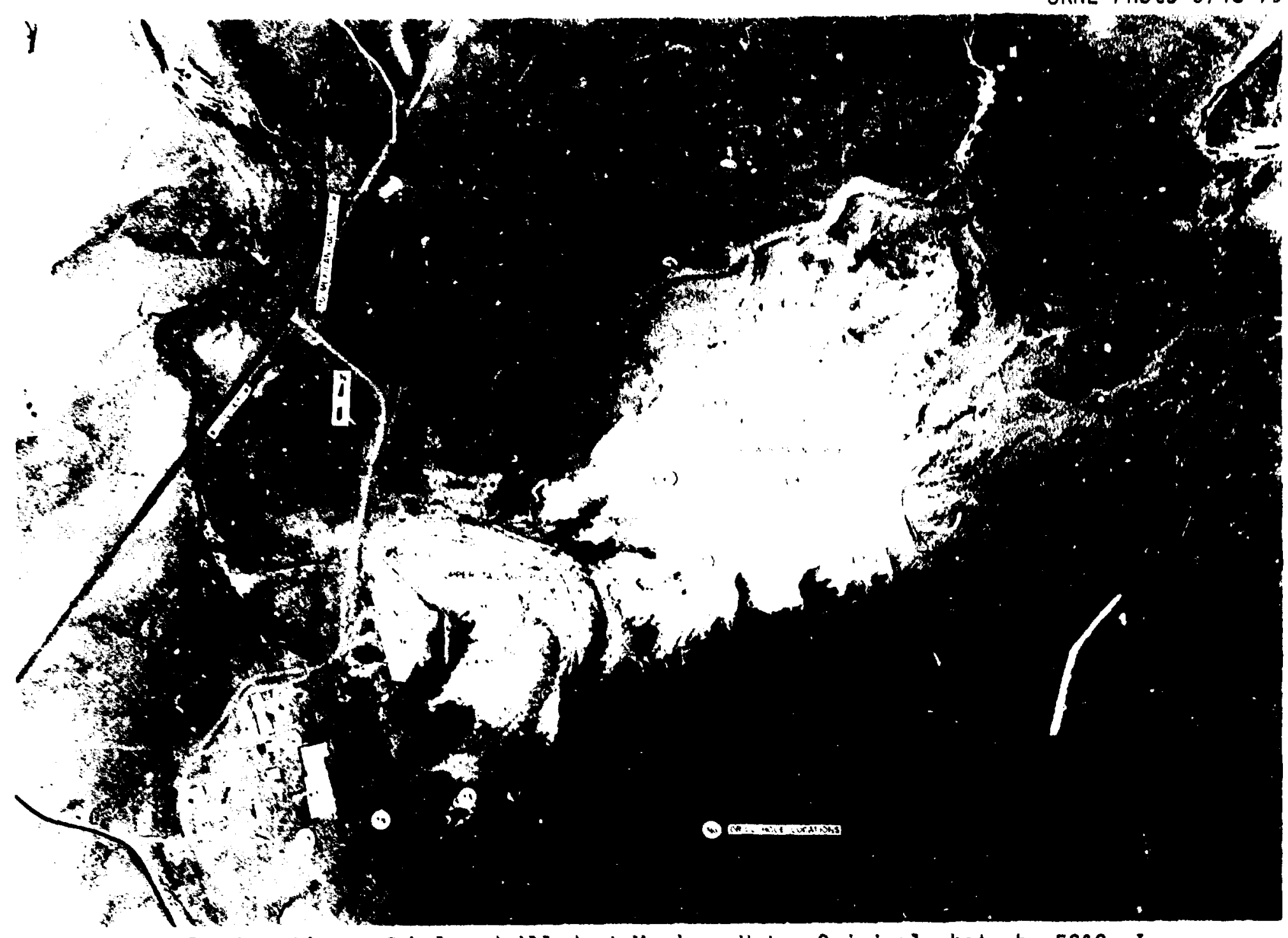

Fig. 5. Locations of holes drilled at Mexican Hat. Original photo by EG\&, Inc. 


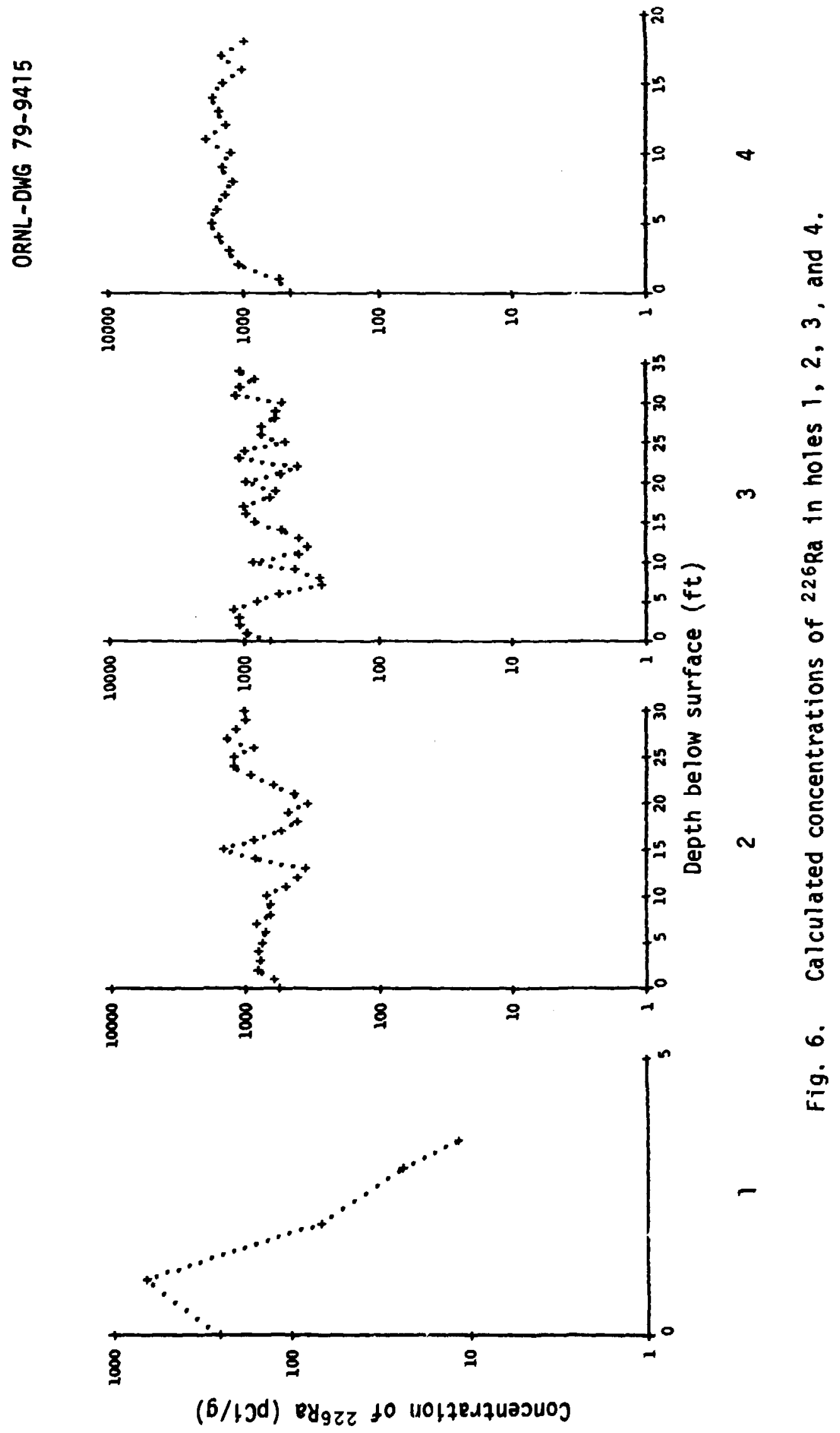


ORNL-DWG 79-9416

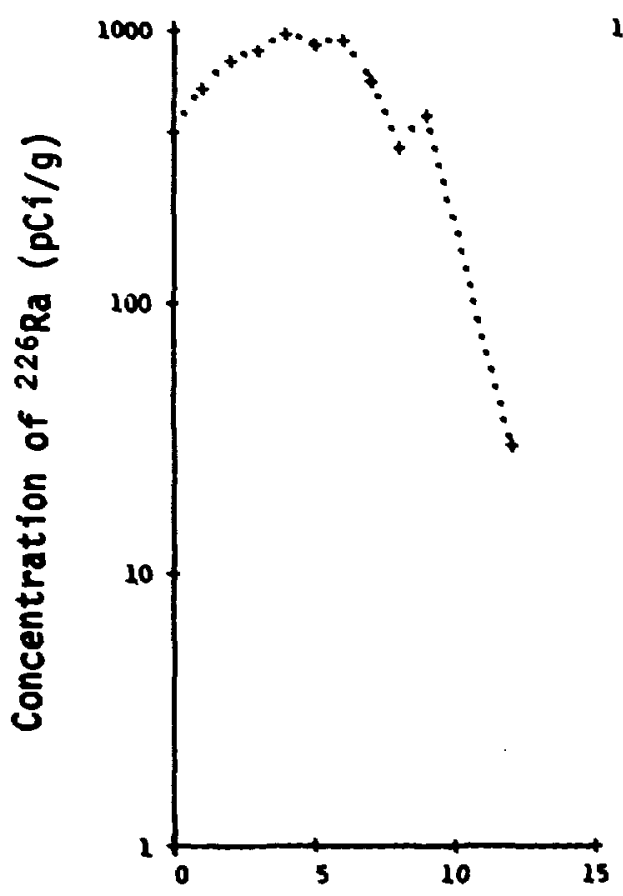

6

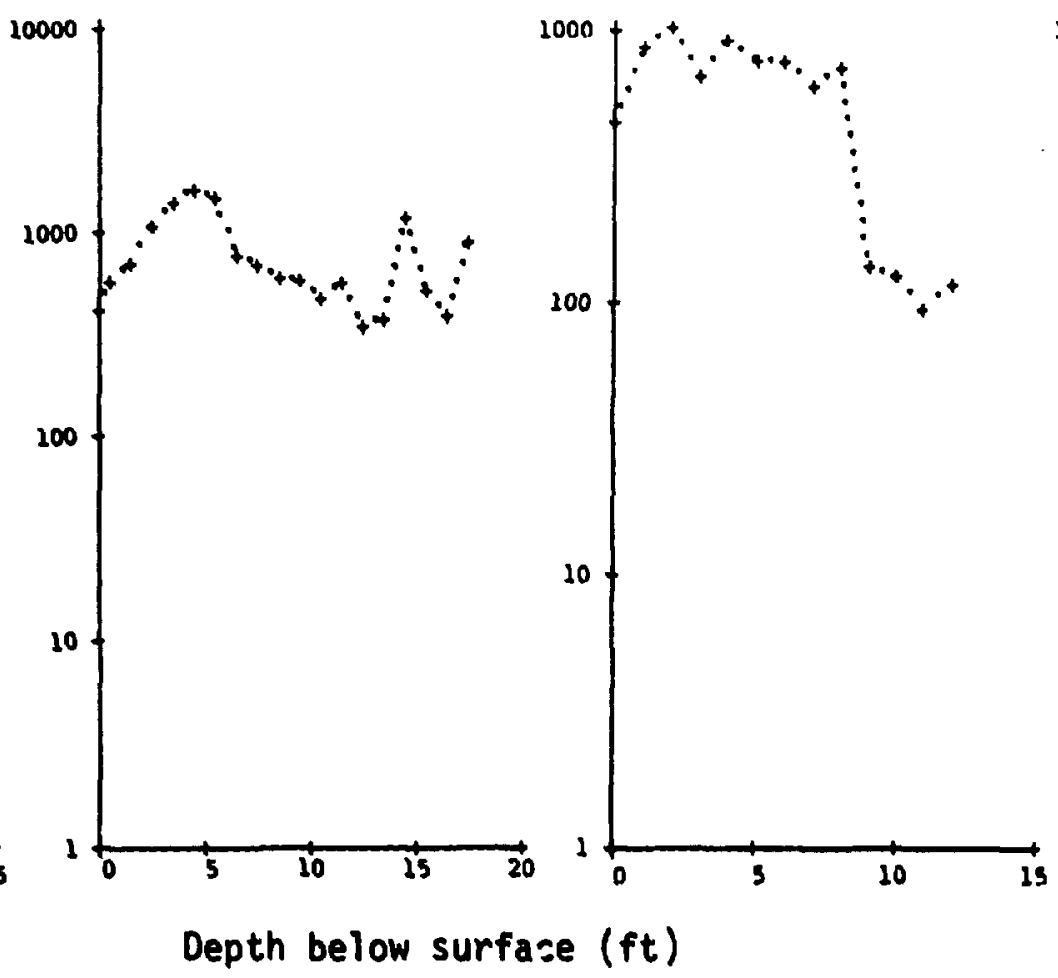

7

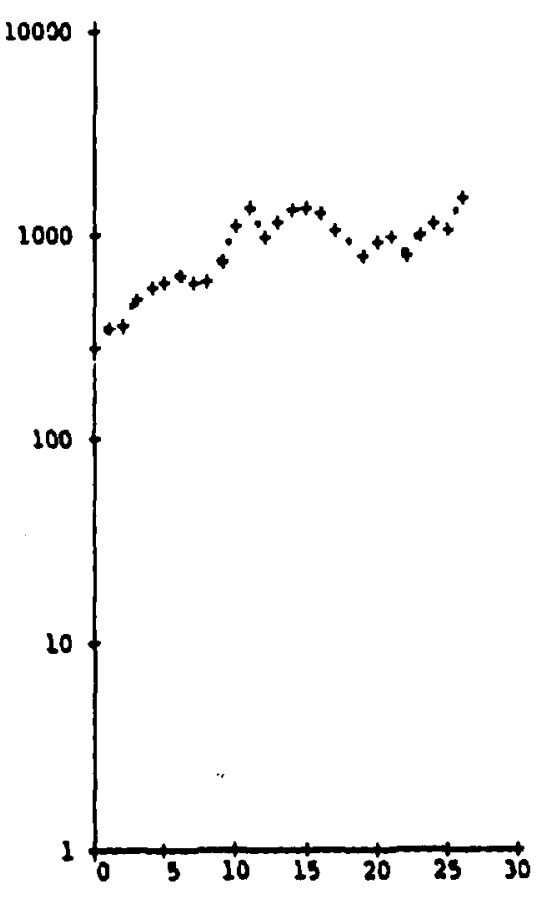

8

9

Fig. 7. Calculated concentrations of ${ }^{226}$ Ra in holes $6,7,8$, and 9. 


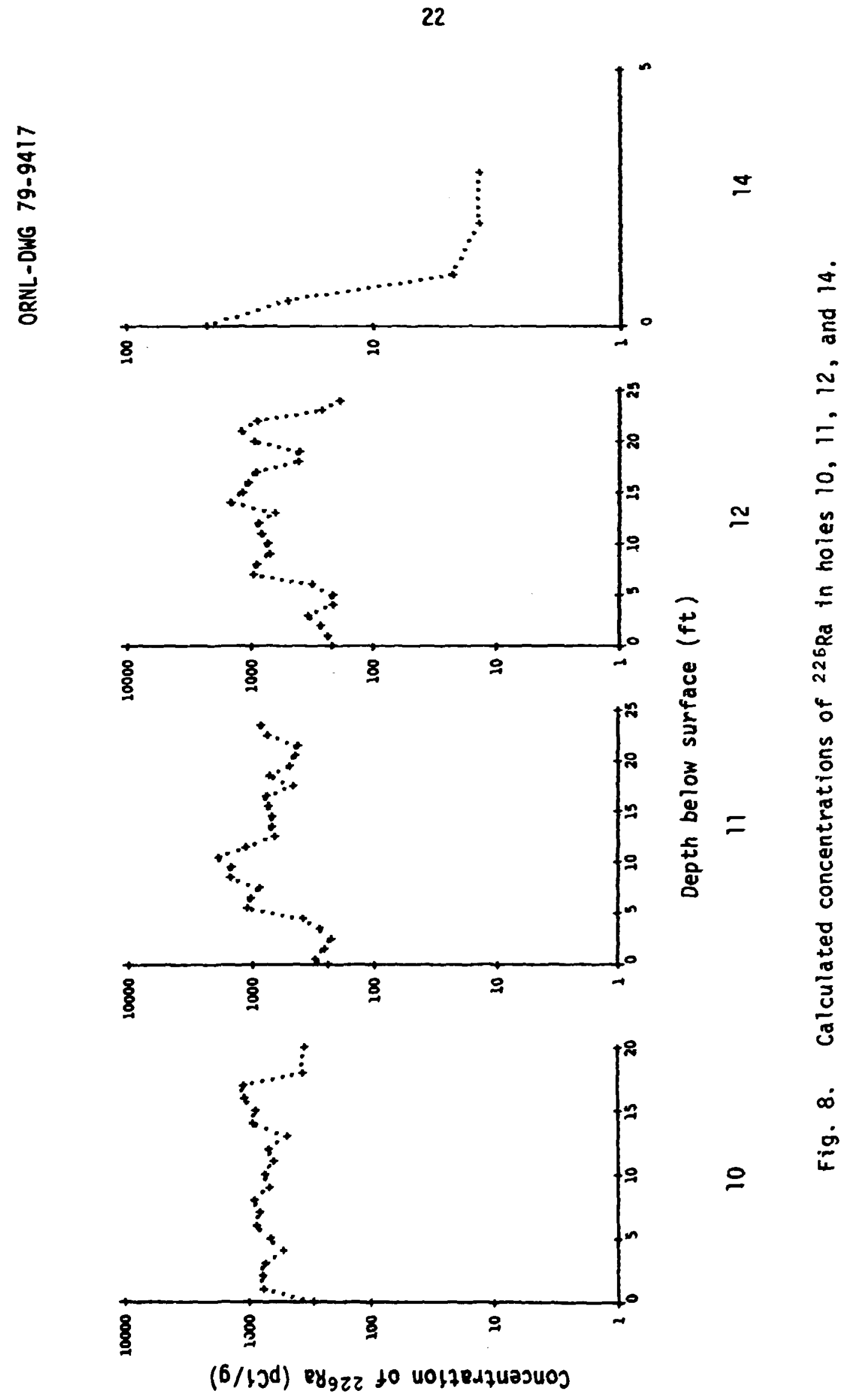




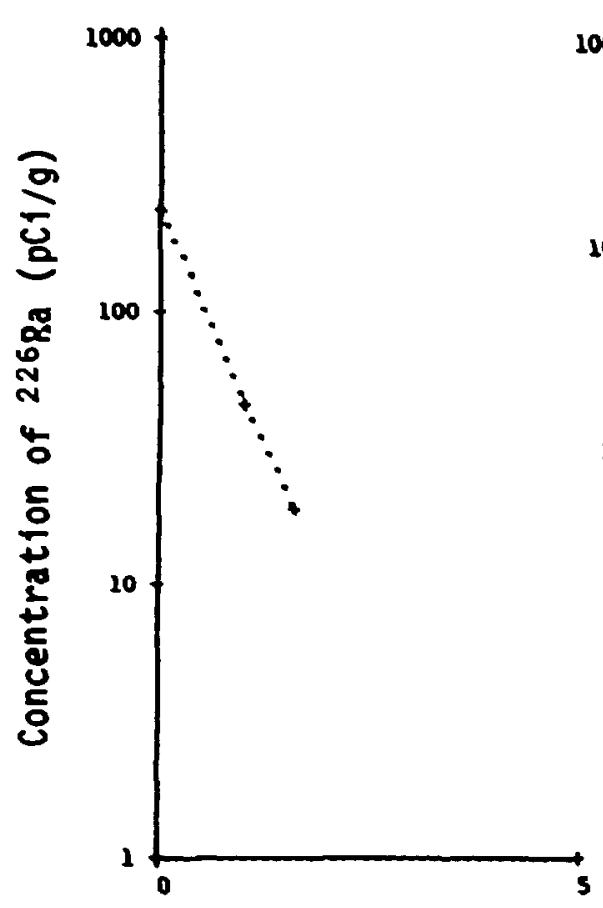

15

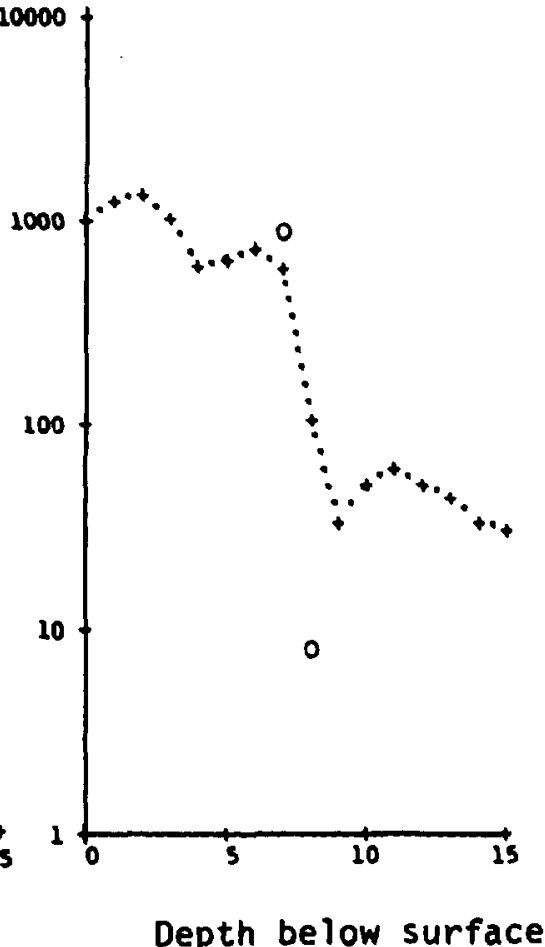

16

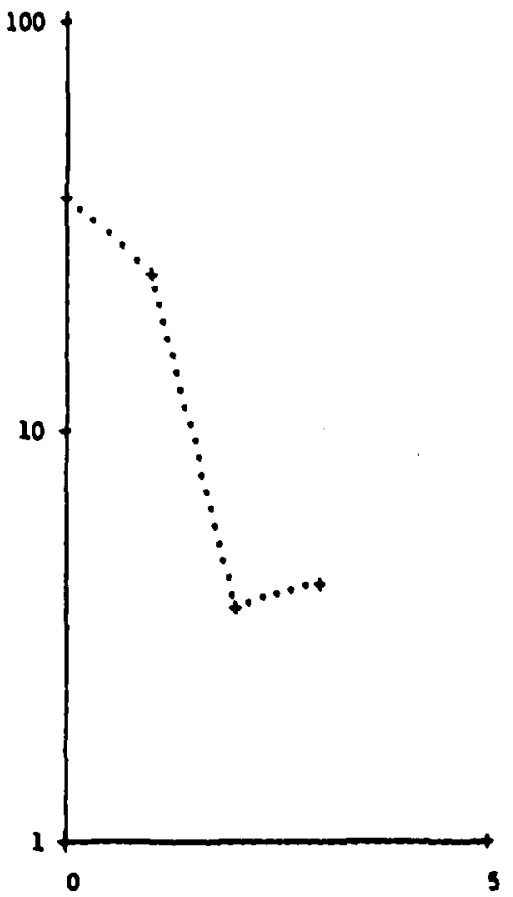

18

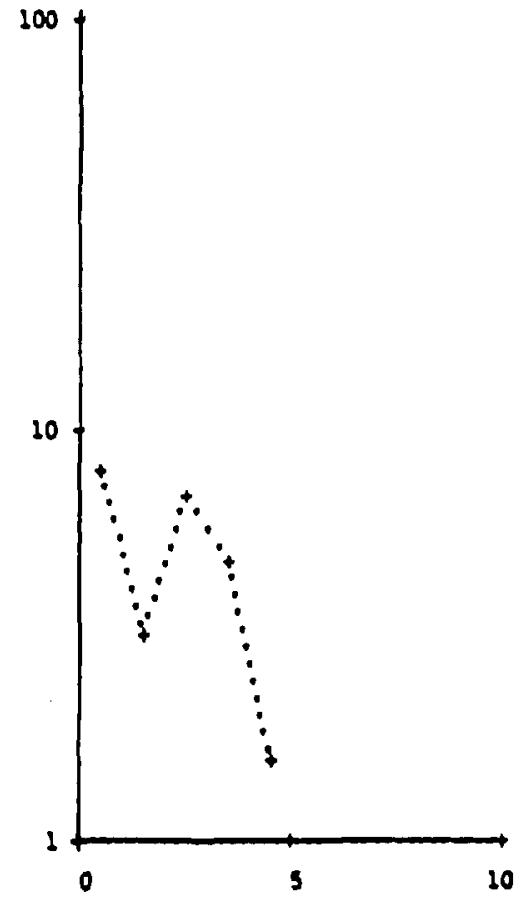

19

Fig. 9. Calculated concentrations of $226 \mathrm{Ra}$ in holes $15,16,18$, and 19. (Values noted by circle in hole 16 represent data from the analysis of individual soll samples.) 
ORNL-DWG 79-9419
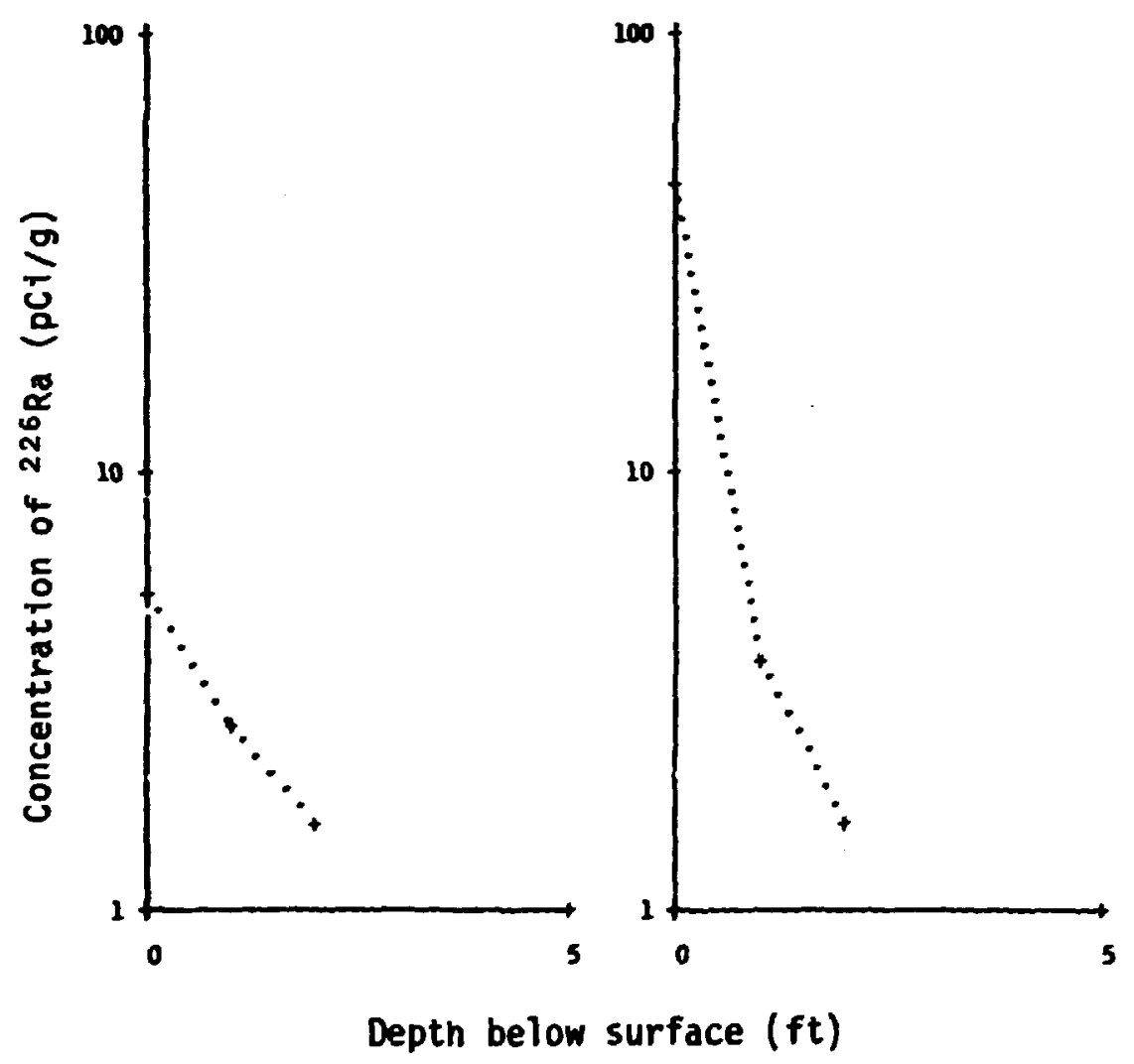

20

21

Fig. 10. Calculated concentrations of ${ }^{226} \mathrm{Ra}$ in holes 20 and 21. 
Fair agreement is observed between calculated and measured values for ${ }^{226}$ Ra concentration for hole 16, Fig. 9. The calculated ${ }^{226}$ Ra concentration in sections of holes where the concentration is low may be too high due to gamma "shine" from an adjacent sect: on of the hole, to contaminated material dropping to the botton of the hole or, possibly, due to the smearing action of the auger bit.

As would be expected, most of the holes showing a high concentration of ${ }^{226}$ Ra are in the tailings area. Hole 19 (fig. 9) in the former mill area has a low calculated concentration at all depths conitored (0-1.5 $\mathrm{m}$ or 0-5 ft), while hole 14 (Fig. 8) exhibits significant contamination at or near the surface, dropping rapidly at greater dep:h.

\section{HEALTH EFFECTS ATTRIBUTABLE TO THE MEXICAN HAT TAILINGS}

There are two housing areas $1.6 \mathrm{~km}$ or less from the Mexican Hat tailings piles. Also, a school is operating at the former will site. Since a high level of radioactivity is present in these tailings and no effort has been made to stabilize the piles, the potential exists for significant population exposures. Unfortunately, collection of all the data needed for an adequate assessment of potential health effects was not possible during the brief survey period at this site.

\subsection{Direct Dose Effects}

The average direct gamma exposure rate measured $1 \mathrm{~m}$ above the ground in the former mill and ore storage area is $180 \mu \mathrm{R} / \mathrm{hr}(0.18 \mathrm{milli}$ roentgen/hr). Continuous exposure at this rate gives an annual gamma dose equivalent of approximately 1600 millirem, more than three times the limit set by 10 CFR 20 for individuals in unrestricted areas. 9 Exposure during a 40-hr work week (2000 hr/year) would result in an annual dose equivalent of 360 millirem. As there are presumably no residenres in this area, the latter figure seems to be a more probable value to use for an assessment of potential health effects among students and other workers at the former mill and ore storage area. 
The average annual death rate from all causes in the $U$. S. population is approximately 1,000 deaths per 100,000 persons per year, and the annual average (as of 1975 ) death rate ${ }^{12}$ from all cancers is 186 deaths per 100,000 persons per year. This average annual death rate includes 179.1 deaths per 100,000 persons per year from all cancers except leukemia, for which the rate is 7.1 deaths per 100,000 persons per year. Data from the BEIR report ${ }^{13}$ indicate that the relative risk of death from all cancers except leutemia is 0.26 per rem. For leukemia, this rate is 26 per rem. Thus, the total weighted relative risk of death from all types of cancer including leukewia per rem (ignoring differences in latency period) is:

$$
\frac{0.26 \times 179.1+2.0 \% \times 7.1}{186.2}=0.27 \%
$$

or about 0.3\%. A one-year exposure to penetrating gamma radiation of 0.36 rea might increase the relative risk of death due to all types of cancer by about one-tenth of one percent $(0.3 \% / \mathrm{rem} \times 0.36$ rem $\approx 0.1 \%)$.

Direct gama measurements were not made at the fialchita and Mexican Hat comonities during the present survey. However, extrapolation of the gama weasurewents in Fig. 3 indicates that insufficient tailings or uranium ore particles reached either housing area to raise the direct gama exposure rate above the background level. Inspection of Douglas and Hans 1974 gama survey data ${ }^{3}$ leads to the same conclusion, and Snelling's 1968 survey report ${ }^{2}$ shows that the gamma exposure rate in the housing area now known as Halchita was at background level at that time. There seems to be no basis in the available data for estimating health effects from direct gama exposure at either Halchita or Mexican Hat, and it is concluded that the population at risk through this exposure pathway is confined almost exclusively to persons occupying the former mill area during the work week.

It should be noted that direct gamma exposure rates over the tailings piles, especially the No. 2 (east) pile, are very high and that access to these areas is unrestricted. Since several spots on the east pile show ganma exposure rates of approximatel: $1.5 \mathrm{millirem} / \mathrm{hr}$, the 500 
millirea/year aliowable gama dose equivalent would be exceeded in less than $350 \mathrm{hr}$.

\subsection{Radon Exposure Pathway}

No radon measurements were made by ORNL at the Mexican Hat site, and the only radon daughter measurements were wade in the Salt Palace, a former will area building that has been rewoved since the time of the 1976 survey. Radon measurements at this site have been reported by FBeDU4 and by Snelling, ${ }^{2}$ who also reported results of some radon daughter measurewents.

Hethods described in the first report in this series, for Salt Lake City, were used to calculate a radon flux rate of $750 \mathrm{pCi} / \mathrm{m}^{2}-\mathrm{sec}$ for the Mexican Hat tailings and a point source term, $1.9 \times 10^{8} \mathrm{pCi} / \mathrm{sec}$. Using an area source mode ${ }^{14}$ and the best available meteorological data for the area, ${ }^{15}$ the dispersion of radon from the Mexican Hat tailings was calculated, and the results are displayed in Table 5. The calculations show that the radon concentrations reaches the approximate annual average background level in the sections with the highest concentrations (southwest and west) at about $1.3 \mathrm{~km}$ from the center of the tailings. This result would not be expected because the prevailing winds are repcrted to be from the southwest and the highest concentration would be expected in the northeast direction, toward Mexican Hat. It is possible that the meteorological data's used is not truly representative of conditions in the vicinity of the Mexican Hat site. However, use of the data in Table 5 to estimate potential health effects gives a conservative estimate of total heaith effects because the Halchita housing area is about $1.0 \mathrm{~km}(0.6 \mathrm{mile})$ toward the southwest where the calculated radon concentration is high, whereas Mexican Hat with a smaller population than Haichita is further away (approximately $1.6 \mathrm{~km}$ ) toward the northeast where the calculated concentration is lower than toward the southwest. 
Table S. 2zzRn concentration (DCi/liter) resulting Prnt the Maxican Hat tallings:

\begin{tabular}{|c|c|c|c|c|c|c|c|c|c|c|c|c|c|c|c|c|}
\hline \multirow{2}{*}{$\begin{array}{l}\text { Distance } \\
(\mathrm{k} / \mathrm{w} / \mathrm{i})\end{array}$} & \multirow[b]{2}{*}{$M$} & \multirow[b]{2}{*}{ MME } & \multirow[b]{2}{*}{ NE } & \multirow[b]{2}{*}{ ENE } & \multirow[b]{2}{*}{ E } & \multirow[b]{2}{*}{ ESE } & \multirow[b]{2}{*}{ si } & \multicolumn{3}{|c|}{ Complass Direction } & \multirow[b]{2}{*}{ SW } & \multirow[b]{2}{*}{ WSW } & \multirow[b]{2}{*}{$W$} & \multirow[b]{2}{*}{ WW } & \multirow[b]{2}{*}{ NW } & \multirow[b]{2}{*}{ MMH } \\
\hline & & & & & & & & ss! & $s$ & sstw & & & & & & \\
\hline$\frac{0.32}{0.20}$ & 1.9 & 2.3 & 4.0 & 4.5 & 4.2 & 3.4 & 3.0 & 2.5 & 4.8 & 6.2 & 9.2 & 9.4 & 7.5 & 5.4 & 3.4 & 1.9 \\
\hline$\frac{0.53}{0.33}$ & 0.46 & 0.7 & 1.3 & 1.7 & 1.7 & 1.1 & 0.64 & 0.83 & 1.3 & 2.3 & 3.8 & 3.5 & 2,7 & 1.6 & 0.69 & 0.46 \\
\hline$\frac{0.97}{0.60}$ & 0.15 & 0.18 & 0.45 & 0.53 & 0.69 & 0.33 & 0.19 & 0.20 & 0.51 & 0.62 & 1.3 & 1.1 & 1.1 & 0.42 & 0.21 & 0.11 \\
\hline$\frac{1.34}{0.83}$ & 0.09 & 0.08 & 0.27 & 0.28 & 0.43 & 0.16 & 0.1 & 0.09 & 0.32 & 0.31 & 0.75 & 0.57 & 0.70 & 0.19 & 0.11 & 0.05 \\
\hline$\frac{2.25}{1.40}$ & 0.03 & 0.03 & 0.11 & 0.12 & 0.18 & 0.07 & 0.04 & 0.04 & 0.13 & 0.13 & 0.33 & 0.24 & 0.29 & 0.07 & 0.04 & 0.02 \\
\hline$\frac{3.86}{2.10}$ & 0.01 & 0.01 & 0.05 & $0 . n 5$ & 0.07 & 0.03 & 0.02 & 0.02 & 0.06 & 0.05 & 0.14 & 0.10 & 0.12 & 0.03 & 0.02 & 0.008 \\
\hline$\frac{5.17}{5.40}$ & 0.005 & 0.008 & 0.03 & 0.03 & 0.04 & 0.02 & 0.01 & 0.009 & 0.03 & 0.03 & 0.08 & 0.06 & 0.07 & 0.02 & 0.01 & 0.004 \\
\hline$\frac{7.08}{8.40}$ & 0.005 & 0.005 & 0.02 & 0.08 & 0.03 & 0.01 & 0.007 & 0.006 & 0.02 & 0.02 & 0.05 & 0.04 & 0.04 & 0.01 & 0.007 & 0.003 \\
\hline$\frac{10.8}{6.7}$ & 0.003 & 0.003 & 0.009 & 0.01 & 0.02 & 0.006 & 0.004 & 0.003 & 0.01 & 0.01 & 0.03 & 0.02 & 0.02 & 0.006 & 0.004 & 0.002 \\
\hline$\frac{40.2}{55.0}$ & 0.0005 & 0.0005 & 0.002 & 0.002 & 0.002 & 0.001 & 0.0006 & 0.0005 & 0.002 & 0.002 & 0.005 & 0.004 & 0.004 & 0.001 & 0.0006 & 0.000 .3 \\
\hline
\end{tabular}

tralculated area source $=750 \mathrm{pCi} / \mathrm{m}^{2} \cdot \mathrm{sec}$. 
If we assume that the data in Table 5 represent the annual average contribution of the Mexican Hat tailings to the total radon concentration in the area and that the annual average wind speed in all directions is $3 \mathrm{~m} / \mathrm{sec}$ ( $7 \mathrm{mph}$ ), the radon daughter concentration in the air at Halchita equivalent to $1 \mathrm{pCi} /$ /iter of ${ }^{222} \mathrm{Rn}$ is $0.001 \mathrm{WL^{ \star }}$ (10\% of equilibrium) and the corresponding value at Mexican Hat is $0.002 \mathrm{WL}$ (20\% of equilibrium). These figures represent outdoor concentrations of radon daughters. For the present health assessment, we will adopt the conservative assumptions that no decay of radon occurs in the time required to reach homes in either comunity; that $1 \mathrm{pCi} / \mathrm{liter}$ of radon outdoors will result in $0.005 \mathrm{WL}$ of daughters indoors; and that continuous exposure to this concentration of daughters will result in an annual exposure of 0.25 (WLM). Walsh's has estimated that an increase of 1.0\%/year in risk of death from lung cancer is associated with a continuous exposure to 1 WLM/year. For Halchita residents where the calculated ${ }^{222} \mathrm{Rn}$ concentration is $1.3 \mathrm{pCi} / \mathrm{liter}$, the increased risk is $0.3 \% /$ year. The corresponding number for the residents at Mexican Hat, where the calculated ${ }^{222} \mathrm{Rn}$ concentration is $0.22 \mathrm{pCi} / \mathrm{liter}$, is $0.06 \%$ year.

The high direct gamma measurements reported by FB\&DU, 4 and ORNL soil analyses in the former mill and ore storage area (Table 2) show that the potential exists for high concentrations of radon in this occupied area irrespective of the contribution from the nearby tailings piles. A single 24-hr outdoor measurement' of radon in this area showed a ${ }^{222} \mathrm{Rn}$ concentration of $2.0 \mathrm{pCi} / \mathrm{liter}$, lower than the calculated annual average contribution of the tailings at $0.3 \mathrm{~km}$ in the $S W$ and WSW sectors in Table 5 ( $9 \mathrm{pCi} / \mathrm{liter}$ ). If we assume that the higher figure represents the annual average ${ }^{222} \mathrm{Rn}$ concentration and that the daughter concentration indoors in this area is $50 \%$ of the equilibrium ratio, as assumed previously, then continuous exposure would result in 2.3 WLM/ year. For a $40-\mathrm{hr}$ work week, this value is reduced to $0.5 \mathrm{WLM} /$ year which, using the above-mentioned risk increase estimator, gives an

\footnotetext{
*The working level (WL) is defined as the concentration of short-lived radon daughters in one liter of air such that the total potential alpha energy is $1.3 \times 10^{5}$ Mev. A working level month (WLM) is exposure to $1 \mathrm{WL}$ for a duration of $170 \mathrm{hr}$.
} 
annual increased risk of $0.5 \%$ for students and faculty at the trade school in this area.

Students and faculty at the grammar school situated between the former mill area and Halchita, reported ${ }^{4}$ to number 160 , represent another population group at risk from exposure to radon emitted by the tailings. The average annual radon concentration at this location was estimated from the data in Table 5 to be $2.4 \mathrm{pCi} / 1$ iter. Assuming that the daughter concentration is at $50 \%$ of equilibrium with ${ }^{222} \mathrm{Rn}$ indoors, the calculated concentration is $0.012 \mathrm{WL}$, which is equivalent (for continuous exposure) to $0.6 \mathrm{WLM} /$ year. For a 180-day school year and a 7-hr school day, this reduces to $0.09 \mathrm{WLM} /$ year. Using the risk increase estimator for this exposure ( $1 \%$ increase in risk per WLM) gives an increased risk of lung cancer death of $0.1 \%$ /year. The results of the calculations discussed above are sumarized in Table 6 . The population weighted increased risk of lung cancer attributable to radon from the tailings pile is $0.2 \%$.

An estimate can be made of increased risk of death from lung cancer that could result from exposure to the background radon concentration in this area $(0.35 \mathrm{pCi} / 1 \mathrm{iter}) .^{2}$ Assuming continuous indoor exposure, an average indoor radon concentration of $0.35 \mathrm{pCi} / \mathrm{liter}$, and a daughter equilibrium of $50 \%$ gives an estimated increased risk of death from lung cancer of $0.09 \% / y e a r$, approximately one-half that estimated for exposure to radon from the tailings pile.

\subsection{Health Effects Attributable to Other Exposure Pathways}

Various other pathways through which people can conceivably be exposed to radionuclides contained in uranium-mill tailings were mentioned in Sect. 3 of this report. Data are not available to thoroughly evaluate any of these sources of health effects, but the available information is discussed here in an effort to throw some light on the likelihood of health effects from exposure modes not discussed above.

Snelling ${ }^{2}$ reported results of measurements of this type at nine stations including one on and two near the No. 2 tailings pile. Other stations were on the No. 1 pile, in the mill area, at the trailer camp 
Table 6. Estimated increased risk of lung cancer death per year attributable to radon dispersed from the Mexican Hat tailings

\begin{tabular}{lcccc}
\hline & $\begin{array}{c}\text { Distance from } \\
\text { center of } \\
\text { tailings }(\mathrm{km})\end{array}$ & $\begin{array}{c}\text { Estimated } \\
\text { indoor 222Rn } \\
\text { daughter con- } \\
\text { centration (WL) }\end{array}$ & $\begin{array}{c}\text { Fraction of year exposed } \\
\text { Population group }\end{array}$ & $\begin{array}{c}\text { Increased annual } \\
\text { risk (\%) }\end{array}$ \\
\hline Halchita & 1.0 & 0.0065 & 1.0 & 0.3 \\
Mexican Hat & 1.6 & 0.0011 & 1.0 & 0.6 \\
Trade School & 0.3 & 0.038 & 0.24 & 0.5 \\
Grammar School & 0.7 & 0.012 & 0.14 & 0.1 \\
Population-weighted average & & & & 0.2 \\
\hline
\end{tabular}


near the grammar school, and at Halchita. Two stations were located approximately $1.6 \mathrm{~km}$ northeast of the tailings. Continuous 24-hr samples were collected at each station on 11 consecutive Jays (Hay 28June 7,1968$)$ at a rate of $0.14 \mathrm{~s}^{3}\left(5 \mathrm{ft}^{3}\right) / \mathrm{min}$. Data ottained during an 11-day period cannot be safely assumed to represent annual averages.

The filters on which Snelling collected airborne particles vere analyzed individual?y for gross alpha coitent and then all the filters collected at each staticn were composited and analyzed for ${ }^{226} \mathrm{Ra},{ }^{230} \mathrm{Th}$, and natural uranium. Snelling concluded that elevated concentrations of airborne radioactivity existec in the downind direction from the tailings but that concentrations of individual radionuclides did not exceed concentration guides $\left(\mathrm{CG}_{a}\right) .9$ However, he pointed out that the tailings pile was still quite moist (clay-like consistency) at the time of his measurenents and that conditions could very well become worse as the pile dried out. He recomended either stabilizing the tailings area or periodic monitoring to ensure that the concentration guides are not exceeded. Neither course of action has been followed, but more recent data obtained by J. M. Hans, Jr. (EPA-ORP-LVF) were reported by FB\&DU (Ref. 4, Table 3-4). Measurements at three locations in 1974 at or near the former mill site showed that the concentration of each of the eight radionuclides found was orders of magnitude below the 10 CFR 20 concentration guides ${ }^{9}$ except for ${ }^{230} \mathrm{Th}$. The concentration of this nuclide at the mill site was found to be $15 \%$ of the concentration guide while that at Mexican Hat was about $1 \%$ of the guide. It appears from the small amount of data available that significant health effects from airborne particulate radioactivity are unlikely, but many more measurements would be required to assure that concentration guide values are being met for all exposed populations.

Grazing of burros has been observed on and near the tailings piles, but consumption of animal meat by residents of the area represents an unlikely exposure mode. No data were obtained during th: ORNL survey at Mexican Hat that permit evaluation of exposure through food pathways and, apparently, none exists in the literature. There is no evidence in 
presently available information that significant exposcires at this site occur through consumption of contaminats $\because$ food.

Data on the concentration of ${ }^{226} \mathrm{Ra}$ in several water samples (see Table 3) show that water streams near the tailings contain low enough amounts of the nuclide to be acceptable for drinking water with one exception, a stagnant pond that contains approximately three times the concentration guide for drinking water. ${ }^{11}$ It seems unlikely that residents of the area would use this pond as a drinking water supply, but it is conceivable that grazing animals could drink from it. Analysis of water samples from the San Juan Piver over a period of more than 10 years showed an average upstream ${ }^{226} \mathrm{Ra}$ cricentration of $0.13 \mathrm{pCi} / \mathrm{liter}$, and downstream from Hexican Hat the value was $0.17 \mathrm{pCi} / 1$ iter. ${ }^{17}$ Potential health effects of water use would be less using river water than from using water from any of the sources shown in Table 3.

Sears et al. ${ }^{7}$ evaluated doses received through exposure pathways for model uranium mill tailings for the case where all of the food consumed in the area is grown in the vicinity of the tailings and for the case where none of the food is grown in the potentially contaminated area. Since no gardens or fruit trees were observed in the immediate vicinity of the tailings, it seems likely that the Mexican Hat case is intermediate between these two cases but probably nearer the latter. The average maximum total-body dose estimated for the no-grown-food case was only $2 \%$ of that for the all-grown-food case. Since the average population total-body dose for the two sites and two milling processes considered by Sears et al. ${ }^{7}$ was only 1.0 man-rem, it seems likely that poteritial health effects of the Mexican Hat tailings through the food pathways are small as compared to the other pathways.

\section{SUMMARY AND CONCLUSIONS}

The inactive uranium-mill tailings at the Mexican Hat site contain a large amount of ${ }^{226} \mathrm{Ra}$. Thus far, no effort has been made either to stabilize the tailings or to restrict access to the area. The local topography and the prevailing winds favor movement of tailings particles north and northeast toward the San Juan River and the small community of 
Mexican Hat. Efforts have been made, however, to restrict water flow from the tailings to the river.

The direct gamma-ray survey showed an average value of 880 (maximum 1570) $\mu R / h r$ measured $1 \mathrm{~m}$ above the surface of the No. 2 (east) tailings while the corresponding value for the ko. 1 (west) tailings pile is 420 (maximum 880) $\mu \mathrm{R} / \mathrm{hr}$ and, in the former mill area (now used by a trade school), the average level is 180 (maximum 570) $\mu \mathrm{R} / \mathrm{hr}$. Since crushed uranium ore was stored on che ground in this area, the high radiation level observed could be due to ore particles rather than tailings. other than dismantling the former mill buildiag, no apparent effort has been made to reduce the radiatin level in this area. ${ }^{18}$

Aralysis of surface and near-surface soil samples for ${ }^{226}$ Ra confirmed the spread of tailings and/or ore particles indicated by the ganma survey, especially in the north and northeast directions from the tailings. The maximum ${ }^{226} R a$ concentration observed in a soil sample outside the tailings area was $314 \mathrm{pCi} / \mathrm{g}$ in the former mill area. With one exception, all the water samples from iis: vicinity of the tailings contained ${ }^{226} \mathrm{Ra}$ concentrations of less than $\mathrm{I} \mathrm{pCi} / \mathrm{liter}$. The exception was a small stagnant pond.

In spite of the high levels of ${ }^{226} \mathrm{Ra}$ in surface soil, the few measurements of radon daughters (made in the Salt Palace) reported here and a few measurements of radon and radon daughters reported by others at this site were not excessively high, according to the Surgeon General's guidelines. ${ }^{19}$ Calculation of radon concentration as a function of distance and direction from the center of the tailings area enabled an estimation to be made of potential health effects among four population groups resulting from inhalation of radon daughters. The populationweighted increase in risk of death from lung cancer attributable to radon from the tailings is $0.2 \%$ year, using conservative assumptions. This compares to an increase in cancer risk for workers and students at the former mill site of $0.5 \%$ /year from direct gamma-ray exposure.

No evidence was found to indicate that significant health effects occur from exposure through other possible exposure pathways than those considered above. 
Data on the below-surface distribution of ${ }^{226} \mathrm{Ra}$ in the tailings piles and other contaminated areas, most of which have not been previously reported, will be helpful in guiding remedial action in the area if that should be undertaken. 


\section{REFERENCES}

1. F. F. Haywood, W. A. Goldsmith, P. T. Perdue, H. F. Fox, and H. H. Shinpaugh, Assessment of Radiotugical Impast oi the Iractive Unanium-

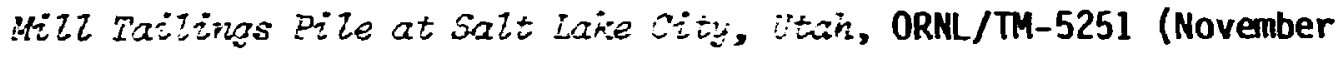
1977).

2. R. N. Snelling, "Enviromental Survey of the Uranium Mill Tailings Pile, Mexican Hat. Utah," Radiol. Heatih Data Ren. 12, 17-28 (1971).

3. R. L. Douglas and J. M. Hans, Jr., Garma Radiztion Sumejs at Enative Uranion MiLZ Sites, Technical Note ORP/LV-75-5 (August 1975).

4. Ford, Bacon and Davis Utah Inc. Phase II-Title I, Engineering Assessment of Inactive Uranium Hizl failings, Uexicar Hai, Utish GJT-3 (March 1977).

5. U. S. Atomic Energy Commission, Ervisonmental Surveis of the Jpanizm FuEZ yole, WASH-1248 (fipril 1977).

6. U. S. Environmental Protection Agency, Environmentai Aratysis of the Uranizon Fuel Cycie, Part I. FueI supply, PB-235804 (October 1973).

7. M. B. Sears, R. E. Blanco, R. C. Dahlman, G. S. Hill, A. D. Ryon, and J. P. Witherspoon, Correlation of Paiioactive Waste Freatment Costs and the Environmental Impact of Waste $E_{j}$ fluents in the Nuclear Fuel Cycle jor jue in Establishing "As-Low-ris-Fracticable" suides-lyizling of uranizon Ores, ORNL-TM-4903, Vol. I (May 1975).

8. J. J. Swift, J. M. Hardin, and H. W. Calley, Potentixl Radiological Impast of Airbome Releases and Direct Gama Sadiation io Individuals Living Hear Inactive Uranium Mill Iaizings Pizes, EPA-520/1-76-001 (January 1976).

9. Code of Federa? Regulatione, Title 10, Part 20 (10 CFR 20) (April 30, 1975).

10. U. S. Public Health Service, Publication 956-Drinking Water Standards (1962). 


\section{REFERENCES (Cont'd)}

11. Code of Federal Regulations, Title 40, Part 141 (July 9, 1976).

12. U. S. Department of Health, Education and Helfare National Center for Health Statistics, Final Mortality Statistics, 1975, Monthly Vital Statistics Report, Vo1. 25, No. 11, Supplement (February 11, 1977).

13. National Academy of Sciences-National Research Council, The Effects on Pomslations of Exposume to Low Levels of Iorizing Radiation (BEIR Report) (November 1972).

14. H. M. Culkowski and M. R. Patterson, A Comprehensive Atmospheric Transport and Diffusion Model, ORNL-NSF-EATC-19 (1976).

15. U. S. Department of Commerce, NOAA, Environment Data Service, Wind Distribution by Five Pasquill Stability Classes (STAR Progrom), Farmiziton, New Mexico, May 1963-April 1964, Job No. 12160, National Climatic Center, Asheville, N. C., August 28, 1970.

16. P. J. Walsh, "Dose to the Tracheo-bronchial Tree Due to Inhalation of Radon Daughters," PP. 192-203 in the Proceedings of the Tenth Midyear Symposium, Health Physics Society, Saratoga Springs, New York, October 11-13, 1976.

17. U. S. Environmental Protection Agency, Region VIII, Radiun-226, Uraniwn, and Other Radiological Data Collected from Water Quality Surveillance Stations Located in the Colorado River Basin of Colorado, Utah, New Mexico and Arizona - January 1961 through June 1972, 8SA/TIB-24, Denver, Colorado (July 1973).

18. P. Bradford, Utah Navajo Development Council, Blanding, Utah, private communication, March 1978.

19. Surgeon General of the United States, Code of Federal Regulations, Title 10, Part 712-Grand Junction Remedial Action Criteria sederal Register, Vo1. 41, No. 252, December 30, 1976. 


\title{
APPENDIX I
}

\section{PHASE I}

\author{
Report on Conditions of Uranium Mill Site and Tailings \\ at Mexican Hat, Utah
}

Site visited May 16, 1974 by Gordon T. Brown, Lucius Pitkin, Inc., (Contractor to USAEC), Grand Junction, Colorado Jon Yeagley, Environmental Protection Agency, Region VIII, Denver, Colorado

David E. Bernhardt, Environmental Protection Agency, Las Vegas, Nevada

Blaine Howard, Utah Division of Health, Salt Lake City, Utah

This Phase I site invastigation was conducted under a cooperative agreement among the Atomic Energy Commission, the Environmental Protection Agency, and the State of Utah. The report was prepared by Lucius Pitkin, Inc., under AEC Contract No. AT(05-1) 912, and is reproduced directly from the best available copy with color photographs from the original report changed to black and white. 


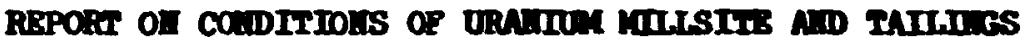

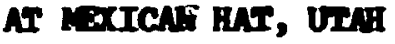

\section{Introduction}

Pertinent information has been accunlated from arailable records of the $A B C, B P A$, the States and companies inrolved. An cn-site vist wes ande to note current conditions, including the dillate and the tailings disposal area, procinity to populated and industrialized ereas, precent onnership, and wether a need for corrective action exists. It is intended that this report wll serve as a basis for deterwining the necessity of a detailed engineering assessunt (Fhase II).

This report on the site et Mexican Hat, Utah, was prepared jointly by the ABC, the BPA, and the State of Utah's Division of Health, Burironnental Health Adinistration.

Surary and conclusions

The uranium wil near Mexicen Hat, Utah, is on the Javajo Indien Reservetion. The mill operated Prou Dovemer 1957 to Pebruary 1965. In that tive the all processed $2.2 \mathrm{million}$ tons of ore and produced a silar quantity of tailings. The site reverted to the control of the favajo fation in 1970 and a trade school has been established in some of the bulldings. All of the diling equipment has been removed. None of the alleite or tailings area is fenced.

The tallings are in two large piles. The western (10. 1) pile covers about 18 acres east of the mill buildings. The eastern (10. 2) pile covers about 32 acres at a lower elevation truediately east of the 10. i pile. The piles are confined by higher ground on the south and west and by dans on the north and east.

The surface of the tailings piles at the tine of the site vist were falriy well crusted, but sowe wind erosion occurs from southnest to northeast in the direction of the prevaling wind, which is also the direction of the surface drainage. Hater erosion is afintal.

As a result of the site vist and review of inforntion contained in this report, It is concluded that the public healts and econonic ispacts of the following actions should be investigated in a further study of the varicen iat site:

I. Wove drifted radioactive aterial sron the aree northent of the tallings plie, the all area, and other areas to the tallings piles; contour and cover the piles and stabilize tham . 
II. Deterine neasures necessary to divert ourface rumorr from the tailings.

III. Deteringe manures necessary to prevent runoff vater from going direetly from the tailings aree to the ine Juan River.

IV. Perfore wore detailed rediantric surveye of the dill, school, and bouaing areas and deternine need for corrective ection.

\section{Location}

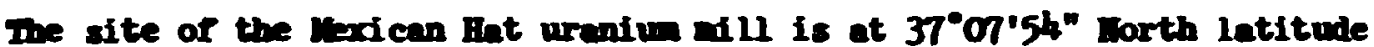

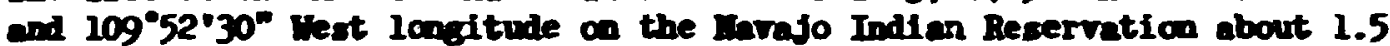
illes southwest of the mexicen lat crossing or state Highnes 47 over the San Juen River in San Junn County, Utah. Figure 1 is a ap of the area. nerial Fhotogragh 1 taken in Jume 1974 views the area fron the nillsite to San Juan Biver.

Omership

The all was built by Texas-zinc Mnerals corporation and operated by that compeny from initial startup in late 1957 until it das acquired by Atlus casporation in 1963. Atlas opereted the fill througl its subsidiary, A2 inderals, until shutdown early in 1965. Ownerahip has now reverted to the Iarajo Wation.

\section{History of Operations}

The Mexican Hat nill operated from Hovember 1957 to Pebruary 1965. In that time the all processed 2.2 dilion tans of ore, with an arerage code of 0.28 percent $\mathrm{U}_{3} \mathrm{O}_{8}$, and produced 5,69 tons of $\mathrm{U}_{3} \mathrm{O}_{8}$ in concentrate for sale to the OSAEC. Photograph 2, looking northessterly, is a view of the all area during the operating period.

\section{Process Description}

Wuch of the ore processed at Nexican Hat care from the White Canyon area and contained a considerable anount of copper sulfide and otber sulfide Aneral. To recover this copper the ground ore vas treated by froth lotation and both the flotation concentrates and tallinge were then acidlesched separately. The leached notation concentrates vere filtered to recover a final copper product, and the filtrate was then comblned with the enin circuit leached slury obtalned fron tbe notation tadifings. A five-stage countercurrent thickeper circuit was used to separate lesched solids and pregnant liquor which was then clarified before solvent extraction. The loaded organle solvent wes atripped with anoulun nitrate colution which was then neutrallized with monesiu hydroxide to precipitate the final uranive product. I/ 


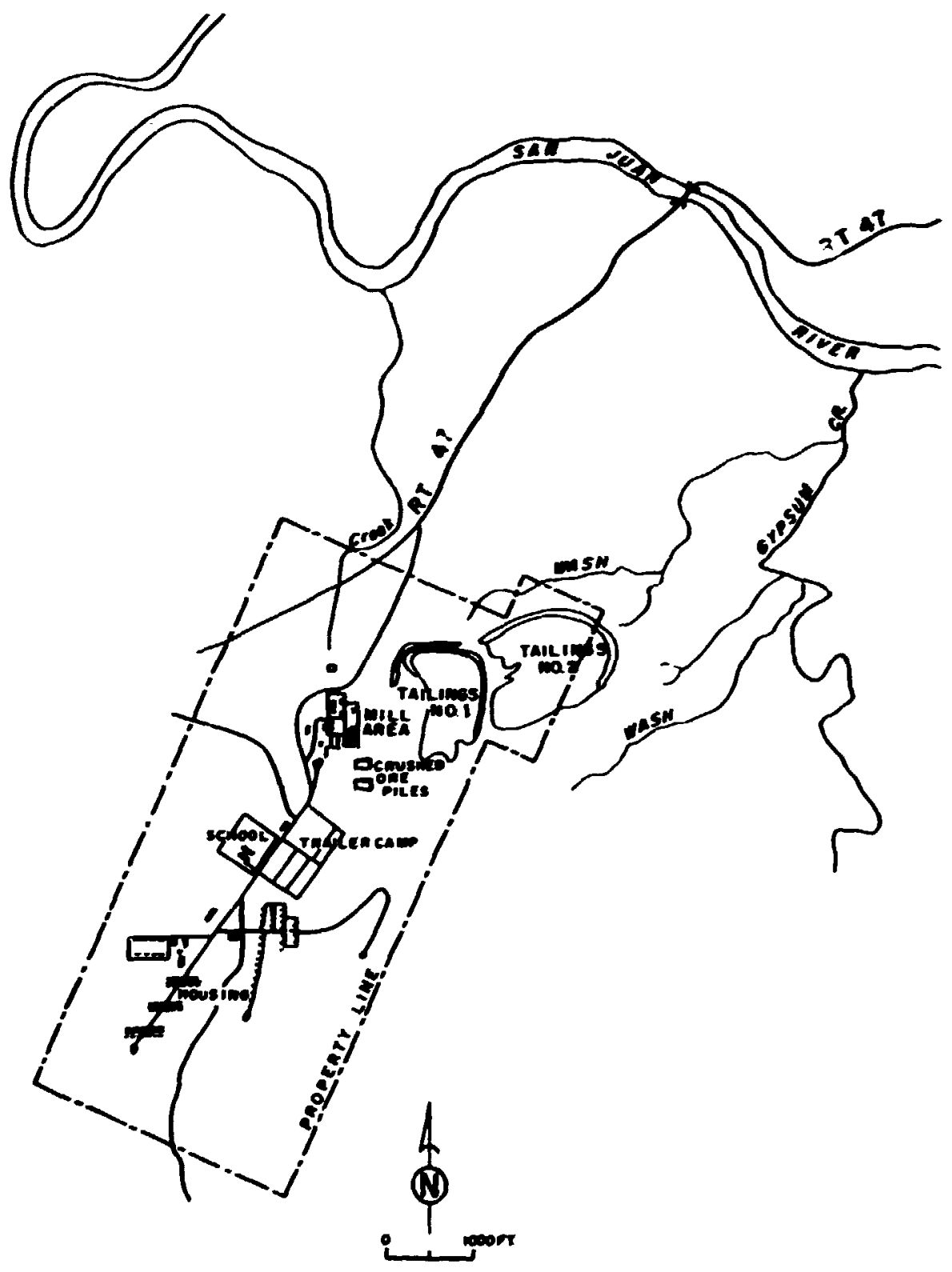

URANIUM MILL TAILINGS AND CONTIGUOUS AREA MEXICAN HAT UTAH

Pigure 1 
Present Milsite

Since the dilsite reverted to the ounership and cantrol of the llavajo Iation in 1970, a Marajo trade school operated by the Uteh Trades Concission has been established in some of the buildings. Tre school teaches carpentry, welding, etc., and operates a job plecement service for its trainees. It has 100 or wore students.

There are two tallings piles bounded by fairly steep hills on the south and lying on ground that slopes geatly towand the San Juan River about one-half ale to the northeast. The 10.1 pile begins about 600 feet east of the dill buildings and covers an erea of about 18 acres. The 10. 2 pile covers about 32 acres imediately east of the dan inpounding the first pile. The total quantity of tailings is estinated at 2.2 dilion tons with an average grade of 0.02 percent $\mathrm{U}_{3} \mathrm{O}_{8}$.

Tailings to each pile vere distributed by a cyclone separator which built up the dans with coarse sand and allowed the slines to flow toward the lover surfaces in the center and southwestern parts of the piles.

Tailings daws were cut through by water erosion in several places, but mot, if not all, such cuts were repaired with a new bern built inside the old ose. (Fhotograph 8). The surfece of the piles at the tilie of the site visit were crusted, eapecially on the Ho. 2 pile. Som sort, loose, fine-grained material was observed along the southwest edge of the 10. I pile (Fhotograph 4) and sowe wind erosion was observed on the northeastern bern of the Io. 2 pile. The prevaling wind is apparently from the soutbwest and sone wind-blown nterial can be seen northenst of the Ho. 2 pile. (Fhotograph 15). Dikes have been built north and northeast of the tailings piles in the washes in an effort to reduce the arount of material washed or blom off the piles from being washed on down to the Sen Juan River. (Photographs 10, 11 and 15). Dikes and diversion ditches were built in 1966 imediately south and west of the tailinge piles to divert surface runoff from the higher ground away from the piles.

\section{Eovironental coaniderations}

Assuming secular equilibrium, the theoretical concentration of Ra-226 is 784 pCi per gren of tailinge and the total Ra-226 inventory theoretically in the 2.2 villion tons of tailings is estimated at 1,560 curies.

Two Radiu vonitoring letwork water quality murveillance stations vere established on the 8 an Juan River. The station upstrean fron Yaxican Hat operated Iron Decerber 1961 until April 1972 and the man Bn-226 coscentration during this period vas 0.13 pci per liter. The domatrean station operated from Deceber 1961 until October 1970 and the wean Ra-226 concentration for solples obtained vas $0.17 \mathrm{pCI}$ per liter. 2/ The maxiau perdunible concentration of Ra-226 in drining water for the general population is 3 pCi pere liter. 


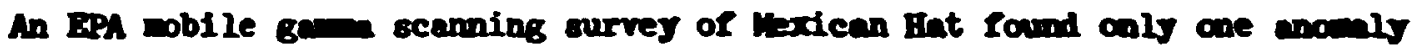
related to tailings in addition to those at the dilleite. Fallinge were apparently used under the floor slab for a basiness building uned as a laundry and for storage. A sidiar BPA survey in Blanding, Otah, 52 diles to the north found 10 anomilies related to tallings, two of which were deternined to be caused by tallings under structures. The tallings at Blanding ight have cone from the Mxican Hat will or from the Honticello All (which is closer) or possibly from other sources.

The population nearest to the Maxicen lint dilaite and tallings is in the former conpans housing, were about 70 forlites or 250 people realde ebout one-half southrest of the pillsite. The elementary school is about a third of a gle couthwest, between the allaite and the residence area. The previling wind is from the southwest, directly aror from the populated aree toward the rilloite and tallings area. The older settlenent of Mexican Hat, at the san Junn R1ver crossing, is about a dile north of the tailings aree.

R. 1. Snelling reported in January 1971 the reoults of a rediological survey done in viny 1968 at the request of the Director, Division of Indien Heelth. Average genen radiation measurenents vere at background level in the housing area southwest of the fillsite, five times background in the all area, and 15 times background in the tallings area. Individual neasurements ranged from below beckground in all areas to as wach as 100 $t$ ines background in the tailings area. $3 /$.

Radon-222 measurenente were at background levels in the houaling area. Two saples in the will ares were respectively two and Aive times beckground. The masured radon concentrations were higher in the tallings area, the highest of all being about 40 tines backfround northeast and downind of the taflings piles. In comparison to sapples collected in other areas, It is possible that measured radon levels will cause elevated working level exposures to occupants of the $\mathrm{dll}$ site structures.

Wone of the dilsite or tallings aree is fenced, and there is no apparent reatriction on entry to the tailings area, nor is there any eridence of entry.

\section{Neteorolosy}

The average annul precipitation is about 5.5 inches and the everage anmual temperature $57^{\circ} \mathrm{F}$. Prevalling winds are soutbwesterly.

\section{Evdrolosy}

The tailinge piles are near the beads of and dry wach channele tributary to Grpoum Wash, an intermittent tributary of the gan Jum River. (Bee mp, Plgure 1). Channel distance from the Mo. 2 tallinga dan to the san Juan River is about a mle. 
Snelling (op. cit.) concluied that although ground water serples near the tailings shored uraniun concentrations sifaificed th sbove buckground, both the wraniwe concentrations and the soluble Ra-226 concentration are still well belor the recomended 10 arizo concentration guides.

Tallinge now in the washes below the tailings piles will gradually be rewored by flash flooding and will cubsequently be diluted by the San Juan River. Surface water quality is not expected to be adversely affected if the tailings piles are stabilized.

\section{Site Visit}

The rexican Hat ste vas visited on vay 16, 1974, by the following persannel (tean):

Gordon T. Brown, Luciue Pithin, Inc., (Contrector to USNEC), Grand Junction, Coloredo, Jon Yeagley, Environdental Protection Agency, Region VIII, Denver, Coloredo,

Darld B. Bernhardt, Environmental Protectica Agency, Las Vegas, Mevada,

Blaibe Howard, Otah Division of Health, Salt Lake City, Utsh. 


\section{References}

1. Herritt, Robert C., The Etractive Metallurgy of Uraniu, Colorado School of vines Research Inst., Ushis Contract, 1971, p. 531.

2. U. S. Bnvironmental Protection Agency, Region VIII, "Radium-226, Uraniun, and other Rediological Date Collected From Water Quality Survelllance Stations Located in the Colorado River Basin of Colorado, Utah, Mew Mexico, and arizone - January 1961 through June 1972", 85N/TIB-24, Denver, Colorado, July 1973.

3. Snelling, Robert 1., "Bnvironientel survey of Uraniun Mall Tailings Pile, Mexican Hat, Uteh", U. S. Burironental Protection Afency, Radiological Heal th Data and Reports, V. 12, 10. 1, 1971, pp 17-28. 


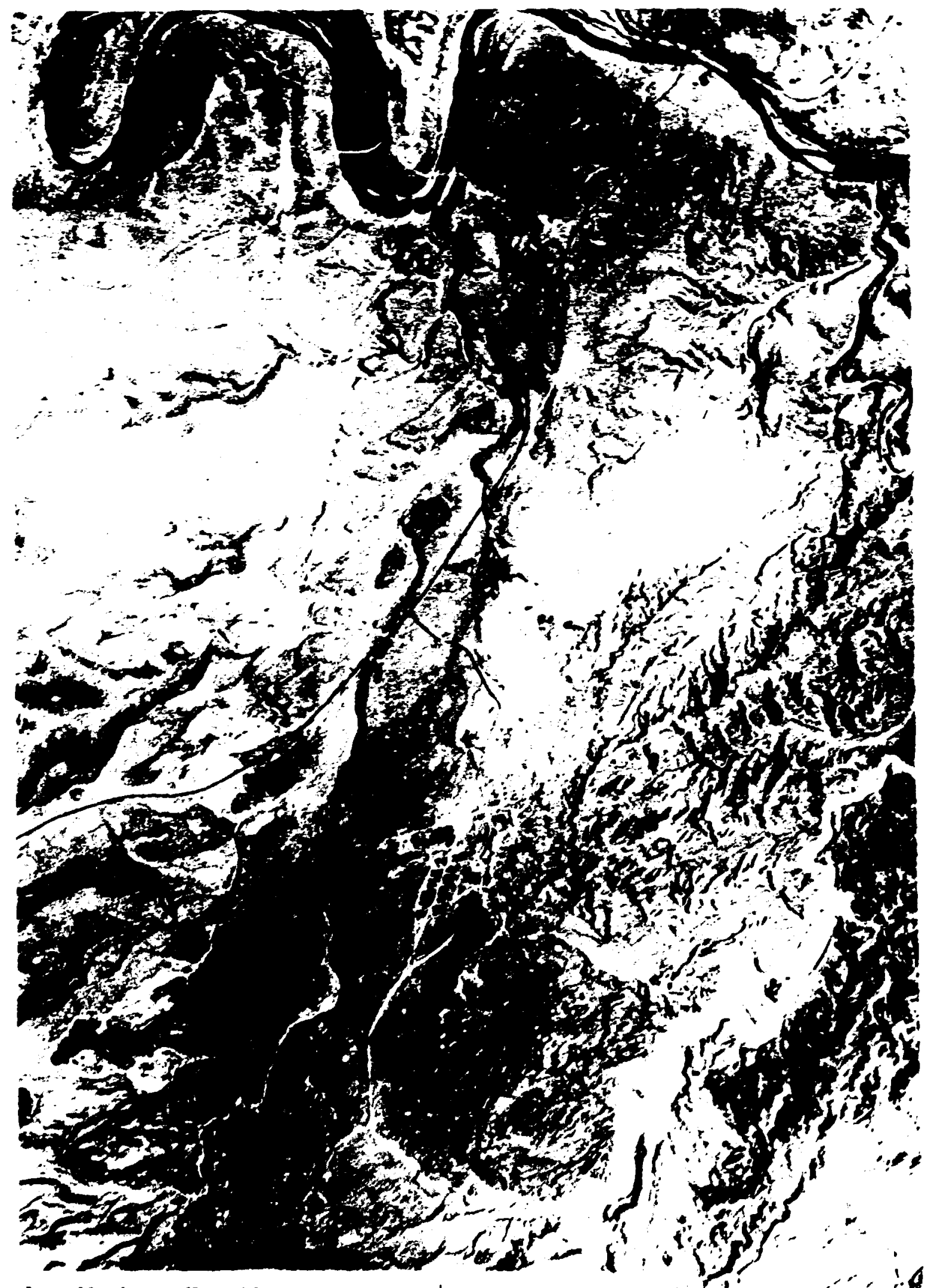

1. Mexican Hat Site - June 1974
Approximate scale - one inch equals 1, joO fort. 


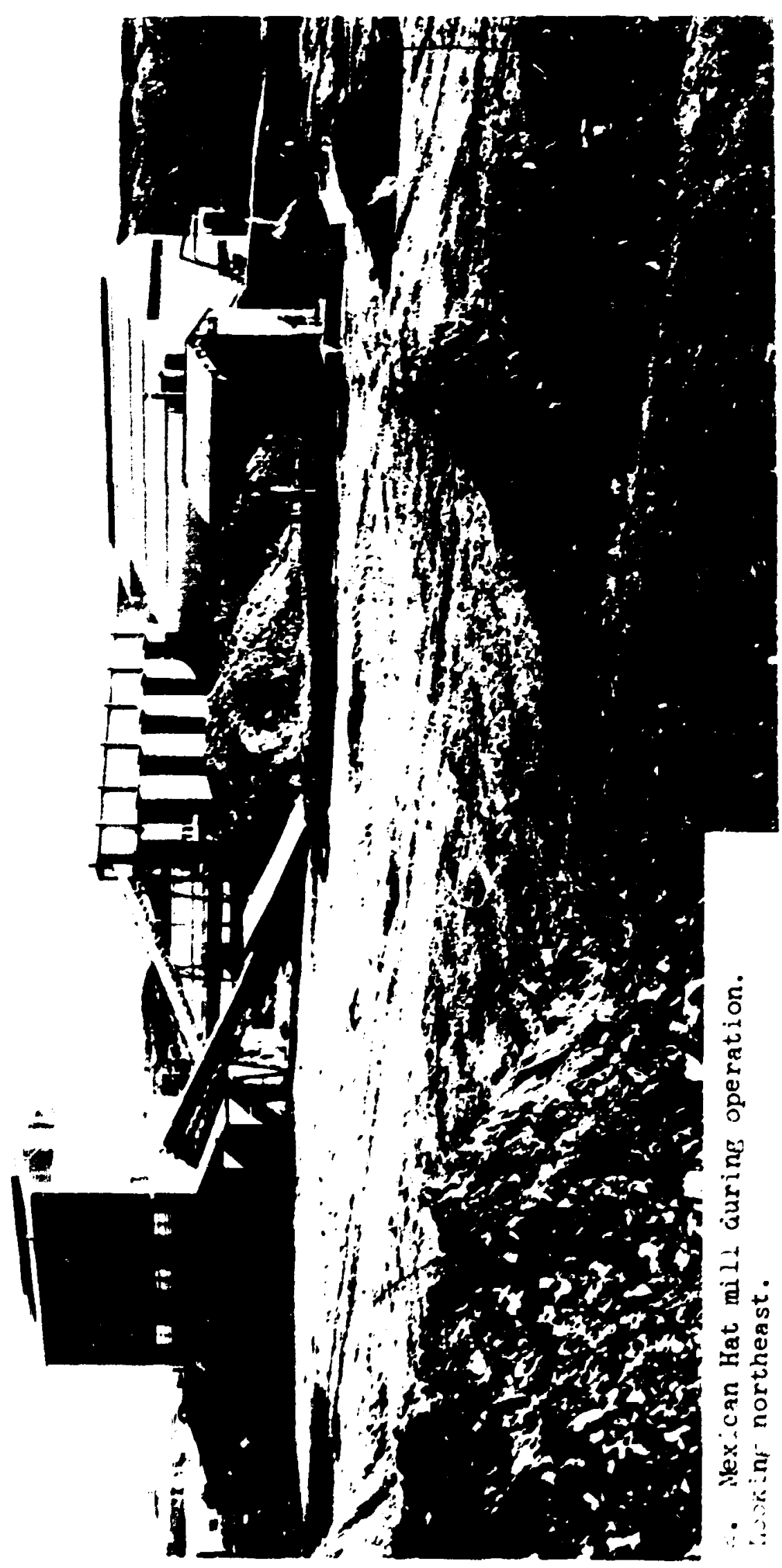


No Photograph 3 available

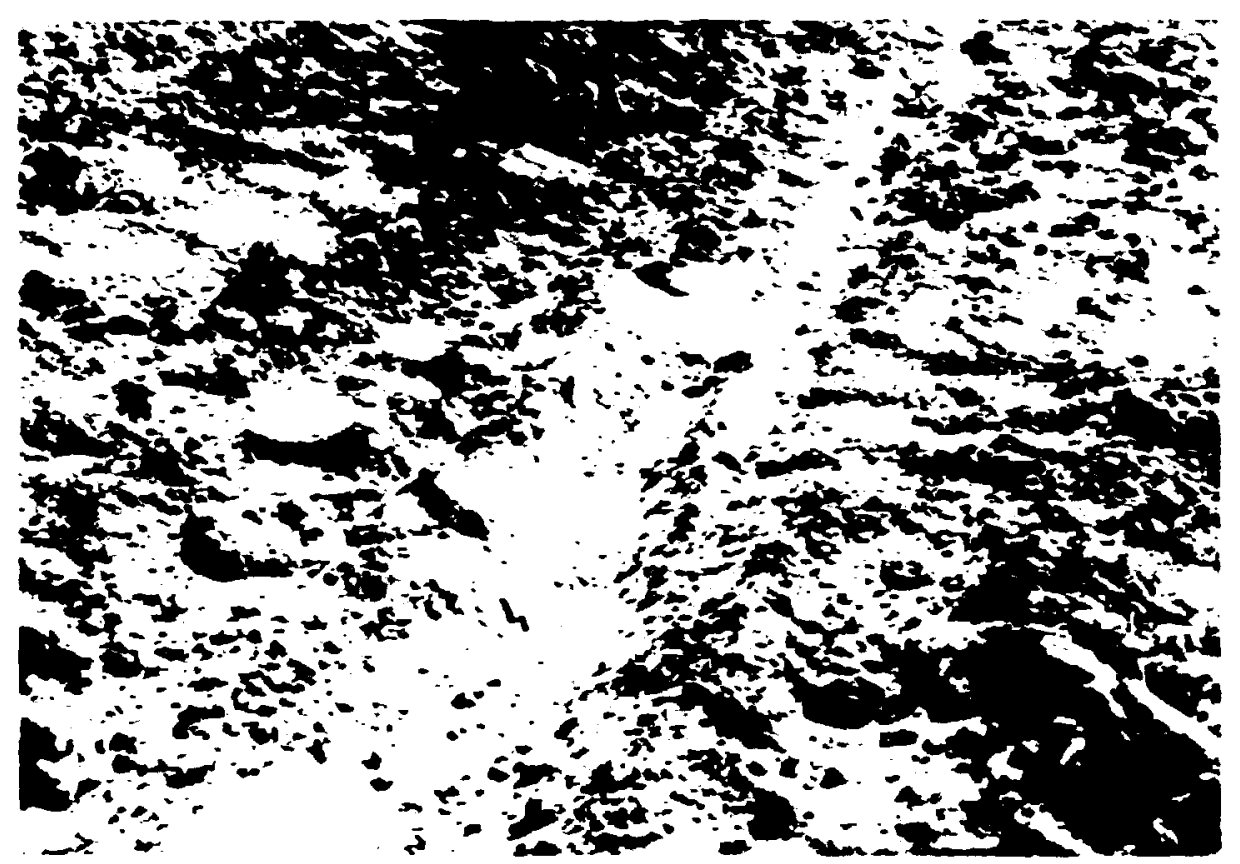

4. Soft, loose, fine-grained tailings noar south:ent edjt of westera pile.

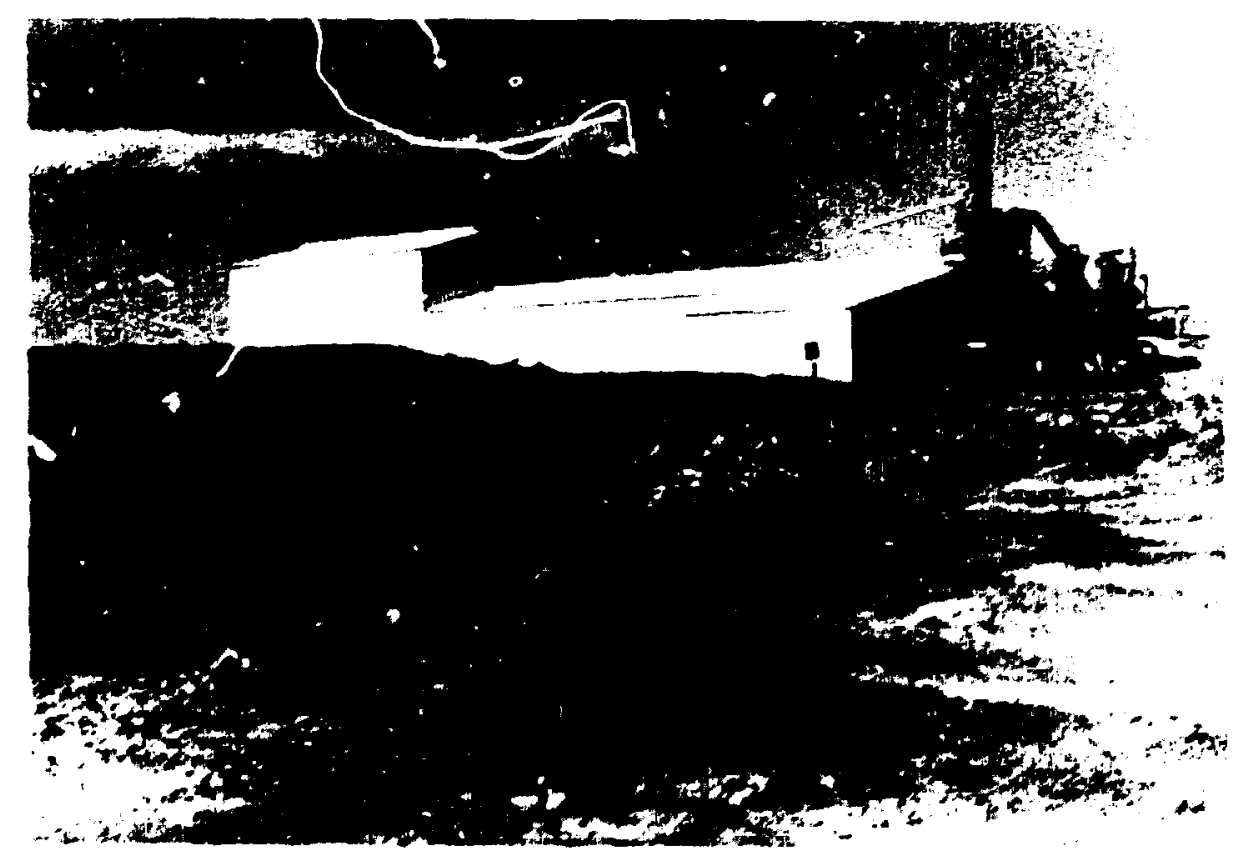

5. Looking southwest from western tailings pile toward mi!! area. 


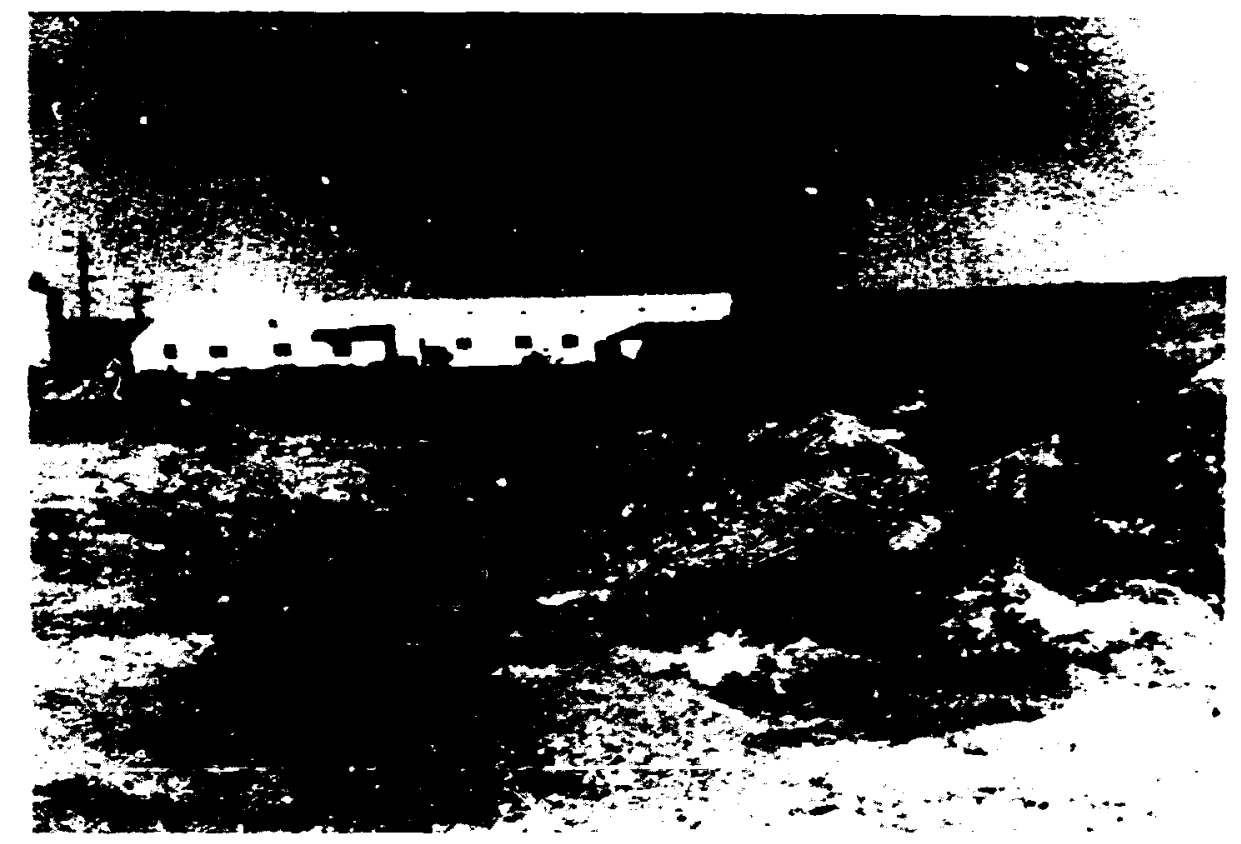

$\therefore \quad$ Lojkine west from western tailingr pile toward mill arse.

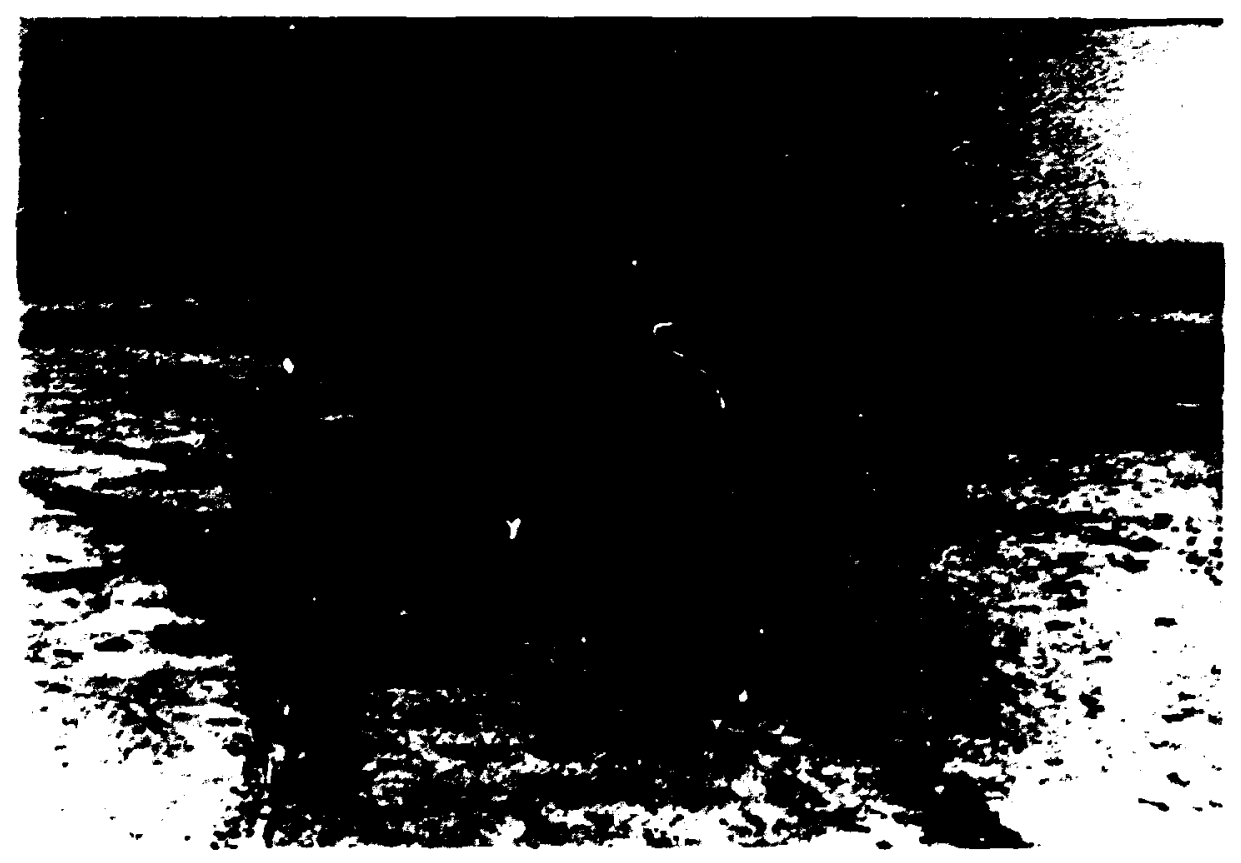

7. Surface of western tailings pile. Looking east. 


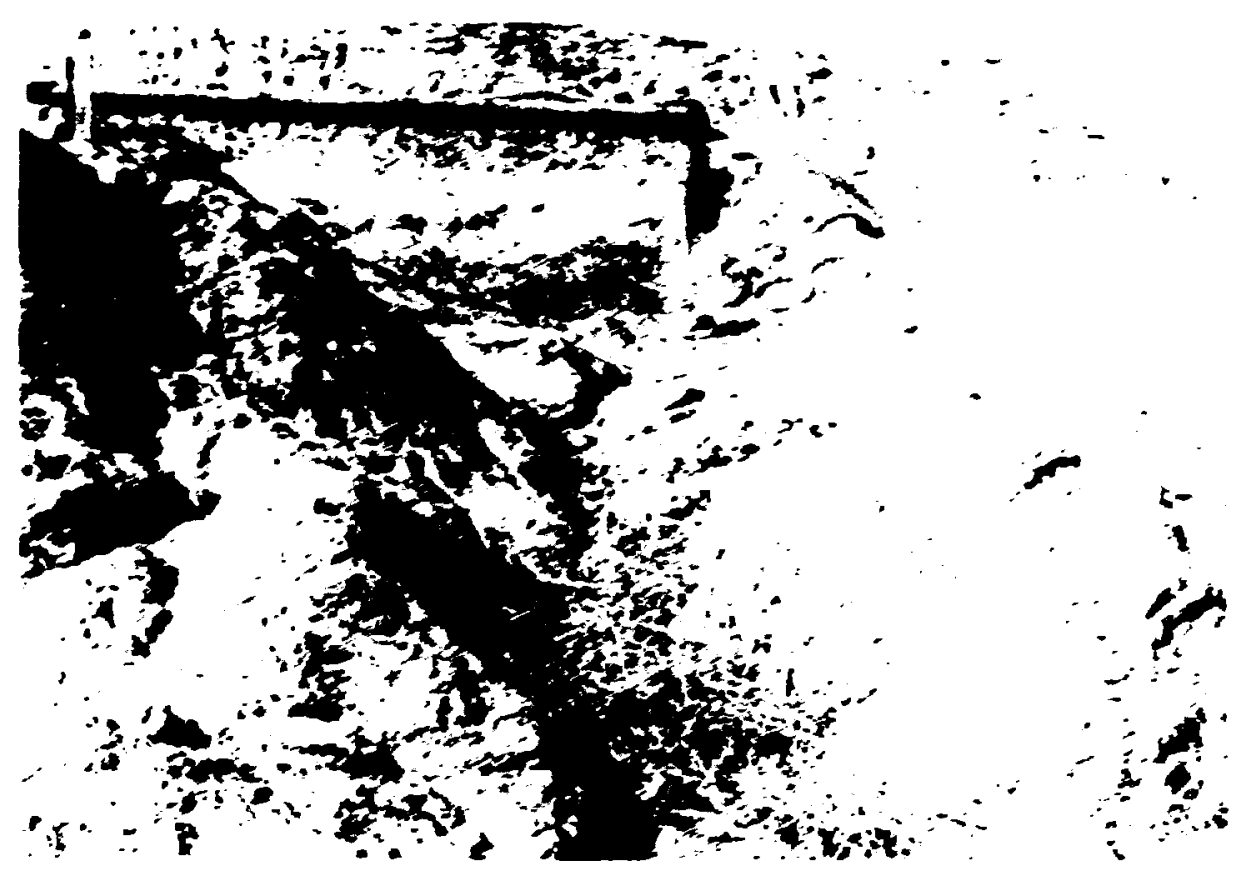

6 . Water crosion on north side of western ta:linfe pi:a.

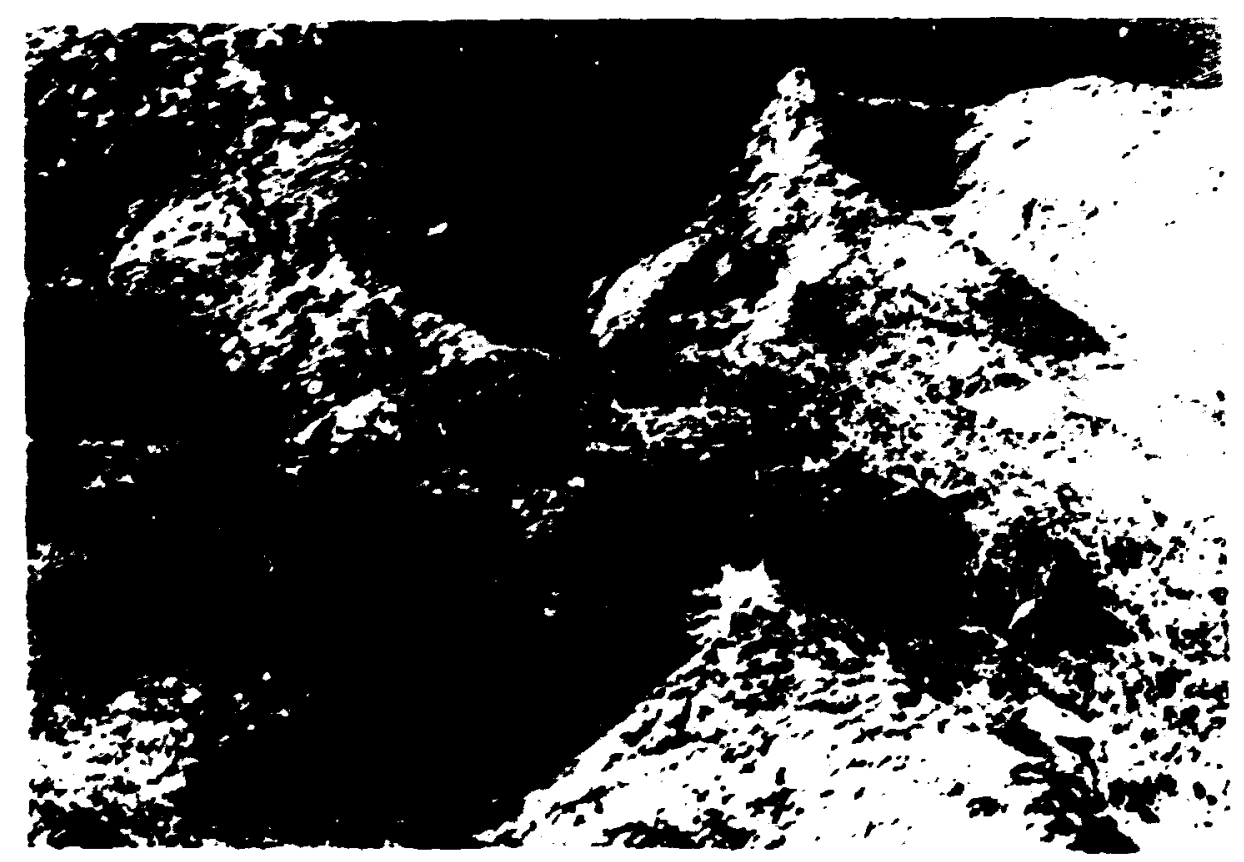

9. Whter erosion on north side of western tailinrs pila. 


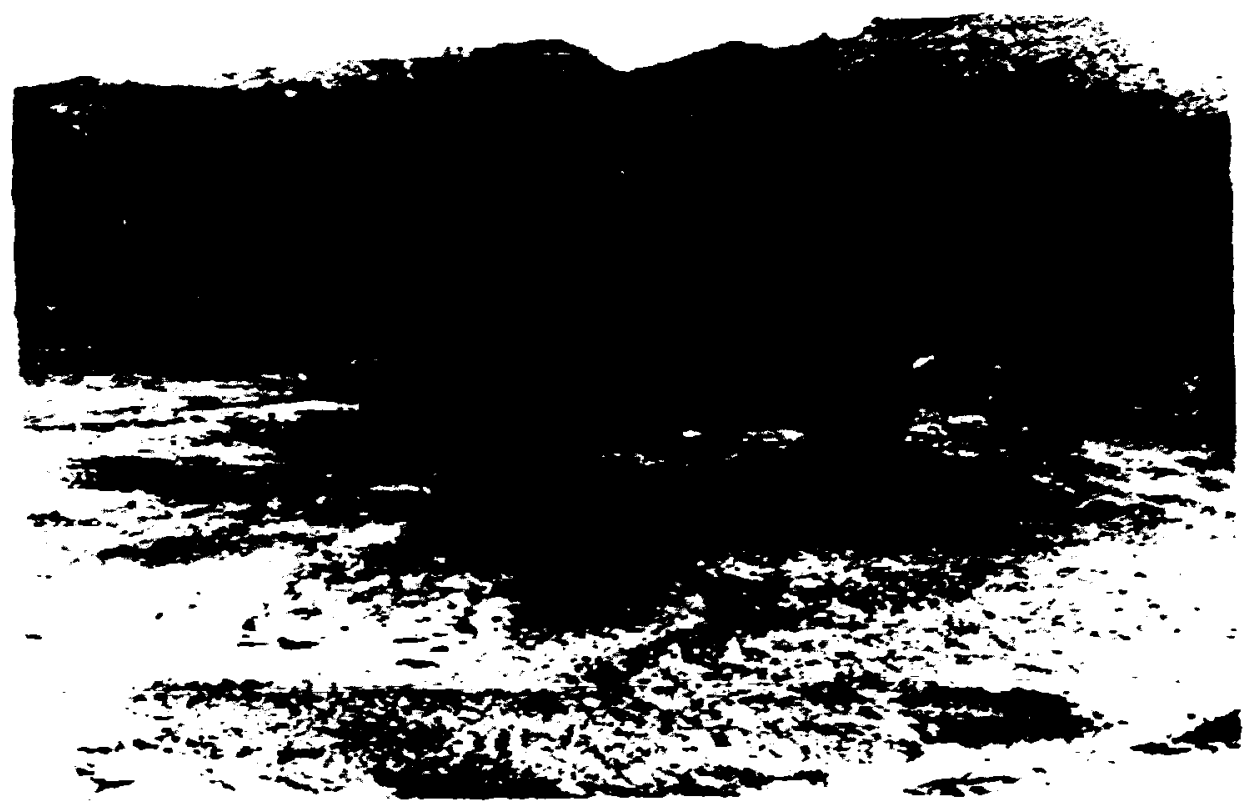

10. Dike to catch runoff from tailings. Looking northeast from north side oi western pile.

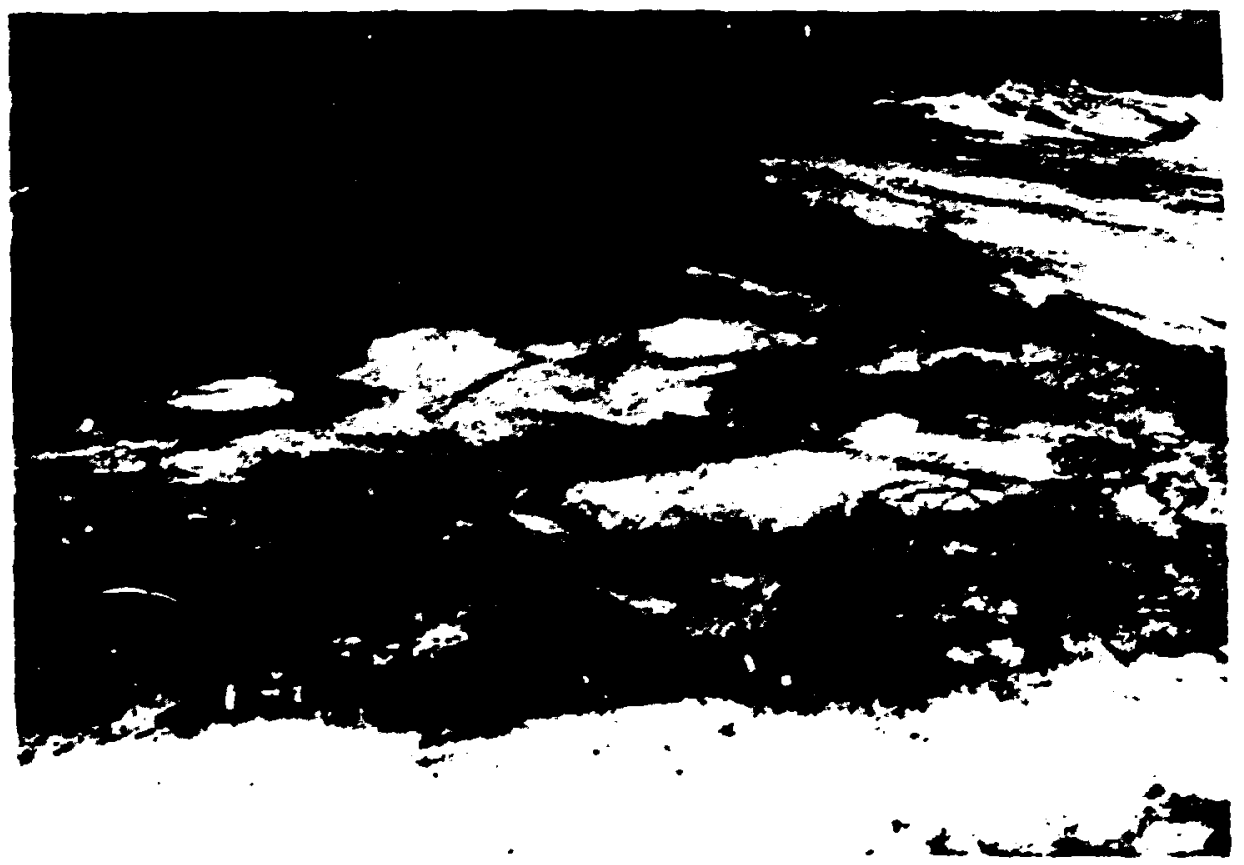

11. Dike to catch runoff from tailings. Looking northeast from north side of western pile. 


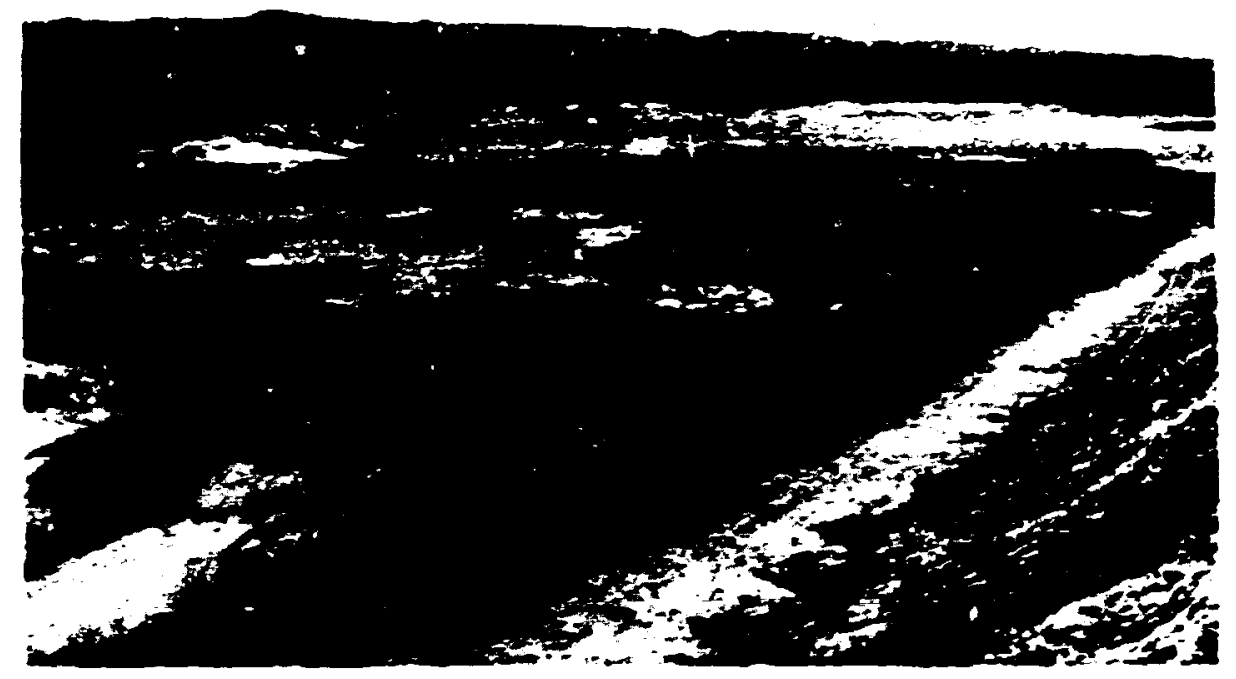

12. Looking east across eastern tailings pile.

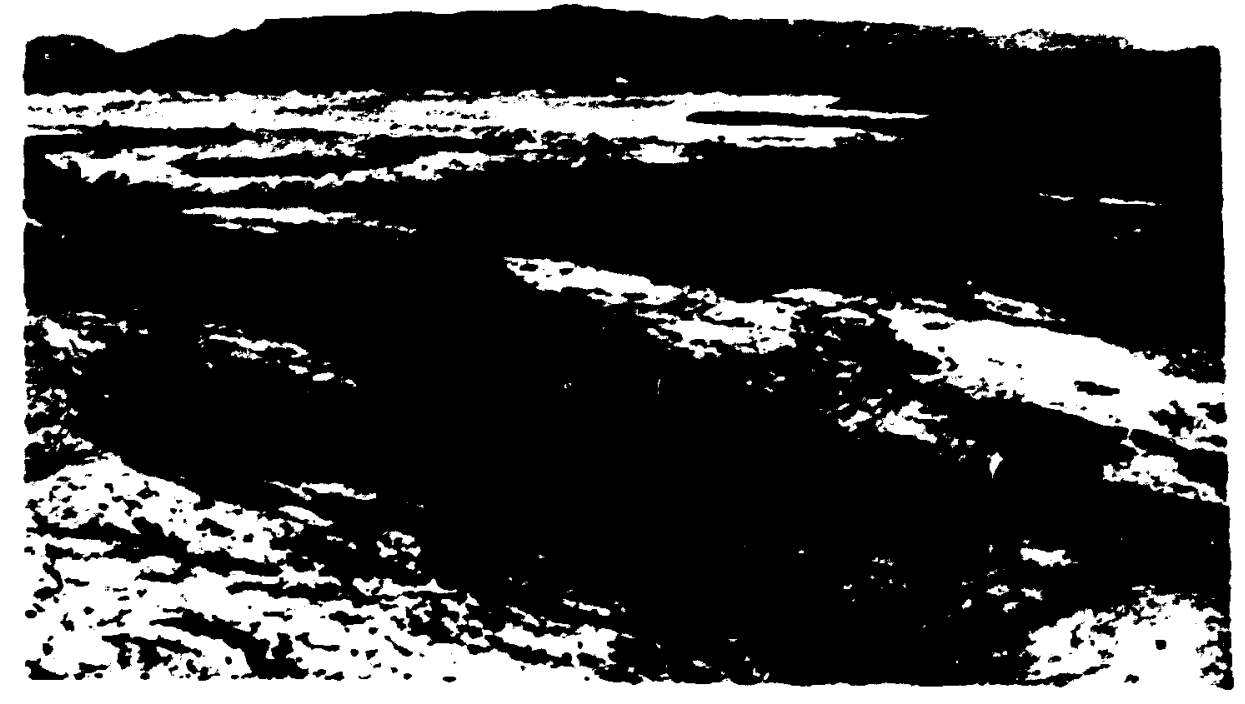

13. Looking east across eastern tailings pile. 


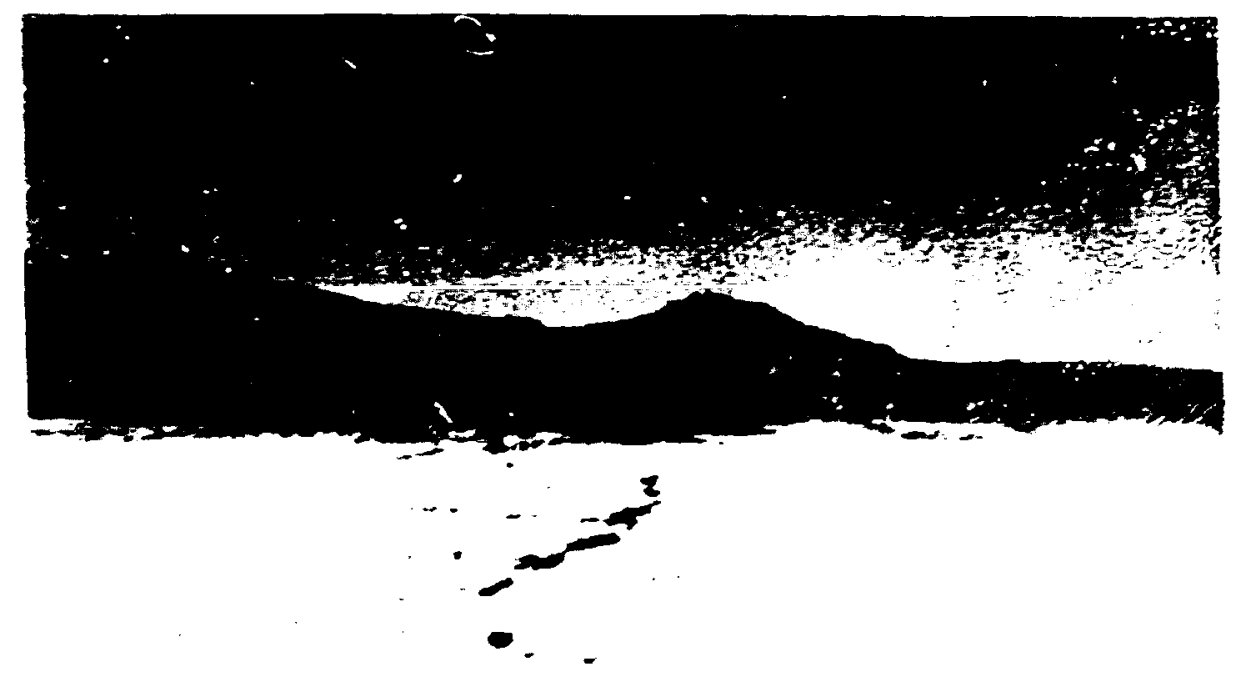

14. Surface of eastern tailines pile. Lookinf sriutinost. 

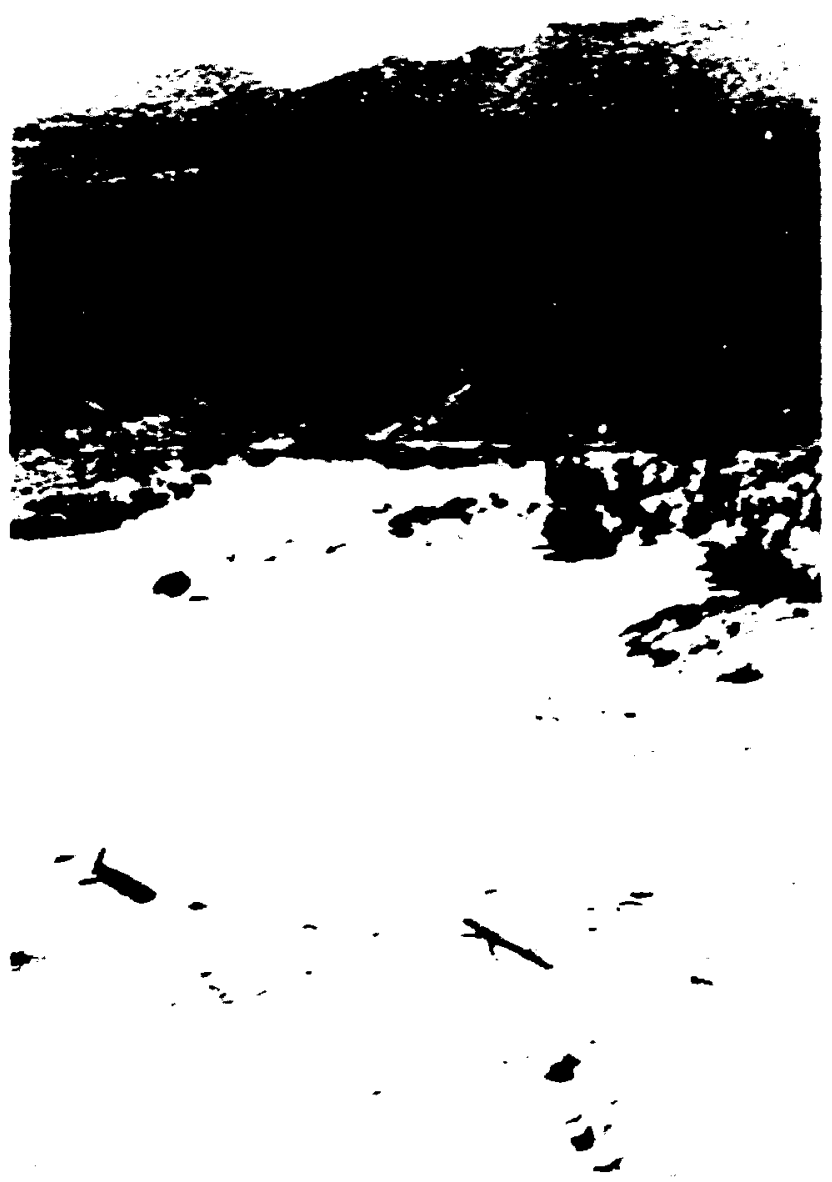

1). Wind-blown material from :astern tniling pile. Iosorinf northerst. 


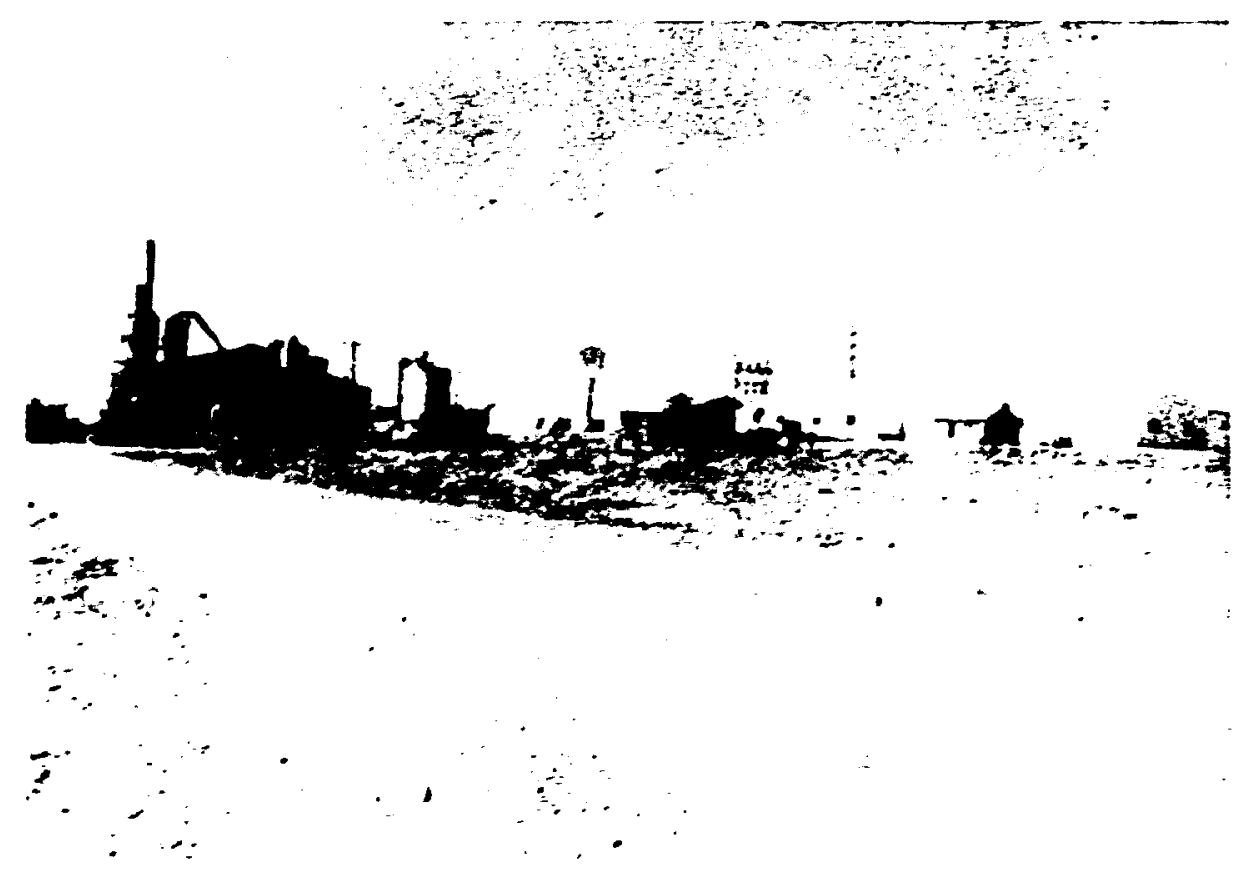

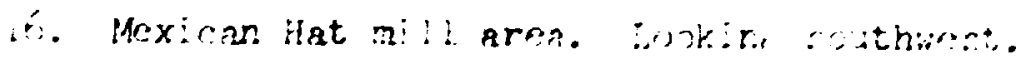


APPENDIX II

Soil Sampling Techniques

and

Radiological Measurements 
Soil Sampiing and Measurement of Radionuclide Concentration as a Function of Depth in Soil

A monitoring and sampling procedure was established for this project in conjunction with FB\&DU to measure the radionuclide concentration in soil as a function of depth. At each site, a set of $15-\mathrm{cm}$ (6-in.) diameter holes was drilled through the tailings and into the subsoil. A polyvinyl chloride (PVC) pipe $(7.6 \mathrm{~cm} 0 . \mathrm{d}$.), sealed on one end, was lowered into each hole, and measurements were made of gama-ray iniensities as a function of depth. A $15-\mathrm{cm}$-long Geiger-Mueller tube shielded with a lead cover containing collimating slits was used for this purpose by lowering it inside the PVC pipe for measurements. Signals from this detector were counted using a portable scaler. ${ }^{1}$

After gamma-ray vs depth profiles were determined, the position of the interface between tailings and subsoil was estimated. Once completed, the drilling rig was moved approximately $1.2 \mathrm{~m}(4 \mathrm{ft})$, and another hole was drilled to the interface level. Samples of soil core were then collected as a function of depth using a split-spoon sampler (each core section was $0.6 \mathrm{~m}$ long).

Most of the penetrating gamma radiation monitored is attributable to ${ }^{226} \mathrm{Ra}$ and its daughters. Therefore, a calibration factor for ${ }^{226} \mathrm{Ra}$ concentration was determined for the collimated gamma-ray probe by comparing the response of this unit (counts per unit time) with a measured value for the radium concentration ( $p$ icocuries per gram) in several soil samples determined by a gamma-ray spectrometry technique. A leastsquares fit of FB\&DU data (first probe) from this comparison yields the equation

$$
R=0.528(C-16)
$$

For this case, $R$ is the ${ }^{226} R a$ activity in picocuries per aram and $C$ is the observed response of the collimated gamma-ray detector $i$, counts per minute; there were 16 background counts per minute for the gamma-ray detector. 
The above expression was useful in estimating the overall distribution of radioactivity in the tailings as well as the total quantity of radium in the tailings area. Surface soil samples were obtained normally by removal of an approximately 3-cm-deep layer of soil from an area of about $25 \times 25 \mathrm{~cm}$. The same procedure was used to obtain samples $15 \mathrm{~cm}$ (6 in.) below the surface except that the top 15-cm layer of soil was discarded and the sample was removed from the next $3-\mathrm{cm}$ layer.

Each sample was dried for $24 \mathrm{hr}$ at $110^{\circ} \mathrm{C}$ in order to remove moisture. The samples were then pulverized in a high speed rotary crusher having plates adjusted to provide particles no larger than $500 \mu \mathrm{m}$. The soil was dispensed into 25-ml polyethylene vials of the type used for liquid scintillation counting and sealed tightly. A soil sample normally consists of 12 of these vials. The net weight of the group of vials was measured to the necrest tenth of a gram.

The sealed sample vials were stored for a period sufficient to allow attainment of equilibrium between ${ }^{226} \mathrm{Ra}$ and its short-lived daughters. Radon- 222 , which has a radioactive half-life of 3.8 days, will reach the same activity as its long-lived parent, ${ }^{226} \mathrm{Ra}$, in about 30 days. The short-lived progeny of ${ }^{222} \mathrm{Rn}$ will have reached equilibrium within the same time. Determination of the activity of any of the daughters in the sample will reflect ${ }^{226}$ Ra activity. After equilibration of radon daughters, the 12 sample vials (or smaller number) were inserted into a sample carousel or holder (Fig. II-1) that was placed on a Ge(Li) detector for counting as described in the section on gamma-ray spectrometry below.

Field Laboratory Facilities and Equipment

A 20-ft mobile laboratory van was used as a field office and for transporting instruments. This van contained an alpha spectrometry counting system for air samples along with air sampling equipment; a Johnston Laboratory radon monitor complete with Lucas-type flasks and an evacuation manifold; gamma-ray detectors; miscellaneous electronic testing equipment; and standard calibration sources. A trailer-mounted, gasoline-powered $12 \mathrm{~kW}$ motor generator, pulled by the van, was used to 


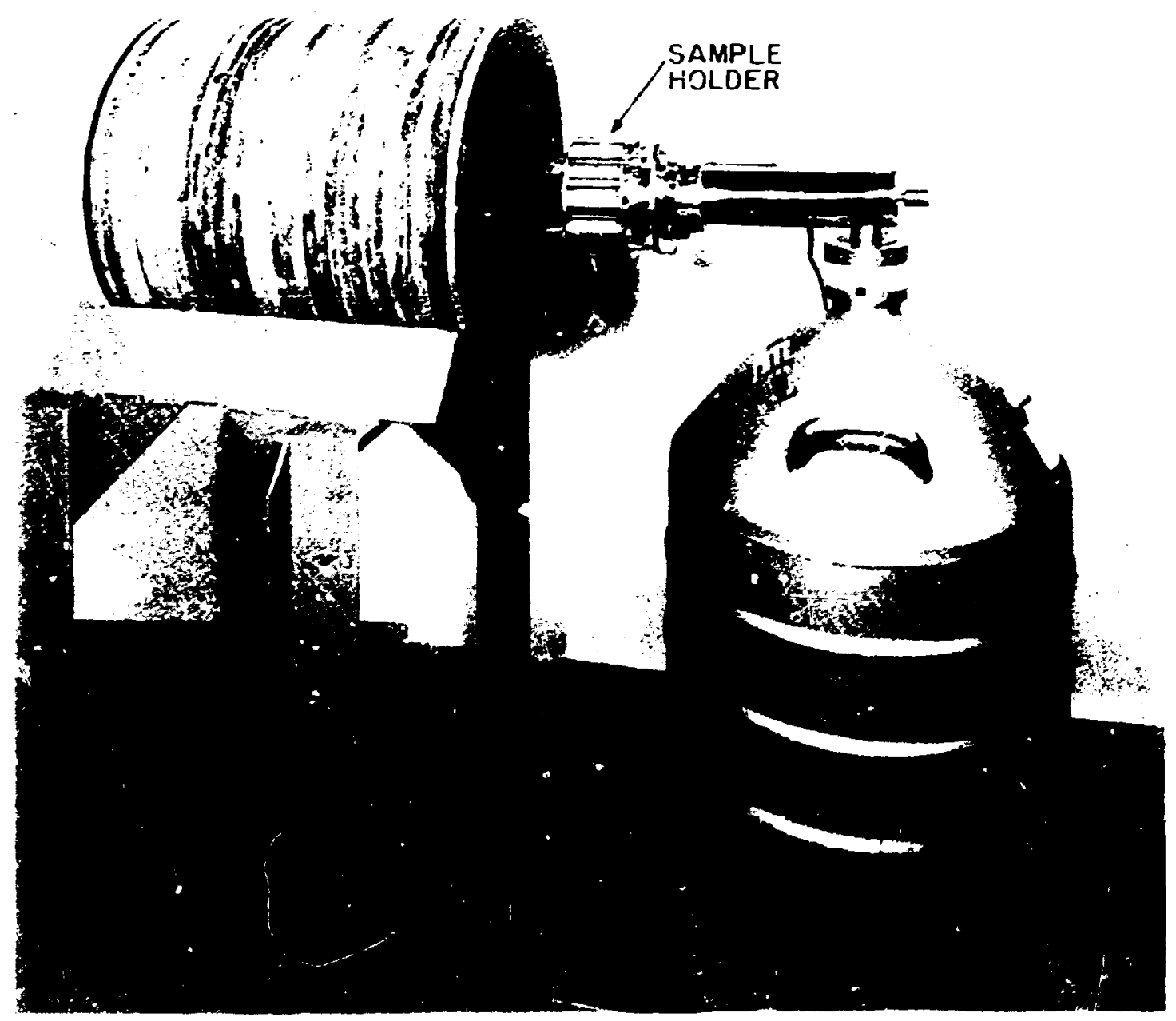

Fig. II-1. Horizontal mounted $\mathrm{Ge}(\mathrm{Li})$ detector system used for counting soil samples (carousel-type sample holder is shown in its counting position). 
supply electrical power in remote locations. A voltage stabilizer was used to provide regulated power for instruments.

A second field laboratory used in the project was an $8 \times 35 \mathrm{ft}$ airconditioned semitrailer with running water, tools, and miscellaneous supplies. It served as an instrument calibration facility, office, and workshop. This trailer required electrical power from an external source. During most of this project, the trailer was parked in Grand Junction and was used as a temporary field office.

\section{Gamma-Ray Spectrometry Systens}

A Harshaw integral $3 \times 3$ in. NaI (TI) crystal, a high sensitivity detector, was used to scan all samples for a preliminary estimate of ${ }^{226} \mathrm{Ra}$ activity. This detector was used ir: a "pickle barrel" type shield, lined with copper and cadmium to shield $x$-rays. Signals from the crystal were sorted by a zomputer-based (PDP-11) pulse-height analyzer. The computer was programmed to control all functions of the analyzer and counter, to analyze the data, and to print out a statistically weighted average of the ${ }^{226}$ Ra activity per unit mass. One advantage of this counting arrangement is that it permits quick sorting; samples can be scanned at the rate of c'buut six per hour (minimum counting period is $5 \mathrm{~min}$ ).* An energy calibration of the $\mathrm{NaI}$ crystal and analyzer was obtained by standardizing with ${ }^{57} \mathrm{Co},{ }^{137} \mathrm{Cs}$, arid ${ }^{60} \mathrm{Co}$. An efficiency calibration was obtained through daily counting of a uranium standard $^{\dagger}(0.05 \%$ uranium mixed with dunite, particle size $=500 \mu \mathrm{m})$. Radium-226 is in equilibrium with the uranium, and this isotope and its daughters provide a source of gamma-ray lines for calibration.

*The principal reason for using this scanning system was to estimaie how much time would be required to count the samples with one of three high resolutions $\mathrm{Ge}(\mathrm{L} i)$ gamma-ray spectrometers.

${ }^{\dagger}$ Standard uranium sample obtained from the former Atomic Energy Commission New Brunswick Laboratory. 
Final data on the concentration of radionuclides in soil samples were determined ty counting all samples with one of three high resoluticn $\mathrm{Ge}(\mathrm{Li})$ spectromet.ers. ese high resolution counting systems consist of one horizontally mivinted $50-\mathrm{cm}^{3} \mathrm{Ge}(\mathrm{Li})$ crystal positioned on a platform for movement into and out of a lead shield (Fig. II-1), and two vartically mounted detectors (Fig. II-2). The detector systems were used to obtain complete photon spectra of the soil samples. Signals from the horizontal Ge(Li) crystal were routed to a 4096-channel pulse height analyzer and signals from the other two $\mathrm{Ge}(\mathrm{Li})$ crystals were routed to iwo 2688 channel regions of a computer based pulse height analysis system. Samples were counted for periods long enough to evaluate the ${ }^{226} \mathrm{Ra}$ concentration to a statistical accuracy of $\pm 5 \%$ or better. Spectra from the horizontally mounted Ge(Li) detector were recorded on magnetic tape and stored frr later analysis using the ORNL IBM computer system. *

The computers were programmed to sort out peaks from ${ }^{232}$ Th daughters including the 909 and $967 \mathrm{keV}$ peaks from ${ }^{228} \mathrm{Ac}$, the $239 \mathrm{keV}$ from $212 \mathrm{~Pb}$, and the 2614 and $583 \mathrm{keV}$ peaks from ${ }^{208} \mathrm{Tl}$. These data permitted measurements of the ${ }^{232} \mathrm{Th}$ concentration and data are reported for many of the samples.

Energy calibration of the $\mathrm{Ge}(\mathrm{Li})$ detectors was controlled through the use of isotopic sources of ${ }^{57} \mathrm{Co},{ }^{22} \mathrm{Na},{ }^{137} \mathrm{Cs},{ }^{50} \mathrm{Co},{ }^{83} \mathrm{Y}$, and ${ }^{40} \mathrm{~K}$. A calibration check was completed each da; prior to beginning sample counting. In order to maintain linearity of the ADC's, a spectrum stabilizer was utilized. This instrument can be adjusted so that two individual photon energies are detected and maintained in tws shannels at separate ends of the scale. These two calibration points helped maintain an ene'gy span of $1 \mathrm{keV}$ per channel. Efficiency calibration was obtained tiirough the use of the same uranium ore standard samples as for the Nai crystal. An analysis of the countinn data was accomplished

\footnotetext{
* Spectra from the two vertically mounted $\mathrm{Ge}(\mathrm{Li})$ detectors were stored on magnetic tape for record purposes, but were analyzed immediately using a Tennecomp Model TP-5/11 computer-based analyzer.
} 


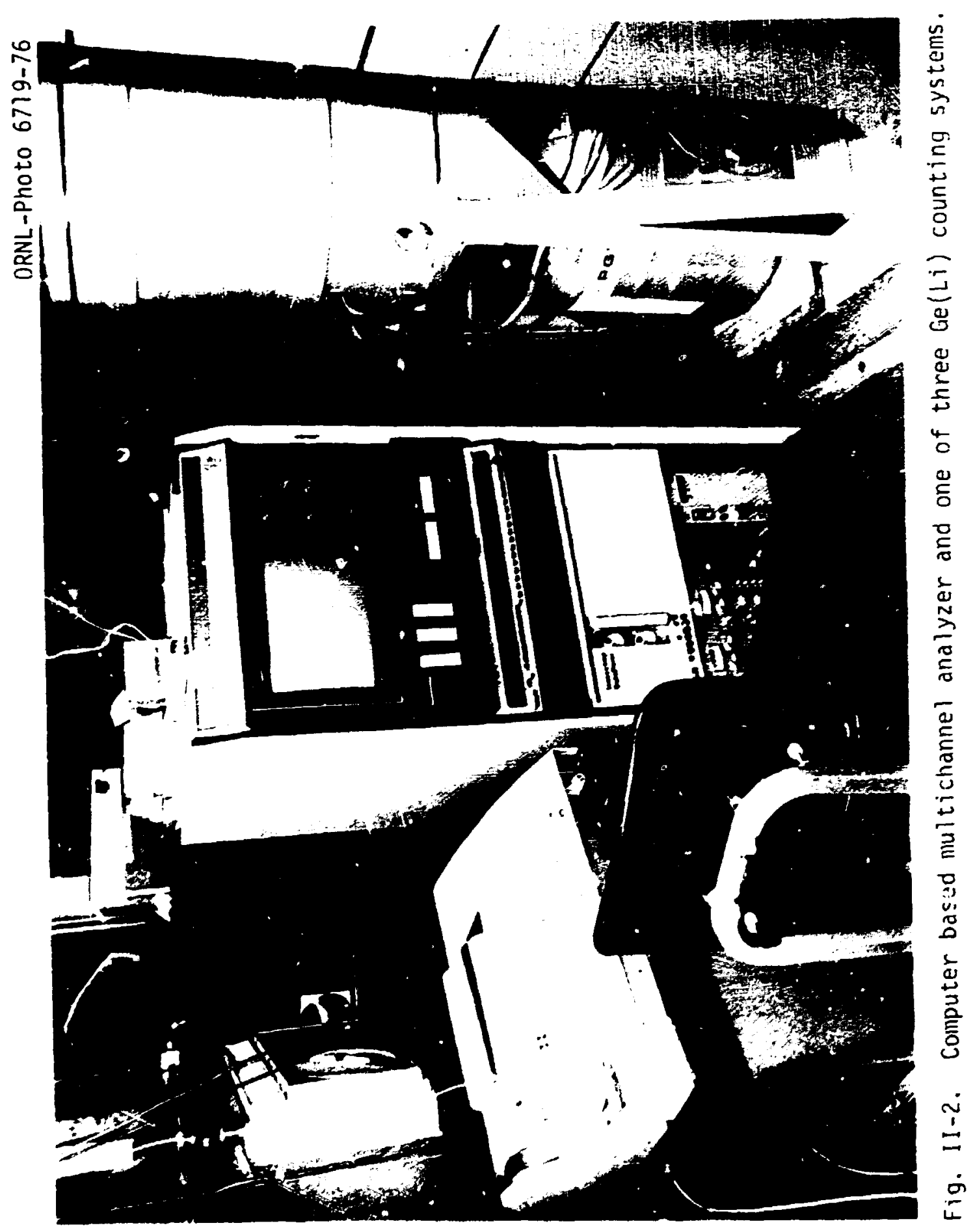


through a linear least-squares fitting routine. Net adjusted areas under photo peaks of interest were compared with an extensive radionuclide library. ${ }^{2}$ Data from the computer were presented for each radionuclide as a weighted mean with standard deviation.

\section{External Gama-Ray Detector}

A gamma radiation survey was made on and around the mill site and tailings pile. The instrument used for these measurements was a "Phil" gamma-ray dosimeter. ${ }^{3}$ The basic unit was a $15-\mathrm{cm}-(6-i n$.$) long 30-\mathrm{mg} /$ $\mathrm{Cm}^{2}$ glass-walled organic-filled Geiger-Mueller (G-M) tube with an energy compensation shield made of tin and lead. Pulses from this unit were counted with a battery-powered portable scaler. Typically, G-M counters are not used for dosimeters because of a peaked response at low photon energies. However, perforated layers of tin $(1.0 \mathrm{~mm})$, and lead $(0.1 \mathrm{~mm})$, were used as an energy compensation filter to flatten this peaked response at photon energies below about $200 \mathrm{keV}$. Sealed sources of ${ }^{137} \mathrm{Cs}$ and ${ }^{226} \mathrm{Ra}$ were used for calibration. It was found that the response of this detector was: $1 \mathrm{mR} / \mathrm{hr}=3400$ counts $/ \mathrm{min}$.

For each gamma-ray-exposure rate measurement, at least three 1-min counts were recorded. The mean of these readings (less instrument backgrourid) was used to determine the exposure rate to external gamma rays.

\section{Radon Daughter Sampler*}

Radon daughter concentrations were measured with a sampling and counting instrument which has been in use at ORNL for several years, 4 and it was also used to make some comparative measurements in the remedial action progran in Grand Junction. 5 The filter counter for this sampling device, shown in Fig. II-3, utilized a modified gas flow alpha

*This section and the following section contain descriptions of devices and methodologies typically used in the radiological surveys of milling facilities. They are included in each report in this series. However, in some instances, the measurements were not pissible. 


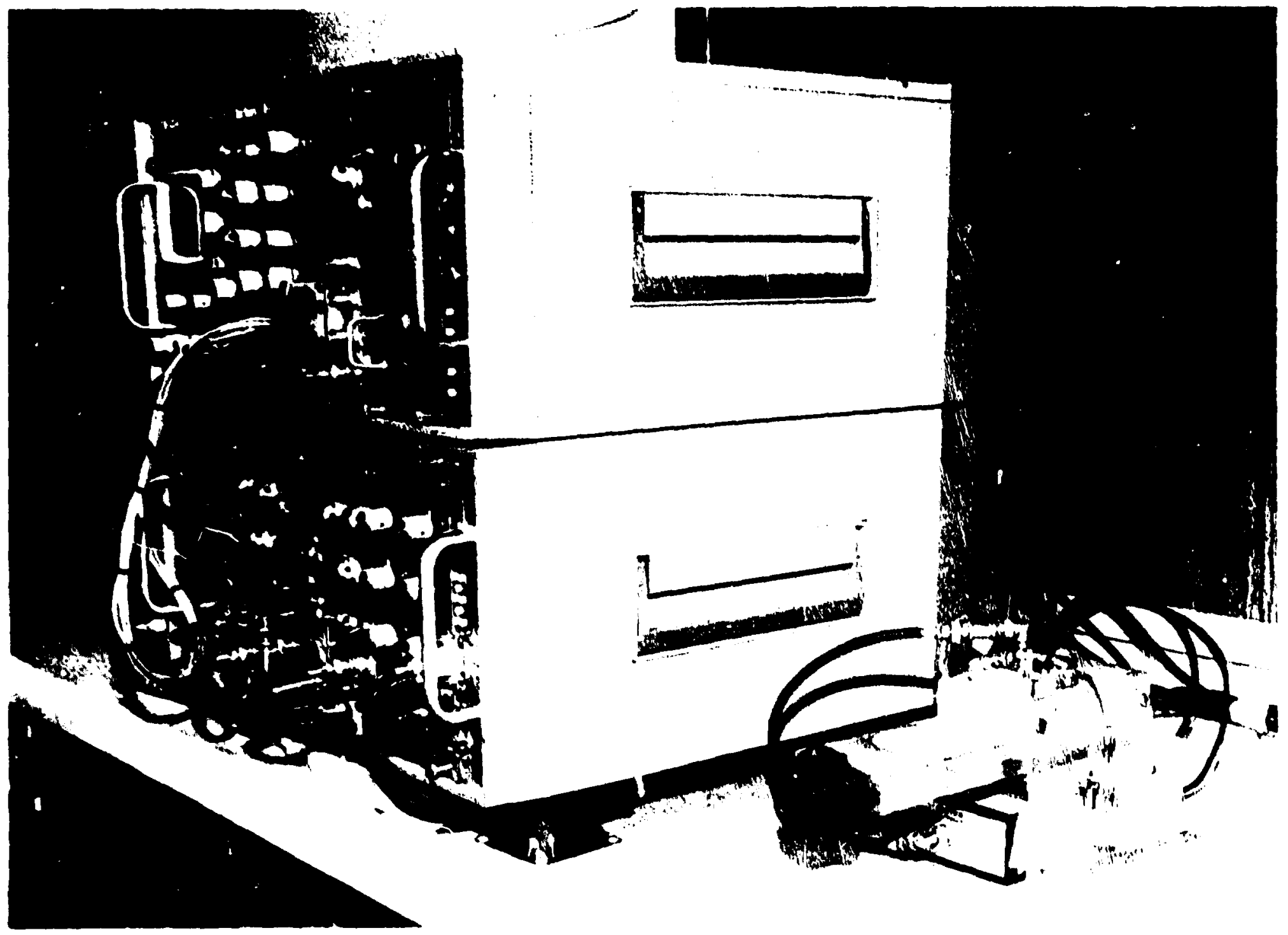

Fig. Il-3. System used for measurement of radon daughter concentrations. 
counter for housing a 450- $\mathrm{mm}^{2}$ silicon diode. Normally, this type detector is op:erated in a vacuum chamber. However, in this case, it was found that by flowing helium at atmospheric pressure through the assembly, absorption of alpha particles is small relative to absorption in air. Alpha particle pulses were recorded with a 100-channel analyzer. A small 225in alpina source standard was used for standardizing the energy scale. Air that was monitored for radon daughters was sampled at a rate of 12 to 14 liters/min. An absolute calibration of the airflow was provided through a comparison of the sampler's mass flow meter and a wet test meter. Samples were normally collected for $10 \mathrm{~min}$, and the first cuunt of the filter was started at 2 min after removal of the sample and continued for $10 \mathrm{~min}$. For this case, a determination was made of the number of counts due to the decay of ${ }^{218} \mathrm{Po}(\mathrm{RaA})$ and $214 \mathrm{Po}$ (RaC'). A second count was started 15 min after removal of the sample and continued for $15 \mathrm{~min}$. In this case, counts were recorded from the decay of 214 po. Data from the counter were stored in a pulse height analyzer and reduced by computer. The code for this analysis is explained in detail elsewhere." Results of the analysis of data using this code were presented as concentrations of RaA, RaB, and RaC'. In addition, a value for the working level concentration was also provided along with an estimate of the error associated with each reported value.

\section{Radon Monitor}

The instrument used by ORNL to measure radon concentrations in air consisted of $95-\mathrm{ml}$ Lucas chambers and a readout unit. * Each chamber was evacuated to approximately $1 \mathrm{~mm} \mathrm{Hg}$ and then opened to atmospheric pressure in the area where a radon measurement was required. No filtration was used for sampled air. The short-lived daughters of radon drawn into the chamber were allowed to decay for 3 to $4 \mathrm{hr}$ prior to counting the flask. Comparison of the results from this instrument and the radon

*LLRC-2 Low Level Radon Counting System manufactured by Johnston Laboratories, Inc. , Baltimore, Md. 
progeny monitor provided an estimate of the degree of equilibrium between radon and its daughters in the selected locations where air samples were taken. 


\section{APPENDIX II REFERENCES}

1. J. H. Thorngate and J. E. Parks, "A Portable Scaler," Bealth Phys. 12, 385-393 (1965).

2. J. F. Emery and F. F. Dyer, "Multi-Element Determination in Environmental Neutron Activation Analysis Using MONSTR," Proceedings of the Second International Conference on Huclear Methods and Enviromental Research, CONF-740701, held at the University of Missouri, Colunbia, Mo., July 29-31, 1974.

3. E. B. Wagner and G. S. Hurst, "A Geiger-Mueller $r$-Ray Dosimeter with Low Neutron Sensitivity," Bealth Phys. 5, 20-26 (1967).

4. P. T. Perdue, H. H. Shinpaugh, J. H. Thorngate and J. A. Auxier, "A Convenient Counter for Measuring Alpha Activity of Smear and Air Samples," Health Phys. 26, 114-116 (1974).

5. G. D. Kerr, "Measurements of Rador. Jaughter Concentrations in Air," pp. 202-207 in Dosimetry for Hwran Exposures and Radiological Impact, ORNL-4979 (July 1974).

6. G. D. Kerr, Measurement of Radon Progeny Consentrations in Air by Alpha-Particle Spectrometry, ORNL-TM-4924 (July 1975). 


\section{APPENDIX IIi}

\section{Water Sampling and Analysis}

Water samples are obtained at appropriate points on and argund the mill site, labeled and stored for later analysis. Each sample is centrifuged and filtered through a $0.45-\mu \mathrm{m}$ filter to remove suspended solids. The samples are then analyzed by radiochemical techniques as described in this appendix. 
Procedure for the Sequential Determination of ${ }^{226} \mathrm{Ra},{ }^{230} \mathrm{Th}$, and $21 \mathrm{cPb}$ in Water from Uranium Mill Tailings Sites

P. M. Lantz

Health and Safety Research Division

Oak Ridge National Laboratory

Oak Ridge, Tennessee

1.0 Radium-226

1.1 Filter the 21.0 liter water sample using a vacuum flask and \$42 Whatman filter paper to remove suspended particles.

1.2 Reduce the volume of the water sample, to which $10 \mathrm{ml}$ of concentrated $\mathrm{HNO}_{3}$ has been added, to less than $250 \mathrm{ml}$ by evaporation.

1.3 Transfer the solution to a 250-ml, long-neck, tapered-joint, flat-bottom Pyrex boiling ilask. Insert a Teflon-coated magnetic stirring bar. Add $37 \mathrm{ml}$ of concentrated $\mathrm{HNO}_{3}$ to make the final concentration $3 M$. Insert the modified, female, tapered joint with gas diffuser and side arm with stopcock. Seal off the gas inlet and close the stopcock to assure containment of ${ }^{222} R n$ in the flask. Store for at least 30 days to await attainment of ${ }^{226}$ Ra-222 Rn equilibrium.

1.4 Next, connect the 250-ml de-emanation fiask to a helium s.jurce and the radon trapping system. Attach an evacuated Lucas chamber. Flush the system with helium gas while bypassing the flask. Stop the gas flow. Immerse the unfired Vycor radon concentrator in a liquid nitrogen bath. Be sure the upstream exit for helium gas is open. Start the magnetic stirrer. Open the flask side arm stopcock to the system and start helium gas flowing through the liquid at a rate not to exceed 2.8 liters $/ \mathrm{hr}$. The radon-helium stream is dried and stripped of organic condensable components by $\mathrm{KOH}$ and ascarite traps. Radon is condensed on the Vycor at liquid nitrogen temperature and thus separated from the helium gas carrier. 
1.5 Stop the de-emanation process after 30 min. Having shut off the gas fluw, close the helium exit. Isolate the radon trap and the evacuated Lucas chamber from the remainder of the system via stopcocks.

1.6 Open the Lucas chamber stopcock and remove the liquid nitrogen from the radon trap to allow the gaseous radon to diffuse into the chamber. To hasten the diffusion, the trap may be gently flamed.

1.7 Bypassing the flask, use a controlled stream of helium to flush residual radon into the Lucas chamber until near atmospheric pressure has been reached. Stop the gas flow and close the stopcock on the Lucas chanber.

1.8 After a delay of 3.0 to $3.5 \mathrm{hr}$ to permit the ${ }^{222} \mathrm{Rn}$ to reach equilibrium with its daughters, place the Lucas chamber over a photomultiplier tube and count the gross alpha for $30 \mathrm{~min}$.

1.9 Subtract the Lucas chamber background, counted under the same conditions, from the gross count. Divide the net count by three to obtain the ${ }^{222} \mathrm{Rn}$ count at that time. Correct the count for time elapsed since de-emanation was terminated and the efficiency of the Lucas chamber for converting alpha discharges to scintillations ( $285 \%$ ). Report the ${ }^{226} \mathrm{Ra}$ in equilibrium with ${ }^{222}$ Rn as picocuries per liter.

2.0 Thorium-230

2.1 Transfer one-half of the water sample remaining from the radon de-emanation process $\left(3 \mathrm{M} \mathrm{HNO}_{3}\right.$ ) to a Pyrex beaker for volume reduction on a magnetic stirrer hot plate.

2.2 Add $0.7 \mathrm{~g} \mathrm{Al}\left(\mathrm{NO}_{3}\right)_{3} \cdot 9 \mathrm{H}_{2} \mathrm{O}, 2.0 \mathrm{ml}(20 \mathrm{mg}) \mathrm{Pb}$ carrier, $1.0 \mathrm{ml}$ $(20.9 \mathrm{mg}) \mathrm{Bi}$ carrier and 5,000 to $10,000 \mathrm{cpm}$ of $234 \mathrm{Th}$ tracer to the water sample before reducing the volume to approximately $20 \mathrm{ml}$.

2.3 Should the sample solution contain undissolved salts, separate liquid and solids by use of centrifuge. Dissolve the 
solids by heating with a minimum volume of distilled water or dilute $\mathrm{HNO}_{3}$. Combine the dissolved solid with the original supernate. Should silicic acid form ir: the solution during volume reduction, as evidenced by its deposition on the beaker walls, cool the solution to room temperature and centrifuge. Add an equal volume of concentrated $\mathrm{HNO}_{3}$ to the supernate. Wash the solids with a small volume $(5.0 \mathrm{ml})$ of $8 \mathrm{M} \mathrm{HNO}_{3}$ and centrifuge. Combine the wash with the adjusted supernate. Discard the solids. Keep the solution cool in an ice bath during precipitation of hydroxides with an excess of ammonium hydroxide to minimize the formation of silicic acid from dissolved silicates. Let stand 5 to 10 min. Centrifuge, pour off the supernatant liquid, and wash the precipitate with dilute ammonium hydroxide. Discard the supernatant and wash liquids. Dissolve the solids in 10-20 $\mathrm{ml}$ of $8 \mathrm{M} \mathrm{HNO}$. Should the solution contain suspended silicic acid, centrifuge, wash the solids with $5 \mathrm{ml}$ of $8 \mathrm{il} \mathrm{HNO}_{3}$ and combine the supernatant liquids. Discard the solids.

2.4 Transfer the $8 \mathrm{MHNO}_{3}$ solution to a conditioned Dowex $4 \times 1$ anion exchange column $5 \mathrm{~mm}$ i.d. $\times 10 \mathrm{~cm}$ long ( $2.0 \mathrm{ml}$ vol.). The column is conditioned by passing through it at least 5 column volumes $(10 \mathrm{ml})$ of $8 \mathrm{M} \mathrm{HNO}_{3}$. The anion-complexed thorium adsorbs on the resin column to the exclusion of the

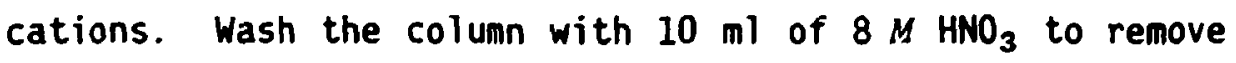
residual bismuth. Combine the effluent and wash solutions, and save them for lead and bismuth recovery.

2.5 Strip the thorium from the column with $5.0 \mathrm{ml}$ of distilled water followed by $10 \mathrm{ml}$ of $6 \mathrm{M} \mathrm{HCl}$.

2.6 Convert the chloride to the nitrate by adding an excess of $\mathrm{HNO}_{3}$ and reducing the solution to near dryness on a rot plate. Dissolve the solids in $5.0 \mathrm{ml}$ of $0.1 .8 \mathrm{HNO}_{3}$.

2.7 Transfer the $0.1 \mathrm{M} \mathrm{HNO}_{3}$ solution to a conditioned Dowex $50 \times$ $1 \mathrm{~mm}$ cation exchange $2.5 \mathrm{~mm}$ i.d. $\times 7 \mathrm{~cm}$ long ( $20.4 \mathrm{ml}$ vol.). The column is conditioned by passing $5.0 \mathrm{ml} 8 . \mathrm{M} \mathrm{HNO}$ through 
it and then washing it free of excess acid with distilled water as indicated by litmus paper.

2.8 Wash the column with $5.0 \mathrm{ml}$ of $2 \mathrm{M} \mathrm{HCl}$ to remove traces of bismuth and other weakly bound cations.

2.9 Strip the thoriun with 5.0 of $8 \mathrm{MHM}_{3}$ and reduce the volume of the solution to a few drops by evaporation.

2.10 Transfer the solution with a suitable pipette onto a 2-in. stainless-steel disc supported on a hot plate by a steel washer 0.75 in. i.d. $x 1.5$ in. $0 . d$. Dry slowly to minimize the deposit area at the center of the disc. Fire the disc to red heat with a gas torch to remove carbonaceous materials.

2.11 Deter-ine the thorium yield by counting the ${ }^{231}$ Th beta with an end vindow counter and compare it with a mounting of like count of the ${ }^{234}$ Th tracer used in the analysis.

2.12 Determine the ${ }^{230} \mathrm{Th}$ alpha disintegrations per minute (dpm) by pulse-height analysis using a diode pickup in a helium atmosphere. Compare the counts of $230 \mathrm{Th}$ alpha in the sample with those in a ${ }^{230}$ Th standard mounting whose dpm is known.

2.13 To correct for the contribution of ${ }^{230}$ Th which may be in the 234 Th tracer, pulse analyze the ${ }^{234}$ Th mounting. Subtract the contribution from the tracer after correcting for yield to obtain the net ${ }^{230} \mathrm{Th}$ content of the water sample.

\subsection{Calculations}

$$
{ }^{230} T h(p C i / l i t e r)=\frac{A B}{C D E F} .
$$

where

$$
\begin{aligned}
& A=\text { Water sample net alpha }(\mathrm{cpm}) \\
& B=230 \mathrm{Th} \text { standard }(\mathrm{dpm}) \\
& C=230 \mathrm{Th} \text { standard }(\mathrm{cpm}) \\
& D=\text { Fraction of } 234 \mathrm{Th} \text { tracer recovered } \\
& E=\text { Volume of sample (liter) } \\
& F=2.22 \mathrm{~d} /(\mathrm{m} \cdot \mathrm{pC} \mathrm{i})
\end{aligned}
$$


3.0 Lead -210

3.1 Evaporate the Oowex $4 \times 1$ effluent and wash from step 2.4 to $\sim 20 \mathrm{ml}$. Cool and slowly add ammonium hydroxide, while stirring in an ice bath, until hydroxide precipitation barely starts. Add 1 to 2 drops of concentrated $\mathrm{HNO}_{3}$ to each $10 \mathrm{mI}$ of solution to give an acidity of 0.2 to $0.4 \mathrm{M}$.

3.2 Slowly bubble $\mathrm{H}_{2} \mathrm{~S}$ through the chilled solution to precipitate metal sulfides. Let the mixture stand 10 to $15 \mathrm{~min}$ and centrifuge. Discard the supernate. Wash the sulfides with 5 to $10 \mathrm{ml}$ of $\mathrm{H}_{2} \mathrm{~S}$-saturated $0.2 \mathrm{M} \mathrm{HNO}_{3}$ solution. Centrifuge and discard the wash.

3.3 Dissolve the sulfide precipitate in a minimum of concentrated $\mathrm{HNO}_{3}$ by heating in a hot water bath. Dijute with 5 to $10 \mathrm{mI}$ of distilled water and filter out the suspended sulfur on \#42 Whatman filter paper. Wash out the centrifuge tube and filter with 5 to $10 \mathrm{ml}$ of distilled water.

3.4 Transfer the solution to a centrifuge tube and precipitate the hydroxides with an excess of ammonium hydroxide. Digest 10 min in a hot water bath. Cool, centrifuge, and wash the precipitate with 5 to $10 \mathrm{ml}$ of dilute $\mathrm{NH}_{4} \mathrm{OH}$. Discard the supernatant and wash liquids.

3.5 Cissolve the hydroxiaes in a minimum of concentrated $\mathrm{HNO}_{3}$ and dilute to $10 \mathrm{ml}$. Add $0.5 \mathrm{ml}$ of concentrated $\mathrm{H}_{2} \mathrm{SO}_{4}$ to precipitate $\mathrm{PbSO}_{4}$. Digest $15 \mathrm{~min}$ in a hot water bath, cool, centrifuge, and wash the $\mathrm{PbSO}_{4}$ with distilled water. Save the supernatant and wash liquids for bismuth recovery.

3.6 Transfer the $\mathrm{PbSO}_{4}$ slurry ontn a tared \#42 Whatman filter paper disc which is supported by the perforated fixed plate of a Hirsch funne1. Dry the $\mathrm{PbSO}_{4}$ and paper with etlyl alcohoi followed by ethyl ether.

3.7 Weigh the filter paper and $\mathrm{PbSO}_{4}$ to determine the yield of $210 \mathrm{~Pb}$. Store the $210 \mathrm{PbSO}_{4}$ sample for 30 days to allow the $210 \mathrm{~Pb}$ to reach equilibrium with its $210_{\mathrm{Bi}}$ daughter. The $210^{\circ} \mathrm{B}$ beta is counted in a low-level gas-proportional counter with a 
1-mil-thick polystyrene cover to shield out any stray alpha emissions .

3.8 Add pellets of $\mathrm{NaOH}$ to the bismuth solution from Step 3.5 to precipitate bismuth hydroxide. Digest for $10 \mathrm{~min}$ in a hot water hath, cool, and centrifuge. Wash the precipitate with $10 \mathrm{ml}$ of distilled water. Discard supernatant and wash liquids.

3.9 Dissnlve the solids in a minimum of $\mathrm{HNO}_{3}$. Add 3-4 drops of concentrated $\mathrm{HCl}$ and dilute to $240 \mathrm{ml}$ with hot distilled water to precipitate $\mathrm{BiOC1}$. Digest for $245 \mathrm{~min}$ in a hot water bath or until the precipitate has settled.

3.10 Pour the hot supernatant liquid through a tared \$42 Whatman filter paper supported by a perforated, fixed-plate, Hirsch funnel. Slurry the $\mathrm{BiOCl}$ onto the filter paper disc with small portions of hot disiililed water. By means of a stirring rod, guide the deposit to che center of the disc. Orf with ethyl alcohol and ethyl ether.

3. 11 Weigh the BiOCl and filter paper in order to determine yield.

3.12 Count the 5.01 day $210^{B i}$ beta, which is in equilibrium with $210 \mathrm{~Pb}$, in a low-level, gas-proportional counter. The counting efficiency of the counter is determined by counting several similar mountings having known 2:0Bi disintegration rates, with varying weights of BiOCl from which a calibration curve is constructed.

3.13 Refer to the calibration curve and convert cpm to dpm by means of an efficiency factor for the weight of sample in question.

3.14 Calculation

$$
210 \mathrm{~Pb} \rightarrow 210 \mathrm{Bi}(\mathrm{PC} \mathrm{i} / 1 \mathrm{iter})=\frac{\mathrm{AB}}{\mathrm{CDEF}},
$$

where

$$
\begin{aligned}
A= & \text { Beta count minus background (cpm) } \\
B= & \text { Correction for decay from } P b \text { separation time } \\
& \text { to counting time }
\end{aligned}
$$




$$
\begin{aligned}
& C=\text { Counter efficiency } \\
& D=\text { Fraction of } B i \text { recovered } \\
& E=\text { Volume of sample (liter) } \\
& F=2.22 \mathrm{~d} /(\mathrm{m} \cdot \mathrm{pC} \mathrm{C})
\end{aligned}
$$

\section{1) Reagents}

4. I Aluminum nitrate.

4.2 Leaa carrier, $10 \mathrm{mg} / \mathrm{ml}$. Dissulved $8.0 \mathrm{~g} \mathrm{~Pb}\left(\mathrm{NO}_{3}\right)_{2}$ in dilute $\mathrm{HNO}_{3}$ and dilute to $500 \mathrm{ml}$ with water.

4.3 Bisnuth carrier, $20.9 \mathrm{mg} / \mathrm{ml}$. Dissolve $5.225 \mathrm{~g}$ bismuth metal in concentrated $\mathrm{HNO}_{3}$ and dilute to $250 \mathrm{ml}$ with بxater.

4.4 Thorium tracer, ${ }^{234} \mathrm{Th}$. Pretreat a 30\% Adogen 364-xylene solution by extracting it with an eyual volume portion of $2 \mathrm{~A} \mathrm{HNO}_{3}$ for $2 \mathrm{~min}$. Dissolve $5.0 \mathrm{~g}$ of recently depleted ${ }^{238} \mathrm{U}$ (as $\mathrm{U}_{3} \mathrm{O}_{8}$ ) in $2: \mathrm{HNO}_{3}$. Extract the thorium and uranium with an equal volume of pretreated $30 \%$ Adugen 364-Xylene in a separator flask by hand shaking at least $2 \mathrm{~min}$. Separate phases and strip thorium from the solvent with $10 \mathrm{ml}$ of $10 \mathrm{M} \mathrm{HCl}$. Convert the chloride solution to $2 \mathrm{~N} \mathrm{iNO}_{3}$ solution for a repeat extraction with solvent to remove traces of uranium. The second $10 \mathrm{M} \mathrm{HCl}$ strip is again converted to the nitrate for counting the ${ }^{234}$ Th beta on a stainless steel disc. The mounting should be examined in a pulse-height alpha analyzer for the presence of ${ }^{230} \mathrm{Th}$. Should the ${ }^{230} \mathrm{Th}$ level be signifi:ant, then another source of depleted $238 \mathrm{U}$ should be sought, or alternatively extract the 234 ih from a batch of $238 \mathrm{Jf}$ from which the thorium had been extracted 1 to 2 months previously.

4.5 Ammonium hydroxide, concentrated.

4.6 Nitric acid, concentrated.

4.7 Hydrochloric acid, concentrated.

4.8 Sodium hydroxide pellets.

4.9 Sulfuric acid, concentrated. 
4. 10 Hydrogen sulfide gas.

4. 11 Dowex $4 \times 1$ and Dowex $50 \times 1$ excrange resins.

\subsection{Apparatus}

5. I Radon de-emanation train with radon concentrator ${ }^{\star}$ and Lucas chamber.

5.2 Radon photomultiplier counter.

5.3 Modified ${ }^{\dagger}$ 250-ml, flat-bottom, boiling flasks.

5.4 Other counting equipment--G-M beia counter; low-level, gasproportional beta counter: pulse-height spectral alpha analyzer.

5.5 Stainless-steel alpha counting discs.

5. 6 Laboratory centrifuge.

5.7 Pyrex centrifuge tubes, $50 \mathrm{ml}$.

5.8 Beakers, assorted.

5.3 on exchange columns.

5.10 Dowex $4 \times 1$ and Dowex $50 \times 1$ exchange resins.

5. Il Hirsch fixed plate funnel.

*The radon concentrator consists of a $20-i m-10 n g U$-tube cons: ructed from $6 \mathrm{~mm}$ o.d. Pyrex glass tubing. Ten centimeters of the U-section is filled with 20 to 40 in. unfired Vycor which has a large surface to volume ratio. When the tube is immersed in 1 iquid nitrogen and radonladen helium gas passes through the tube, the condensable radon adheres to the Vycor surface. The stripped helium gas exits the system. Upon removal of the coolant the radon vapor diffuses through 10 to $15 \mathrm{~cm}$ of capillary tubing to the evacuated Lucas chamber. Flushing the $U$-tube and attached capillary tubing with 20 to $30 \mathrm{ml}$ of helium transfers essentially $100 \%$ of the radon to the Lucas chamber. Since the efficiency of Lucas chambers for counting alphas may vary from 75 to $85 \%$, it is necessary to calibrate each chamber with an equilibrated ${ }^{226}$ Ra standard solution.

tThe radium-radon equilibrating flask consists of a flat-bottom 250-ml boiling flask with a femile 24/40 tapered joint. A saber-type sintered glass gas diffuser is sealed into a male 24/40 taper joint section so that when it is inserted in the flask it will extend well into the equilibrating solution. A suitable inlet gas connection is provided on the opposite end of the diffuser tube. Onto the shoulder of the male $24 / 40$ joint is soaled a short length of small bore ( $5 \mathrm{~mm}$ i.d.) glass tubing with a glass stopcock terminating with a connector suitable for ronking up with the radun trapping system. 


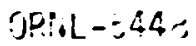

[ist. Sategory $U C-41$

IOTEP:IFL OISTRIEUTION

1-i. Centräi Research Library

3. Uocument Reference Section

4-5. Laboratory Pecords

6. Laboratory Records, OPioL, R.C

7. ORIil Patent office

c. O. L. Anderson

9. C. F. Bäes III

Ii). B. A. Eerven

11. N. O. Cottrell

12. D. i1. Davis

13. R. in. Coane

14. H. W. Dickson

15. J. S. Eldridge

16. 3. S. Ellis

17-21. W. A. Goldsmith

\author{
¿Z-47. F. F. Hayrood \\ 4c. G. S. Hill \\ 49. C. F. Holoway \\ 50. S. V. Kaje \\ 51. L. M. McEowell-Eoyer \\ 52. H. R. Meyer \\ 53. T. W. Dakes \\ 54. D. C. Parzyck \\ 55. P. T. Perdue \\ 56́. C. R. Richmond \\ 57-59. P. S. Rohwer \\ 60. M. T. Riyan \\ 61. A. D. P.yon \\ 62. T. Scott \\ 63. W. H. Shinpaugh
}

\section{EXTERIiTLL OISTRIBUTIOH}

64. Kenneth P. Gaker, Division of Operational and Environinental Safety, Department of Energy, Washington, DC 20545

65. Nathaniel F. Barr, Division of Health and Environmental Effects Assessments, Lepartment of Energy, Washington, DC 20545

66. Charles J. Earton, Science Applications, Inc., 800 Oak Ridge Turnpike, Oak Ridge, TN 37830

67. R. G. Beverly, Union Carbide Corporation, P. 0. Box 1049, Grand Junction, CO ¿1501

68. Jon A. Broadway, Environmentai Protection Agency, P. 0. Box 3009, Montgomery, AL 36109

69. Z. G. Burson, EG\&G, Inc., 680 East Sunset Drive, Las Vegas, NV 89101

70. Richard Campbell, ETW, Department of Energy, Albuquerque Operations office, Albuquerque, NM 87115

71. W. R. Chappell, Center for Environmental Sciences, Box 136, University of Colorado, Denver, C0 80202

72. Ruth Clusen, Assistant Secretary for Environment, Department of Energy, Washington, DC 20545

73. Joseph A. Coleman, Deputy Director, Office of Technology Impacts, Departnient of Energy, Washington, OC 20545

74. Enrico F. Conti, Office of Standards Development, Nuclear Regulatory Conmission, Washington, DC 20545

75. Ernest Coriz, Energy Resources Board, Box 2770, Santa Fe, NM 87501

76. G. Cowper, Head, Health Physics Branch, Chalk River Nuclear Laboratories, Chalk River, Ontario, Canada 
77. William T. Crow, Office of Nuclear Material Safety and Safeguards, Nuclear Regulatory Commission, 79ls Eastern Avenue, Silver Springs, $M O 20555$

76. Floyd L. Culler, Office of the President, Electric Power Research Instrtute, P. O. Eox 10412, Palo Alto, CA 94303

79. Jerry Davis, liuclear Regulatory Resparch, ivuclear Regulatory Cormission, Wasnington, DC 20555

c0. L. J. Deal, Acting Chief, Environmental Protection and Public Safety Branch, Division of Operational and Environmental Safety, Department of Energy, Washington, DC 20545

c1. Dale i. Denham, Battelle Pacific Horthwest Laboratories, Eattelle Boulevard, P. 0. Box 999, Richland, Wf 99352

¿2. Frank J. Doyle, Bureau of Mines, Department of the Interior, Pittsburgh, PA 15213

83. R. D. Evans, 4621 E. Crystal Lane, Scottsdale, AZ 85353

24. Tom F. Gesell, School of Public Health, The University of Texas, P. 0. Box 20186, Houston, TX 77025

85. Donald C. Gilbert, Arizona Atomic Energy Commission, 1601 W. Jefferson, Phoenix, AZ 85007

36. D. H. Groelsema, Office of Nuclear Waste Management, Remedia? Action Program, Department of Energy, Mail Stop B-107, Washington, DC 20545

87. A. 1. Hazle, Colorado Department of Health, $4210 \mathrm{E}$. 11 th Avenue, De. .r. C0 80220

88. Jack Healy, Office of Environmental Policy Analysis, Los Alamos Scientific Laboratory, Los Alarios, iN 87545

89-91. D. W. Hendricks, Environmental Protection Agency, P. 0. Box 15207, Las Vegas, NV 89121

92. Darryl L. Hessel, Battelle Pacific Northwest Laboratories, Battelle Boulevard, P. 0. Box 999, Richland, WA 99352

93. Jerry Hinkle, Division of Technology Assessments, Department of Energy, Washington, DC 20545

94. Peter $W$. House, Director, Office of Technology Impacts, Department of Energy, Washington, DC 20545

95. Indian Health Service, Window Rock, AZ 86515

96. Bernard N. Jaroslow, Argonne National Laboratory, Division of Environmental Impact Studies, $9700 \mathrm{~S}$. Cass Avenue, Argonne, IL B0439

97. J. E. Jobst, EG\&G, Inc., 680 E. Sunset Drive, Las Vegas, NV 89101

98. J. E. Johnson, Dept. of Radiobiology and Radiation Biology, Colorado State University, Fort Collins, CO 80523

99. Jacob Kastner, Office of Standards Development, Nuclear Regulatory Commission, 5650 Nicholson Lane, Rockville, MD 20555

100. Edward R. Landa, Department of Interior, Geological Survey, Northeastern Region, Stop 432, Reston, VA 22092

101. Stan Lichtman, Environmental Protection Agency, 401 M St., S.W., MS-ANR-460-ORP, Washington, OC 20460

102. Leonard E. Link, Argonne National Laboratory, 9700 S. Cass Avenue, Argonne, IL 60439

103. P. R. Magno, Environmental Protection Agency, Washington, DC 20555 
104. j. P. Maher, Division of Technology fissessments, Department of Energy, washington, oC 20545

105. G. Markos, Dept. of Seology and Geological Engineering, South Jakota School of Mines, Rapid City, SD 5?701

106. Roger iattson, Office of Standards Development, Nuciear Pegulatory Comission, Washington, OC 20460

167. Bill J. Mcilurray, Battelle Pacific Northwest Laboratories, Eattelle Bnulevard, P. 0. Eox 999, Richland, WA 99352

ijos. W. A. Aills, Environmental Protection figency, Roon 635, Waterside idall East, 401 if Street, S.W., Washington, OC 20460

109. K. Z. Morgan, School of iluclear Engineering, Georgia Inst itute of Technology, fitlanta, GA 30332

110-113. W. E. Hott, Director, Division of Environmental Control Technology, Department of Energy, Washington, DC 20545

114. J. C. llelson, Civil Engineering Dept., Colorado State University, Fort Collins, CO 20523

115. John W. Poston, School of lluclear Engineering, Georgia Institute of Technology, North Avenue, Atlanta, GA 30322

i16-117. K. W. Rausey, Uffice of Nuclear Waste Management, Department of Energy, Washington, DC 20545

1!ó-120. Harley W. Reno, Manager, Environmental Sciences, EG\&G, Inc., Idaho Operations, Box 1625, Idaho Falls ID 83431

121. William f. Rettberg, Harza Engineering Company, $150 \mathrm{~S}$. Wacker Drive, Chicago, IL 60606

122. Russeil Rhozdes, Occupational, Radiation Protection and Air Quality Control Division, State of Hew Mexico, Environmental Improvelient Agency, P. 0. Box 234¿, Santa Fe, NM $87 j 01$

123. C. J. Roberts, Argonne National Laboratory, EIS Division Euilding 10, Argonne, IL 60439

124. C. E. Roessler, Department of Environmental Engineering Sciences, University of Florida, Gainesville, FL 32611

125-126. Vern Rogers, Ford, Bacon and Davis Utah Inc., P. 0. Box 8009, Salt Lake City, UT 10014

127. D. M. Ross, Division of Operational and Environmental Safety, Department of Energy, Washington, DC 20545

120. Leland C. K use, Office of Nuclear Material Safety and Safeguards, ivuclear Regulatory Commission, 7915 Eastern Avenue, Silver Springs, MD 20555

129. B. J. Salmonson, Exxon ifinerals Company, P. 0. Box 2180 , Houston, TX 77001

130. K. J. Scriager, ALARA, Inc., P. O. Box 86n, Lyons, CO 80540

131. K. J. Schneider, Battelle Pacific Northwest Laboratories, Battelle Boulevard, P. 0. Box 999, Richland, WA 99352

132. S. D. Shearer, Camp, Dresser and McKee, Inc., 3445 Executive Center Drive, Austin, Tx 78731

133-136. Jay Silhanek, Environmental Protection Agency, Waterside Mall, East Jower, Washington, DC 20460

137. C.W. Sill, Denaitment of Energy, Idaho Falls, 1083401

138. Donald R. Storie, 2136 Suncrest Lane, Chattanooga, TN 37421

139-140. John G. Themelis, Department of Energy, P. 0. Box 2527, Grand Junction, CO 81501 
14i. ii. ii. Thonasson, Division of Technology Assessments, Department of Energy, Washington, DC 20545

142. William E. Thompson, Division of Fuel Cycle and Material Safety, Nuclear Regulatory Commission, Washington, DC 20555

143. Harold $W$. Tso, Environmental Protection Commission, Navajo Tribe, Nindow Rock, AZ 86515

144. Eruce W. Wachnolz, Division of Technology Ássessments, Department of Energy, Washington, DC 20545

145. Murray Walsh, R.E.C.S., 34 whitelock Cres., Willowdale, Ontario, Canada M-2KIVE

146. George Wehmann, Idaho Vational Laboratory, 3955 Georgia Lane, Ammon, ID 33401

147. F. W. Whicker, Dept. of Rádiology and Radiation Biology, Colorado State University, Fort Collins, CO 80523

148. Edwaro R. Williams, Director, Division of Policy Analysis, Office of Technology Impacts, Department of Energy, Washington, DC 20545

149. George Wu, Division of Waste Management, iucleär Regulatory Commission, MS-4335s, Washington, DC 20555

150. Robert Wynveen, Argonne National Laboratory, $9700 \mathrm{~S}$. Cass Avenue, Argonne, IL 60439

151. Office of Assistant Manager, Energy Research and Development, Department of Energy, Oak Ridge Operations, Dak Ridge, Tii 37830

152-407. Given distribution as shown in T10-4500 under Health and Safety category UC -41 (25 copies - NTIS) 